\title{
Autoantibodies in the nervous system
}

\author{
Citation for published version (APA):
}

Mané Damas, M. (2020). Autoantibodies in the nervous system: pathophysiology and new therapeutic strategies. [Doctoral Thesis, Maastricht University]. Ipskamp Printing BV. https://doi.org/10.26481/dis.20201216md

Document status and date:

Published: 01/01/2020

DOI:

10.26481/dis.20201216md

Document Version:

Publisher's PDF, also known as Version of record

\section{Please check the document version of this publication:}

- A submitted manuscript is the version of the article upon submission and before peer-review. There can be important differences between the submitted version and the official published version of record.

People interested in the research are advised to contact the author for the final version of the publication, or visit the DOI to the publisher's website.

- The final author version and the galley proof are versions of the publication after peer review.

- The final published version features the final layout of the paper including the volume, issue and page numbers.

Link to publication

\footnotetext{
General rights rights.

- You may freely distribute the URL identifying the publication in the public portal. please follow below link for the End User Agreement:

www.umlib.nl/taverne-license

Take down policy

If you believe that this document breaches copyright please contact us at:

repository@maastrichtuniversity.nl

providing details and we will investigate your claim.
}

Copyright and moral rights for the publications made accessible in the public portal are retained by the authors and/or other copyright owners and it is a condition of accessing publications that users recognise and abide by the legal requirements associated with these

- Users may download and print one copy of any publication from the public portal for the purpose of private study or research.

- You may not further distribute the material or use it for any profit-making activity or commercial gain

If the publication is distributed under the terms of Article $25 \mathrm{fa}$ of the Dutch Copyright Act, indicated by the "Taverne" license above, 
COPYRISHT BY Marina Mané Damas, Maastricht 2020 COVER DESIGN: Marina Mané Damas

PRINTED BY: IPSKAMP PRINTING

ISBN: 978-94-6421-167-2

All rights reserved. 


\title{
Autoantibodies in the nervous system:
}

\section{pathophysiology and new therapeutic}

\author{
strategies
}

\author{
DISSERTATION \\ to obtain the degree of Doctor at \\ Maastricht University on the authority of the Rector Magnificus \\ Prof.dr. Rianne M. Letschert \\ in accordance with the decision of the Board of Deans, \\ to be defended in public \\ on Wednesday 16 th of December 2020 at 10.00 hours
}

by

Marina Mané Damas 


\section{Supervisor:}

Prof. Dr. Pilar Martinez

\section{Co-supervisors:}

Dr. Mario Losen

Dr. Rob Rouhl

\section{Assessment Committee:}

Prof. Dr. B.P.F. Rutten (Chair)

Prof. Dr. G.M.J. Bos

Dr. J.G.J. Hoeijmakers

Prof Dr. E. Tuzun (University of Istanbul, Turkey)

Dr. E. Hofman (Argenx, Gent, Belgium) 


\section{Table of content}

CHAPTER 02 Autoimmunity in psychotic disorders. Where we stand, challenges and opportunities

CHAPTER 03 Unidentified neuronal surface IgG autoantibodies in a case of Hashimoto' s encephalopathy

CHAPTER 04 Prevalence of neuronal antibodies in a cohort of early onset psychotic disorders: the PSYANTIB study

CHAPTER 05 Novel treatment strategies for myasthenia gravis with autoantibodies against the AChR

CHAPTER 06 Silencing of Dok-7 in Adult Rat Muscle Increases Susceptibility to Passive Transfer Myasthenia Gravis

CHAPTER 07 Therapeutic efficacy of MLN9708 (ixazomib) in experimental autoimmune myasthenia gravis and primary thymic cell cultures from myasthenia gravis patients

CHAPTER 08 General discussion, limitations and conclusions

CHAPTER 09 Valoritzation

CHAPTER 11 List of publications 

01.

General introduction 
General introduction 


\section{Abstract}

The immune system is a host defence system, which has two major pillars, innate and adaptive immunity. Even though it is designed to protect us against external harmful agents, it can also play detrimental roles. When this happens, the adaptive immune system can cause diseases of the central and peripheral nervous system, involving the activation of an immune response against self-antigens leading to highly specific cellular reactions, inflammation and antibody secretion, known as antibody-mediated autoimmune disorders.

Impairment of nervous conduction and synaptic transmission by autoantibodies can manifest itself in many ways, depending on the targeted antigen, its location and on the action mechanisms involved in the pathophysiology, leading to a large number of different autoimmune disorders [1, 2]. Demyelinating disorders such as multiple sclerosis, neuromyelitis optica and Guillain-Barré syndrome, encephalomyelitis including NMDAR encephalitis, progressive encephalomyelitis with rigidity and myoclonus (PERM) and neuromuscular disorders like myasthenia gravis and neuromyotonia are important antibody-mediated disorders of the central and peripheral nervous system [3].

Symptomatic and immunosuppressive drugs are used as treatment for antibody-mediated autoimmune disorders. However, treatments can fail or have a poor response in some patients, and may cause side effects resulting from lack of specificity. 


\section{The adaptive immune system and its players}

The immune system protects the body against pathogens by eliminating external harmful agents such as viruses, bacteria or fungi thanks to two different responses that differ in time and specificity: innate and adaptive immunity. The adaptive immune response is a very precise and elaborate reaction resulting from a previous exposition to the pathogen.

B lymphocytes and their progeny plasma cells are specialized white blood cells. They are, as part of the adaptive immune response, responsible for the production of the antibodies. The secretion of antibodies is maintained by the activation of reactive B cells that will differentiate into short-lived plasma cells and finally into specialized long-lived plasma cells. Additionally, they serve as antigen-presenting cells, resulting in the secretion of pro-inflammatory cytokines and recruitment of other cells involved in the immune response.

Antibodies, also referred to as immunoglobulins, are heterodimeric glycoproteins in a "Y" shape consisting of four chains, two heavy $(\mathrm{H})$ and two light (L), each of them with constant $(\mathrm{C})$ and variable (V) regions. The constant regions together form the Fc fragment, responsible of the recruitment of several cells involved in the immune response, while the variable regions compose the Fab fragment, which exclusively identifies a specific region, known as epitope, of the target antigen. Immunoglobulin $G$ (IgG) is the major class of the five classes of immunoglobulins present in humans and one of the most abundant proteins in human serum (10-20\% of plasma protein) [4]. IgGs can be further classified into four different subclasses [5]. Each subclass differs in heavy chain structure and has a unique effector function profile with respect to antigen binding, immune complex formation, complement activation, triggering of effector cells, half-life and placental transport. lgG 1 and lgG3 bind strongly to soluble and cell membrane proteins; they stimulate other effector cells via Fcy receptors [6] and activate complement via the "classical pathway" [7], resulting in inflammation, tissue damage and loss of antigen function. IgG2, however, is mostly secreted as a response to bacterial polysaccharide antigens and has a reduced capacity to activate complement. Finally, lgG4 is directed against proteins and allergens and lacks the capacity to fix complement.

\section{Tolerance and autoimmunity}

The high specificity of antibodies to foreign particles results from a sophisticated and highly regulated mechanism which prevents recognition of self-antigens by a process known as tolerance which includes multiple selection steps that deplete or functionally silence autoreactive T cells. However, when this orchestrated mechanism to discriminate between non-self and self-antigens fails, antibodies become autoantibodies that attack self-antigens inducing autoimmunity with pathological consequences [8]. 
Currently, a growing $2.5 \%$ of the general population suffer from autoimmune diseases caused by autoantibodies [9].

Autoantibodies were first discovered in serum from patients with systemic lupus erythematosus (antinuclear antibodies) and rheumatoid arthritis (rheumatoid factors). These autoantibodies bound to nuclear antigens and immunoglobulins respectively [10]. Autoantibodies can be directed against nucleic acids, lipids and proteins, which can be located in the nucleus or cytoplasm, on the cell surface or in the extracellular space. The pathogenicity of autoantibodies against extracellular and circulating molecules has been extensively confirmed and autoantibodies play a pivotal role in the pathogenesis of many diseases by inducing cellular damage and inflammation.

\section{Autoimmunity to cell surface antigens}

In the mid-50s, autoantibodies against the thyroid stimulating hormone (TSH) receptor were described in autoimmune hyperthyroidism as the first autoantibodies targeting a receptor [11, 12]. Autoimmunity against cell surface receptors are T cell dependent, B cell-mediated autoimmune-disorders [13]. In these diseases, it was of paramount importance to identify the presence of circulating antibodies and locate the targeted antigen.

Neuronal receptors, ion channels and associated proteins are essential for the correct neurotransmission signalling involved in processes including learning and memory as well as muscle contraction. Nevertheless, these proteins are sometimes affected by the presence of autoantibodies and have been described in many autoimmune disorders. Autoantibodies influence their effector mechanisms for example by stimulating or blocking the targeted receptor, resulting in the disruption of synaptic transmission or the deterioration of the synaptic structures [14]. Obviously, the resulting phenotype depends on the properties of the receptor under attack, the characteristics of the autoantibodies involved and their effector mechanisms. Complement mediated lysis, antibody-mediated cell cytotoxicity, immune complex mediated damage, receptor signalling and cell architecture modulation, receptor internalization, opsonisation, and inhibition of repair mechanisms are some antibody pathogenic mechanisms observed in the nervous system [3].

Autoantibodies against the muscle nicotinic acetylcholine receptor (AChR) in myasthenia gravis (MG) or against the N-methyl-D-aspartate-(NMDA)-receptor in NMDA encephalitis share some pathogenic mechanisms $[15,16]$, nevertheless with very different clinical manifestations. 


\section{Myasthenia gravis}

MG is an autoimmune disease caused by autoantibodies against the AChR and associated proteins at the neuromuscular junction $[17,18]$. It has an annual incidence of 8 - 10 cases per 1 million persons and a prevalence of 150 - 250 cases per million, affecting individuals of all ages and both genders [19]. Weakness and fatigue of the skeletal muscles that aggravate after exercise are the marked clinical signs of MG. Thymic abnormalities are often associated with it. Specifically, follicular hyperplasia is observed in $50-60 \%$ patients and around $15 \%$ of patients with MG present with a thymoma. Additionally, $50 \%$ of thymoma patients develop MG [20-22].

Autoantibodies against the AChR are present in $85 \%$ of MG patients. The AChR is a pentameric molecule with different subunits: $\alpha, \beta, \gamma, \delta$ and $\varepsilon$ in the adult muscle, of which two are $\alpha$-subunits. Interestingly, the $\alpha$ region keeps the main epitope targeted by autoantibodies, known as the main immunogenic region (MIR) [23-25]. The high concentration of AChRs at the top of the folds of the neuromuscular junction is crucial for an effective signal transmission form the nerve to the muscle. The muscle-specific kinase (MuSK) and lipoprotein receptor-related protein 4 (Lrp4) are elemental proteins involved in the development and maintenance of the structure of the neuromuscular junction [26, 27]. Autoantibodies against these two proteins have also been detected in patients with MG, however, in lower percentages.

In AChR-MG, IgG1 and IgG3 are the principal isotypes which induce pathogenicity by three main mechanisms $[18,28]: 1)$ activation of the classical complement cascade with in the formation of the membrane attack complex (MAC) [29, 30], 2) antigenic modulation [31], which both result in loss of AChR density and destruction of the postsynaptic folds, and 3) direct inhibition of ACh-AChR binding or blocking the AChR channel [32]. In MUSK-MG, IgG4 causes the disease [33]. With a reduced capacity to bind complement, these autoantibodies disrupt the association between MuSK-Lrp4 and prevents the communication with agrin, required for developing stable synapses [34]. Additionally, IgG4s can exchange arms between them, having the capability to recognize two different antigens. This property is known as Fab arm exchange and occurs spontaneously in vivo [35]. IgG1 is the main isotype identified for Lrp4-MG [36]. Its pathogenic mechanisms are not yet well understood.

\section{Autoimmune encephalopathies}

Autoimmune encephalopathies mostly present as a subacute encephalitis with limbic features (cognitive disturbance, psychiatric symptoms and epilepsy), and are associated with autoantibodies against several neuronal surface proteins (receptors, ion channels and associated proteins). Currently, up to 16 autoimmune encephalopathies targeting neuronal antigens have been described [37], of which the N- 
methyl-D-aspartate receptor (NMDAR) is the most commonly targeted antigen [38]. NMDAR binds glutamate, the main excitatory neurotransmitter in the brain. Their annual incidence has been estimated at 3-5 cases per million, young women and children being predominantly affected [39]. Malignant diseases are highly prevalent in autoimmune encephalitis, as the antibodies might be a paraneoplastic phenomenon [15].

Autoantibodies against the NMDAR recognize a highly conserved epitope present in the GluN1 subunit of this heterotetrameric molecule [15,40]. Even though other isotypes have been reported, lg $G$ is the only isotype with a proven pathogenic role [41]. With a predominance of IgG1, NMDAR autoantibodies cause antigenic modulation and selective internalization of the NMDAR in neurons [42]. Even though antibodies are predominantly IgG1 [43], the few studies available showed no complement deposition in brain biopsies from patients with NMDAR encephalitis. This could be due to the low concentration of complement components in the CSF [44-46].

Clinical manifestations of NMDA-receptor encephalitis mostly start with a prodromal phase of headache or fever for hours to days, followed by clinical symptoms of abnormal behaviour and psychiatric manifestations (e.g. anxiety, hallucinations, and psychosis) and cognitive dysfunction during the following weeks. Later, patients develop seizures, abnormal movements, and eventually coma and severe autonomic dysregulation [47]. However, approximately $4 \%$ of NMDAR encephalitis patients present isolated psychotic episodes without clear neurological manifestations [48]. NMDAR autoantibodies have been described with a higher prevalence in a cohort of children with a first psychosis episode [49] and women with post-partum psychosis [50].

Besides the presence of psychiatric manifestations in antibody-mediated autoimmune forms of encephalitis, psychotic disorders are associated with inflammation and autoimmunity [51, 52]. An unbalance in the homeostasis of different neurotransmitter systems has been observed in these disorders $[53,54]$. Altogether, this raises the question whether autoantibodies targeting neuronal surface antigens and altering the neuronal synapses could be the underlying cause of some forms of neuropsychiatric disorders. Despite the controversy in the field, probably as a result of the heterogeneity in the patient population and the detection methods $[41,55]$, no evidence for this association has been clearly found so far $[56,57]$. However, it is of interest to investigate the presence of known but also novel neuronal surface autoantibodies in patients with psychotic disorders, especially if they have an atypical disease course, to describe the role of these autoantibodies and their target antigen(s). 


\section{Treatment approaches for antibody-mediated autoimmunity}

Treatment strategies for antibody-mediated disorders include a combination of symptomatic treatment and non-specific immunosuppressants. High dose corticosteroids and other drugs (e.g., azathioprine, methotrexate, MMF) aim to decrease the immune response by suppressing the activation and proliferation of lymphocytes, including B cells. This approach, however, has little effect on long-lived plasma cells [58]. Plasmapheresis and high-dose intravenous IgG (IVIG) consist on the removal or neutralization of autoantibodies which is especially indicated for treating acute exacerbations thanks to the fast effect of these procedures. The beneficial effect, however, is not long-lasting due to the production of new antibodies. Cell therapies targeting B cells (e.g. rituximab), show good results mainly in MuSK-MG [59], suggesting different pathogenic mechanisms among different disease types. Proteasome inhibitors targeting long-lived plasma cells have shown to be beneficial in preclinical experimental settings $[60,61]$ and in some refractory cases [62-64].

Repurposed and novel preclinical treatments should be investigated in order to reduce the significant side effects resulting from the currently available treatment options and to efficiently treat a still substantial percentage of patients that do not present an optimal treatment response or do not respond at all $[58,60,65-70]$.

\section{Take home message}

There is a need to elucidate the pathophysiology underlying antibody-mediated disorders. The identification of these autoantibodies and their targets will result in an early diagnosis, which is usually associated with a prompt treatment and better prognosis. Additionally, the disentanglement of the pathogenic mechanisms will help to understand these disorders and result in the development of more specific therapeutic strategies. 


\section{Overview of the thesis}

Autoimmunity against neural surface receptors, ion channels and associated proteins represents a field of noteworthy interest because of its far-reaching implications in the field of neuropsychiatry including the identification of the target, the understanding of the pathophysiological mechanisms and the development of novel therapeutic strategies. The research lines of this thesis largely merge towards profiling the role of autoantibodies against neural surface proteins in antibody-mediated autoimmune disorders in the central as well as in the peripheral nervous system. The first three chapters focus on the potential role of neuronal surface autoantibodies in psychotic disorders, while the following chapters focus on novel therapeutic strategies for antibody-mediated disorders in the peripheral nervous system, using MG as a generic model. 


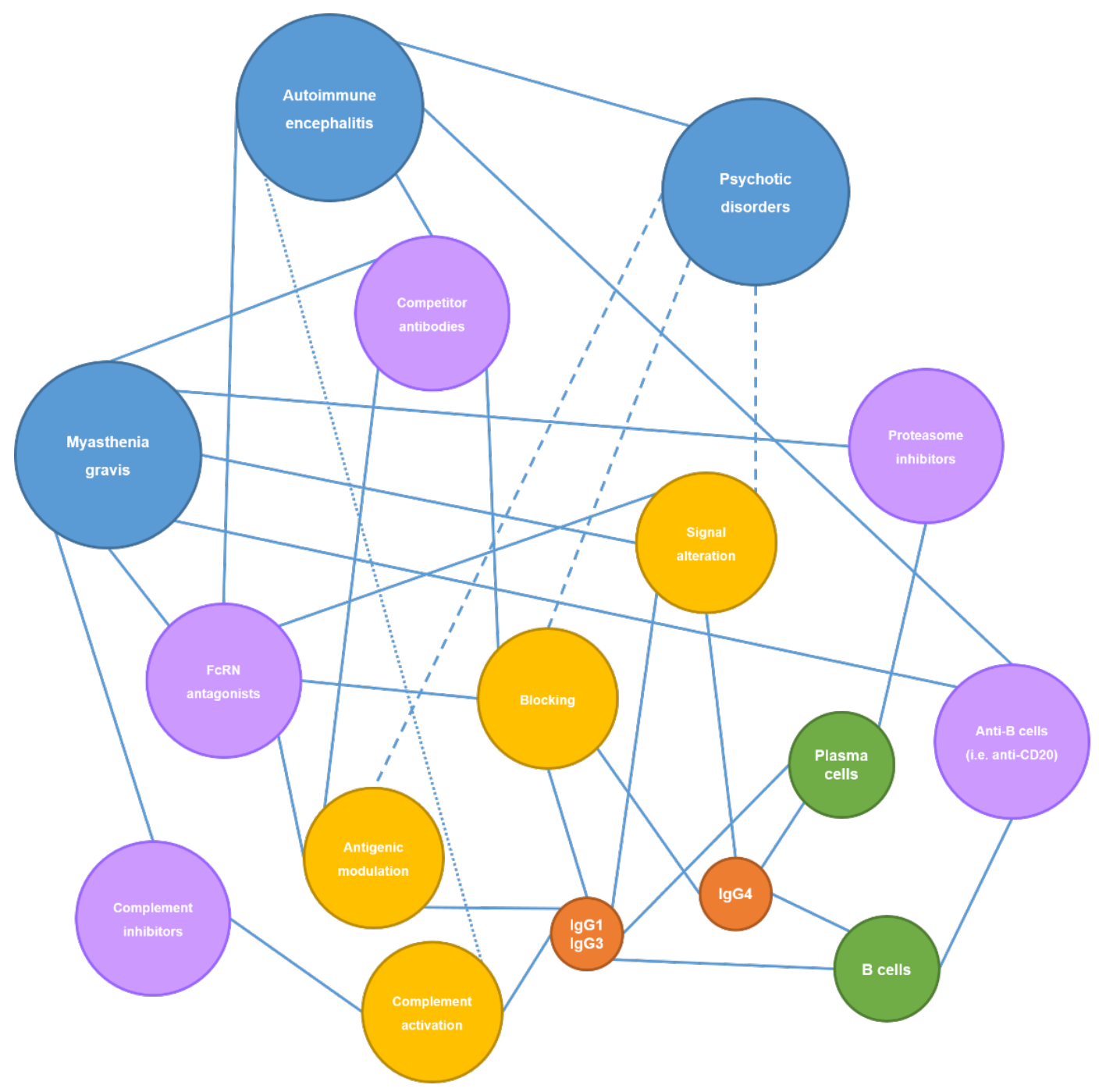

Figure 1. Association network of the different topics discussed in this thesis including the disorders (blue), treatments (purple), the action mechanisms (yellow), the immunoglobulin isotypes (orange) and the antibody producing cells (green). 
After a brief introduction on the role of the immune system in receptor antibody-mediated autoimmune disorders and a brief overview of the main disorders addressed in this thesis namely autoimmune encephalitis and MG, CHAPTER 2 reviews the current status quo of autoimmunity in psychotic disorders, the relevance of the identification of the pathogenic antigens for a prompt and differential diagnosis. More specifically, CHAPTER 3 describes a case report of a patient with mild cognitive impairment and thyroid peroxidase (TPO) autoantibodies, co-occurring with undefined neuronal surface autoantibodies. A clinical study with de novo recruited psychotic patients to assess the presence of autoantibodies against neuronal receptors in blood and cerebrospinal fluid (CSF) is described in CHAPTER 4. In this study, cognitive and psychiatric manifestations as well as neurological signs are addressed in order to common and distinct signatures of reactive patients.

In search for alternative therapeutic strategies for autoimmunity, CHAPTER 5 gives an overview of the classic immunomodulatory therapies currently used in MG with antibodies targeting the AChR as a classic antibody-mediated autoimmune disorder. The lack of specificity and the presence of unwanted effects, takes us to the second part of the chapter, focused on innovative therapeutic strategies for symptomatic and immunomodulatory treatment approaches. Thanks to the extensive knowledge on the pathogenic mechanisms of AChR-MG, CHAPTER 6 studies the effect of silencing of Dok-7, essential for the correct clustering of the AChRs at the neuromuscular junction and its potential therapeutic role. The final study presented in CHAPTER 7 describes the effect of a second-generation proteasome inhibitor, ixazomib in AChR-MG. Using patient derived in vitro assays and the standardized model for MG, the demonstration of an efficient and safe dose dependent effect takes a step further for the application of this treatment in patients.

The key outcomes and discoveries of this thesis are summarized in CHAPTER 8. Overall strengths and limitations along with future perspectives of this thesis are described with criticism concerning the research field of antibody-mediated autoimmune disorders. 


\section{References}

1. Tozzoli, R., Receptor autoimmunity: diagnostic and therapeutic implications. Autoimmunity Highlights, 2020. $11(1)$ : p. 1 .

2. Ludwig, R.J., et al., Mechanisms of Autoantibody-Induced Pathology. Frontiers in immunology, 2017. 8: p. 603-603.

3. Beasley, S.J. and J.M. Greer, Autoantibodies and their potential roles in diseases of the nervous system. Clinical and Experimental Neuroimmunology, 2015. 6(4): p. 370-386.

4. Vidarsson, G., G. Dekkers, and T. Rispens, IgG Subclasses and Allotypes: From Structure to Effector Functions. Frontiers in Immunology, 2014. 5(520).

5. $\quad$ PH, S., IgG subclasses. A historical perspective. . Monogr Allergy, 1988. 23: p. 1-11.

6. Bruhns, P., et al., Specificity and affinity of human Fcy receptors and their polymorphic variants for human IgG subclasses. Blood, 2009. 113(16): p. 3716-3725.

7. Bindon, C.I., et al., Human monoclonal IgG isotypes differ in complement activating function at the level of C4 as well as Clq. The Journal of experimental medicine, 1988. 168(1): p. 127-142.

8. Schwartz, R.H., Historical overview of immunological tolerance. Cold Spring Harbor perspectives in biology, 2012. 4(4): p. a006908-a006908.

9. Eaton, W.W., et al., Epidemiology of autoimmune diseases in Denmark. Journal of autoimmunity, 2007. 29(1): p. 1-9.

10. Robbins, W.C., et al., Complement Fixation with Cell Nuclei and DNA in Lupus Erythematosus. Proceedings of the Society for Experimental Biology and Medicine, 1957. 96(3): p. 575-579.

11. Adams, D.D., Long-Acting Thyroid Stimulator: How Receptor Autoimmunity was Discovered. Autoimmunity, 1988. 1(1): p. 3-9.

12. Adams DD, P.H., Abnormal responses in the assay of thyrotropin. Proc Univ Otago Med Sch., 1956. 34: p. 11-2.

13. Yi, J.S., et al., B cells in the pathophysiology of myasthenia gravis. Muscle \& nerve, 2018. 57(2): p. 172184.

14. Ludwig, R.J., et al., Mechanisms of Autoantibody-Induced Pathology. Frontiers in Immunology, 2017. 8(603).

15. Dalmau, J., et al., Clinical experience and laboratory investigations in patients with anti-NMDAR encephalitis. The Lancet. Neurology, 2011. 10(1): p. 63-74.

16. Leypoldt, F., T. Armangue, and J. Dalmau, Autoimmune encephalopathies. Annals of the New York Academy of Sciences, 2015. 1338(1): p. 94-114.

17. Phillips, W.D. and A. Vincent, Pathogenesis of myasthenia gravis: update on disease types, models, and mechanisms. F1000Research, 2016. 5: p. F1000 Faculty Rev-1513.

18. Gomez, A.M., et al., Antibody effector mechanisms in myasthenia gravis-Pathogenesis at the neuromuscular junction. Autoimmunity, 2010. 43(5-6): p. 353-370.

19. Carr, A.S., et al., A systematic review of population based epidemiological studies in Myasthenia Gravis. BMC neurology, 2010. 10: p. 46-46.

20. Romi, F., Thymoma in myasthenia gravis: from diagnosis to treatment. Autoimmune diseases, 2011. 2011: p. 474512-474512.

21. Cron, M.A., et al., Thymus involvement in early-onset myasthenia gravis. Annals of the New York Academy of Sciences, 2018. 1412(1): p. 137-145. 
22. Berrih-Aknin, S. and R. Le Panse, Myasthenia gravis: A comprehensive review of immune dysregulation and etiological mechanisms. Journal of Autoimmunity, 2014. 52: p. 90-100.

23. Unwin, N., Refined Structure of the Nicotinic Acetylcholine Receptor at $4 \AA$ Resolution. Journal of Molecular Biology, 2005. 346(4): p. 967-989.

24. Paz, M.L. and F.J. Barrantes, Autoimmune Attack of the Neuromuscular Junction in Myasthenia Gravis: Nicotinic Acetylcholine Receptors and Other Targets. ACS Chemical Neuroscience, 2019. 10(5): p. 2186-2194.

25. Noridomi, K., et al., Structural insights into the molecular mechanisms of myasthenia gravis and their therapeutic implications. eLife, 2017. 6: p. e23043.

26. Shen, C., W.-C. Xiong, and L. Mei, LRP4 in neuromuscular junction and bone development and diseases. Bone, 2015. 80: p. 101-108.

27. Strochlic, L., A. Cartaud, and J. Cartaud, The synaptic muscle-specific kinase (MuSK) complex: New partners, new functions. BioEssays, 2005. 27(11): p. 1129-1135.

28. Koneczny, I. and R. Herbst, Myasthenia Gravis: Pathogenic Effects of Autoantibodies on Neuromuscular Architecture. Cells, 2019. 8(7): p. 671.

29. Engel, A.G., Myasthenia gravis and myasthenic syndromes. Annals of Neurology, 1984. 16(5): p. 519534.

30. Lindstrom JM, S.M., Lennon VA, Whittingham S, Duane DD., Antibody to acetylcholine receptor in myasthenia gravis. Prevalence, clinical correlates, and diagnostic value. Neurology, 1976. 11: p. 10549.

31. Drachman, D.B., et al., Myasthenic Antibodies Cross-Link Acetylcholine Receptors to Accelerate Degradation. New England Journal of Medicine, 1978. 298(20): p. 1116-1122.

32. Drachman, D.B., et al., Functional Activities of Autoantibodies to Acetylcholine Receptors and the Clinical Severity of Myasthenia Gravis. New England Journal of Medicine, 1982. 307(13): p. 769-775.

33. Huijbers, M.G., et al., MuSK IgG4 autoantibodies cause myasthenia gravis by inhibiting binding between MUSK and Lrp4. Proceedings of the National Academy of Sciences of the United States of America, 2013. 110(51): p. 20783-20788.

34. Reddel SW, M.M., Phillips WD., Clinical and scientific aspects of muscle-specific tyrosine kinase-related myasthenia gravis. Curr Opin Neurol. , 2014. 5: p. 558-65.

35. Koneczny, I., et al., IgG4 autoantibodies against muscle-specific kinase undergo Fab-arm exchange in myasthenia gravis patients. Journal of Autoimmunity, 2017. 77: p. 104-115.

36. Shen, C., et al., Antibodies against low-density lipoprotein receptor-related protein 4 induce myasthenia gravis. The Journal of clinical investigation, 2013. 123(12): p. 5190-5202.

37. Dalmau, J., C. Geis, and F. Graus, Autoantibodies to Synaptic Receptors and Neuronal Cell Surface Proteins in Autoimmune Diseases of the Central Nervous System. Physiological reviews, 2017. 97(2): p. 839-887.

38. Gable, M.S., et al., The frequency of autoimmune N-methyl-D-aspartate receptor encephalitis surpasses that of individual viral etiologies in young individuals enrolled in the California Encephalitis Project. Clinical infectious diseases : an official publication of the Infectious Diseases Society of America, 2012. 54(7): p. 899-904.

39. Granerod, J., et al., New estimates of incidence of encephalitis in England. Emerging infectious diseases, 2013. 19(9): p. 1455-1462.

40. Gleichman, A.J., et al., Anti-NMDA Receptor Encephalitis Antibody Binding Is Dependent on Amino Acid Identity of a Small Region within the GluN1 Amino Terminal Domain. The Journal of Neuroscience, 2012.32(32): p. 11082-11094. 
41. Hara, M., et al., Clinical and pathogenic significance of IgG, IgA, and IgM antibodies against the NMDA receptor. Neurology, 2018. 90(16): p. e1386-e1394.

42. Ehrenreich, H., Autoantibodies against $\mathrm{N}$-methyl-d-aspartate receptor 1 in health and disease. Current opinion in neurology, 2018. 31 (3): p. 306-312.

43. Tüzün, E., et al., Evidence for antibody-mediated pathogenesis in anti-NMDAR encephalitis associated with ovarian teratoma. Acta neuropathologica, 2009. 118(6): p. 737-743.

44. Manto, M., et al., In vivo effects of antibodies from patients with anti-NMDA receptor encephalitis: further evidence of synaptic glutamatergic dysfunction. Orphanet journal of rare diseases, 2010. 5: p. 31-31.

45. Dalmau, J., et al., Anti-NMDA-receptor encephalitis: case series and analysis of the effects of antibodies. The Lancet. Neurology, 2008. 7(12): p. 1091-1098.

46. Hughes, E.G., et al., Cellular and synaptic mechanisms of anti-NMDA receptor encephalitis. The Journal of neuroscience : the official journal of the Society for Neuroscience, 2010. 30(17): p. 58665875 .

47. Liu, C.-Y., et al., Anti-N-Methyl-D-aspartate Receptor Encephalitis: A Severe, Potentially Reversible Autoimmune Encephalitis. Mediators of inflammation, 2017. 2017: p. 6361479-6361479.

48. Kayser, M.S., et al., Frequency and characteristics of isolated psychiatric episodes in anti-N-methyl-daspartate receptor encephalitis. JAMA neurology, 2013. 70(9): p. 1133-1139.

49. Pathmanandavel, K., et al., Antibodies to Surface Dopamine-2 Receptor and N-Methyl-D-Aspartate Receptor in the First Episode of Acute Psychosis in Children. Biological Psychiatry, 2015. 77(6): p. 537547.

50. Veerle Bergink, M.D., Ph.D. „, et al., Autoimmune Encephalitis in Postpartum Psychosis. American Journal of Psychiatry, 2015. 172(9): p. 901-908.

51. Khandaker, G.M., et al., Inflammation and immunity in schizophrenia: implications for pathophysiology and treatment. The lancet. Psychiatry, 2015. 2(3): p. 258-270.

52. Knight, J.G., et al., Rationale for a trial of immunosuppressive therapy in acute schizophrenia. Molecular Psychiatry, 2007. 12(5): p. 424-431.

53. Weickert, C.S., et al., Molecular evidence of $\mathrm{N}$-methyl-D-aspartate receptor hypofunction in schizophrenia. Molecular psychiatry, 2013. 18(11): p. 1185-1192.

54. Wen, Z., et al., Synaptic dysregulation in a human iPS cell model of mental disorders. Nature, 2014. 515(7527): p. 414-418.

55. Lennox, B.R., et al., Prevalence and clinical characteristics of serum neuronal cell surface antibodies in first-episode psychosis: a case-control study. The lancet. Psychiatry, 2017. 4(1): p. 42-48.

56. Hoffmann, C., et al., Absence of Autoantibodies Against Neuronal Surface Antigens in Sera of Patients With Psychotic Disorders. JAMA Psychiatry, 2019.

57. de Witte, L.D., et al., Absence of N-Methyl-D-Aspartate Receptor IgG Autoantibodies in Schizophrenia: The Importance of Cross-Validation Studies. JAMA Psychiatry, 2015. 72(7): p. 731-733.

58. Gomez, A.M., et al., Targeting plasma cells with proteasome inhibitors: possible roles in treating myasthenia gravis? Annals of the New York Academy of Sciences, 2012. 1274(1): p. 48-59.

59. Díaz-Manera, J., et al., Long-lasting treatment effect of rituximab in MuSK myasthenia. Neurology, 2012. 78(3): p. 189-193.

60. Gomez, A.M., et al., Proteasome Inhibition with Bortezomib Depletes Plasma Cells and Autoantibodies in Experimental Autoimmune Myasthenia Gravis. The Journal of Immunology, 2011. 186(4): p. 25032513. 
61. Gomez, A.M., et al., Proteasome inhibition with bortezomib depletes plasma cells and specific autoantibody production in primary thymic cell cultures from early-onset myasthenia gravis patients. Journal of immunology (Baltimore, Md. : 1950), 2014. 193(3): p. 1055-1063.

62. Behrendt, V., et al., Bortezomib Treatment for Patients With Anti-N-Methyl-d-Aspartate Receptor Encephalitis. JAMA Neurology, 2016. 73(10): p. 1251-1253.

63. Titulaer, M.J., M.S. Kayser, and J. Dalmau, Prevalence and treatment of anti-NMDA receptor encephalitis - Authors' reply. The Lancet Neurology, 2013. 12(5): p. 425-426.

64. Scheibe, F., et al., Bortezomib for treatment of therapy-refractory anti-NMDA receptor encephalitis. Neurology, 2017. 88(4): p. 366-370.

65. Silvestri NJ, W.G., Treatment-refractory myasthenia gravis. J Clin Neuromuscul Dis. , 2014. 4: p. $167-78$.

66. Mantegazza, R. and C. Antozzi, When myasthenia gravis is deemed refractory: clinical signposts and treatment strategies. Therapeutic advances in neurological disorders, 2018. 11: p. 17562856177491341756285617749134.

67. Howard Jr., J.F., et al., A randomized, double-blind, placebo-controlled phase II study of eculizumab in patients with refractory generalized myasthenia gravis. Muscle \& Nerve, 2013. 48(1): p. 76-84.

68. Zebardast, N., et al., Rituximab in the management of refractory myasthenia gravis. Muscle \& Nerve, 2010. 41 (3): p. 375-378.

69. Titulaer, M.J., et al., Treatment and prognostic factors for long-term outcome in patients with antiNMDA receptor encephalitis: an observational cohort study. The Lancet. Neurology, 2013. 12(2): p. 157-165.

70. Lee, W.-J., et al., Rituximab treatment for autoimmune limbic encephalitis in an institutional cohort. Neurology, 2016. 86(18): p. 1683- 
General introduction 


\section{2.}

\section{Autoimmunity in psychotic disorders. Where we stand, challenges and opportunities}

Marina Mané-Damas, Carolin Hoffmann, Shenghua Zong, Amanda Tan, Peter C. Molenaar, Mario Losen, Pilar Martinez-Martínez

Department of Psychiatry and Neuropsychology, School of Mental Health and Neuroscience, Maastricht University, Maastricht, the Netherlands

Autoimmunity Reviews. 2019 Sep;18(9):102348. Doi: 10.1016/j.autrev.2019.102348. Epub 2019 Jul 16. 
Autoimmunity in psychotic disorders. Where we stand, challenges and opportunities 


\section{Abstract}

Psychotic disorders are debilitating mental illnesses associated with abnormalities in various neurotransmitter systems. The development of disease-modifing therapies has been hampered by the mostly unknown etiologies and pathophysiologies.

Autoantibodies against several neuronal antigens are responsible for autoimmune encephalitis. These autoantibodies disrupt neurotransmission within the brain, resulting in a wide range of psychiatric and neurologic manifestations, including psychosis. The overlap of symptoms of autoimmune encephalitis with psychotic disorders raised the question as to whether autoantibodies against a number of receptors, ion channel and associated proteins could ultimately be responsible for some forms of psychosis. Here we review our current knowledge, on antibody mediated autoimmunity in psychotic disorders, the different diagnostic methods and their limitations, as well as on varying therapeutic approaches targeting the immune system.

\section{Keywords}

Channelopathies, psychosis, neuropsychiatric, autoantibodies, immunotherapy 


\section{Highlights}

- Antibodies can alter receptor and channel functions leading to psychotic symptoms.

- Neurological signs can be subtle or misinterpreted in patients with prominent psychotic symptoms.

- The use of standardized assays and CSF is essential to define autoimmunity in psychotic disorders.

- Specificity and sensitivity variations create controversial results in the field.

- Larger, homogeneous and systematically described cohorts need to be studied. 


\section{Table of content}

1. Introduction

2. Autoimmunity

2.1. Autoimmune mechanisms in channelopathies

3. Blood-brain-barrier

4. Antibody-mediated channelopathies in neuropsychiatric disorders

4.1. Incidence of autoantibodies in psychotic disorders

4.2. Case reports of patients with strong psychotic manifestations

5. Sensitivity and specificity

5.1. Sensitivity and false negatives

5.2. Specificity and false positives

5.3. Considerations for combining diagnostic assays

6. Effect of immunosuppression and new therapeutic approaches

7. Conclusions 


\section{Abbreviations}

AChR acetylcholine receptor

AMPAR a-amino-3-hydroxy-5-methyl-4-isoxazolepropionic acid receptor

BBB blood brain barrier

CASPR2 contactin-associated protein 2

CBA cell-based assay

CNS central nervous system

CSF cerebrospinal fluid

D2DR dopamine receptor D2

DPPX dipeptidyl aminopeptidase-like protein 6

$\mathrm{GABA}_{A} R$ gamma-aminobutyric acid A receptor

$\mathrm{GABA}_{B} \mathrm{R}$ gamma-aminobutyric acid $\mathrm{B}$ receptor

GAD glutamic acid decarboxylase

GlyR glycine receptor

Ig immunoglobulin

IHC immunohistochemistry

IVIG intravenous immunoglobulin

LGII leucine-rich glioma inactivated protein I

MAC membrane attack complex

NMDAR N-methyl-d-aspartate receptor

RIA radioimmunoassay

VGKC/C voltage-gated potassium channel/complex 


\section{Introduction}

Psychotic disorders like schizophrenia and bipolar disorder have been well documented in terms of prevalence, demographics and co-morbidity. The pathophysiology of these disorders, however, remains poorly understood. Robust evidence suggests that synaptic transmission within dopaminergic and glutamatergic pathways is altered, which may result in a disequilibrium between inhibitory-excitatory mechanisms. Diminished function of neurotransmitter receptors like dopamine- and N-methyl-Daspartate receptors (NMDAR) and dysfunction of ion channels such as voltage-gated potassium channels (VGKC), have all been shown to play an important role in the development and progression of schizophrenia [1-3]. Interestingly, antibodies and venom peptides targeting purinoceptors (P2X7), transient receptor potential cation channels (TRPC4 and TRPC5), cannabinoid receptor, nicotinic alpha7 receptor, gamma-aminobutyric acid $A$ receptor $\left(G A B A_{A} R\right)$ and a-amino-3-hydroxy-5-methyl-4isoxazolepropionic acid receptor (AMPAR) are currently approved or under clinical trial indicated for cognitive impairment, anxiety, depression and schizophrenia [4,5]. Furthermore, there are genetic risk factors: studies in large, pooled, cohorts have indicated that there are variations in the genetic coding for ion channels (common and rare gene variants), which thereby could increase the risk for psychotic disorders. Single nucleotide polymorphisms in genes encoding for the L-type calcium channel, affecting the gene activity of two subunits (CACNAIC and CACNB2), have been identified as risk loci, with shared effects in five major neuropsychiatric disorders, including schizophrenia and bipolar disorder [6]. Alterations in neurexin genes, coding for proteins involved in synaptic differentiation and transmission, have been associated with higher risk of developing schizophrenia [7,8] and autism [7,9-11]. Moreover, there are also genetic factors that affect the immune system. Gene variants encoding for human leukocyte antigen (HLA) regions (major histocompatibility complex (MHC) molecules), involved in building an immune response through antigen presentation, have also firmly been associated with an increased risk of schizophrenia [12,13].

The idea that autoimmunity may play a role in neuropsychiatric disorders began to take root in the last decade. Dr. Dalmau was the first to describe a group of patients with encephalitis associated with ovarian teratoma. After developing prodromal symptoms such as fever, headache and nausea, patients presented with a variety of severe psychotic and neurological manifestations, including anxiety, delusions, mania, short-term memory loss and seizures. Extensive analysis showed that serum and cerebrospinal fluid (CSF) contained antibody reactivity towards neuronal tissue, which was also present in the tumor. Autoantibodies reacted specifically against the NRI subunits of the NMDAR. After immunosuppressive treatment and tumor resection, most of the patients recovered completely, regaining their normal social behavior and cognitive abilities in the absence of any remaining 
neuropsychiatric manifestations. This previously unassociated collection of symptoms was termed autoimmune encephaltitis [14].

It is not entirely unexpected, of course, that antibodies targeting neuronal receptors can cause psychotic symptoms. Neurotransmitter receptor antagonists such as phencyclidine, quinuclidinyl benzilate and lysergic acid diethylamide, that block NMDAR, muscarinic acetylcholine receptor and 5-HT receptor, respectively, are well-known to be potent hallucinogens. Agonists of the cannabinoid receptors also have the capacity to induce psychosis [15-20]. The different mechanisms by which autoantibodies alter synaptic transmission likely impacts the widespread function of neurons and neural networks, culminating in serious mental (and neurological) disturbances (Fig. 1).
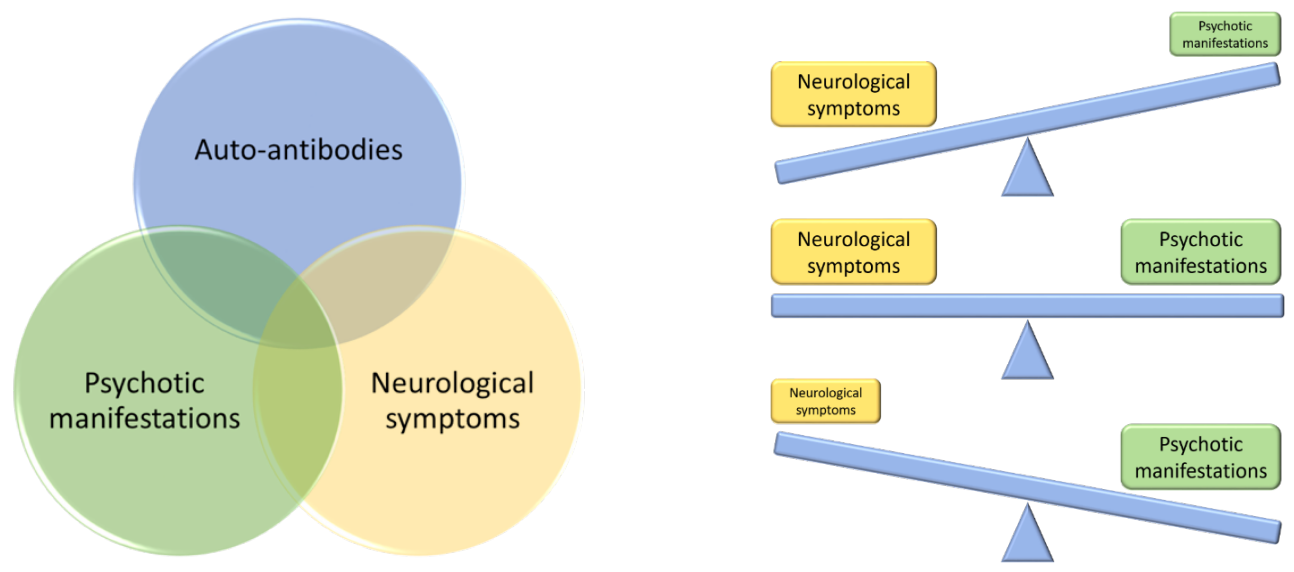

Fig. 1. Venn diagram of the relationship between neurological, psychotic and autoimmune disorders. The overlap between the different diseases is being described in this review. Autoimmune encephalitis is a case in point, where autoantibodies (blue) and neurological symptoms (yellow) have been found with or without psychotic manifestations (green). However, the balance between the neurological symptoms and the psychotic manifestations can vary largely among the different disorders where autoantibodies are the organic cause of the pathology. These could lead in some cases to misdiagnoses and the use of anti-psychotic drugs instead of immunotherapy. This review focuses on the findings regarding the area shared by the 3 disciplines, where psychiatric and neurological manifestations are caused by the presence of autoantibodies. However, the scales represent the different expression of psychotic and neurological manifestations in different cases, raising the possibility of having a new subgroup of patients with autoimmune psychotic disorders with subtle or undetectable neurological symptoms. 
This article reviews what is known about the occurrence of autoantibodies against neuronal neurotransmitter receptors, voltage-gated ion channels and associated proteins. We also summarize the effect of the autoantibodies in the patholophysiology of neuropsychiatric disorders and the corresponding treatment options.

\section{Autoimmunity}

Autoimmune diseases occur in 7-9\% of the general population [21]. Specialized cells are generated in the adaptative response, namely $T$ and $B$ lymphocytes. This requires a maturation process with several built-in check points to detect and delete defective cells. One of these mechanisms is the acquisition of tolerance, which is generated centrally and peripherally in the lymphoid organs, where the lymphocytes are screened for their ability to distinguish between self and non-self-antigens [22]. Failure of this machinery can lead to autoimmunity where different cell mechanisms are involved. Autoimmune disorders can show a wide expression of phenotypes ranging from endocrine, musculoskeletal to neurological syndromes. Diseases where ion channels, on the surface of nerve or muscle membranes, are affected by autoantibodies, or altered by point mutations in the genome, have been named channelopathies [23,24].

\subsection{Autoimmune mechanisms in channelopathies}

Immunoglobulins (Igs) in the soluble form, commonly known as antibodies, are synthesized and released by B cells and plasma cells; differentiated B cells, developed in the lymphoid follicles, spleen and lymph nodes, are used as defence weapons in the adaptative immune response. $\lg M, \lg D, \lg G(1-4), \lg A(1-2)$ and IgE are different Ig isotypes with a shared general structure (Fig. 2), but differ in characteristics such as size, capacity to activate complement, FCR binding and response to antigen, which is based on the heavy chain of the constant region. IgG is the most abundant and has the longest half-life; its isoforms are the most studied in autoimmune diseases [25]. IgGl and IgG3 subclasses have the capacity to bind to protein antigens and induce endocytosis through cross-linking and can damage tissue as a result of complement activation, leading to loss of antigen function [26-28]. In contrast, the capacity to fix complement is lower or non-existent for the subclasses IgG2 and IgG4, which have higher affinity to polysaccharide antigens $[29,30]$. 


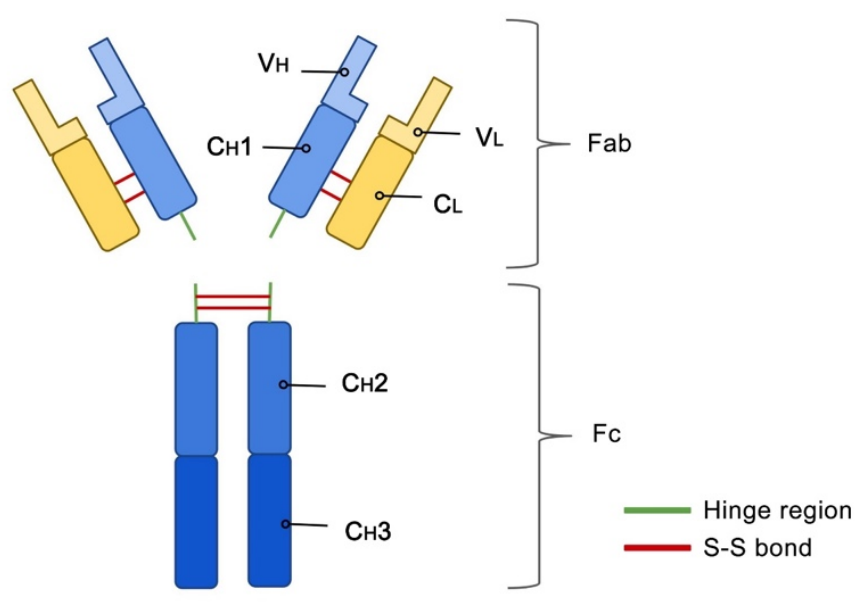

Fig. 2. General structure of an immunoglobulin. Immunoglobulins, commonly known as antibodies, are heterodimeric glycoproteins consisting of four chains, two heavy $(\mathrm{H})$ and two light $(\mathrm{L})$, each of them with constant $(\mathrm{C})$ and variable $(\mathrm{V})$ regions. Each $\mathrm{H}$ chain is composed by $3 \mathrm{C}(\mathrm{CH} 1-3)$ and $1 \mathrm{~V}(\mathrm{VH})$ regions, linked with a disulfide bound at the $\mathrm{CH} 2$. The $\mathrm{L}$ chains are formed by $\mathrm{a} \mathrm{C}(\mathrm{CL})$ and $\mathrm{a} V(\mathrm{VL})$ region and they are linked with the $\mathrm{H}$ chains one to one through the $\mathrm{CHI}$, in a "Y" shape molecule. The constant regions together form the Fc fragment, while the variable regions compose the Fab fragment.

IgG-mediated autoimmune disease mechanisms against membrane receptors ion channels and their associated proteins (Fig. 3) are summarized as follows:

a) Stimulation, inhibition or blocking of receptor or channel function. This mechanism has been observed in: i) infantile-onset neuropsychiatric disorders with psychomotor retardation, cerebellar ataxia, dyskinesia and in some cases, seizures due to the blocking of the folate receptor [31]; ii) autoimmune basal ganglia disorders with altered function of the dopamine receptor D2 (D2DR), comparable to the inhibitory effect of dopamine [32]; iii) cases of autoimmune encephalitis with hyper excitability in neurons in contact with antibodies targeting dipeptidyl aminopeptidase-like protein 6 (DPPX) [33] and iv) GABABR derived antibodies from limbic encephalitis patients which have been proposed to cause functional blockage of the receptors, seizures and memory dysfunction [34,35].

b) Antigenic modulation. The binding of $\mid g G 1$ leads to cross-linking of antigens, inducing internalization or endocytosis of the antigen-antibody complex, commonly followed by the degradation of the antigen. Examples are the cross-linking and selective internalization of NMDAR [14] as shown in cultured neurons [36-38] and also in an animal model of NMDAR 
encephalitis where reduction of membrane-associated NMDAR is observed [39]. Reduction in the number of receptors in the synapse has also been observed in vitro by autoantibodies to AMPAR [40,41], GABA ${ }_{A}$ [42], IgLON5 [43], neurexin-3 [44] and glycine receptor (GlyR) [45].

c) Complement activation and inflammation. Antigen-antibody complexes (IgG1 and IgG3 isotypes) lead to the activation of the complement system $[46,47]$. The activation of the complement system leads to i) chemo-attraction and activation of phagocytes; ii) opsonization and engulfment by phagocytes and iii) formation of membrane attack complex (MAC) in cell membranes leading to lysis, extensive tissue damage and loss of tissue architecture. Activation of the classical complement pathway is an important mechanism in Rasmussen's encephalitis, where antibodies against the subunit 3 of the AMPAR have been detected [48]. Autoantibodies to GlyR, associated to progressive encephalomyelitis with rigidity and myoclonus (PERM), were shown to induce deposition of $\mathrm{C} 3 \mathrm{~b}$ in an in vitro assay with colocalization of the patient autoantibodies, which are predominantly of the IgG1 subclass [49]. Complement mediated pathology has been reported in the voltage-gated potassium channel complex (VGKCC) encephalitis with autoantibodies against contactin-associated protein 2 (CASPR2). In this case the patient presented brain atrophy detected by MRI and deposition of the final complement complex was observed in a hippocampus biopsy [50]. Complement activation in brain biopsies was studied in different subjects, including patients with anti-NMDAR and anti-VGKCC antibodies. In this study, 3 out of 4 patients with VGKCC autoantibodies, independently of the antigen specificity [leucine-rich glioma inactivated protein I (LGI1) or CASPR2], showed reactivity to neurons and complement deposition on neurons in brain tissue. However, none of the 3 patients with NMDAR autoantibodies presented with complement deposition [51]. Another two studies presented similar results, with no evidence of complement deposition in brain biopsies from NMDAR encephalitis patients [52,53]. Based on the Ig isotype, complement mediated pathology could be hypothesized in $G A B A_{B} R, G A B A_{A} R$, mGluR5 and neurexin-3, where $\lg G 1$ is the most prevalent isotype described [54].

d) Loss or block of antigen-associated proteins. An important example of this is the VGKCC, where the autoantibodies are often directed against associated proteins, LGI1 and CASPR2 [55,56]. Antibodies to LGI1 can disrupt the interaction with scaffolding proteins like ADAM22 or ADAM23 [56,57]. Autoantibodies from patients with NMDAR encephalitis are found to interrupt the contact between NMDAR and Ephrin B2/EphB2 receptors, stabilizing and helping the receptor clustering in the postsynaptic membrane [58-61]. As a compensatory mechanism, increased EphB2 levels have been observed in vitro and in vivo [37]. A decrease of DPPX and Kv4.2 expression has been detected in presence of DPPX antibodies when incubated with hippocampal neurons [33,54]. 


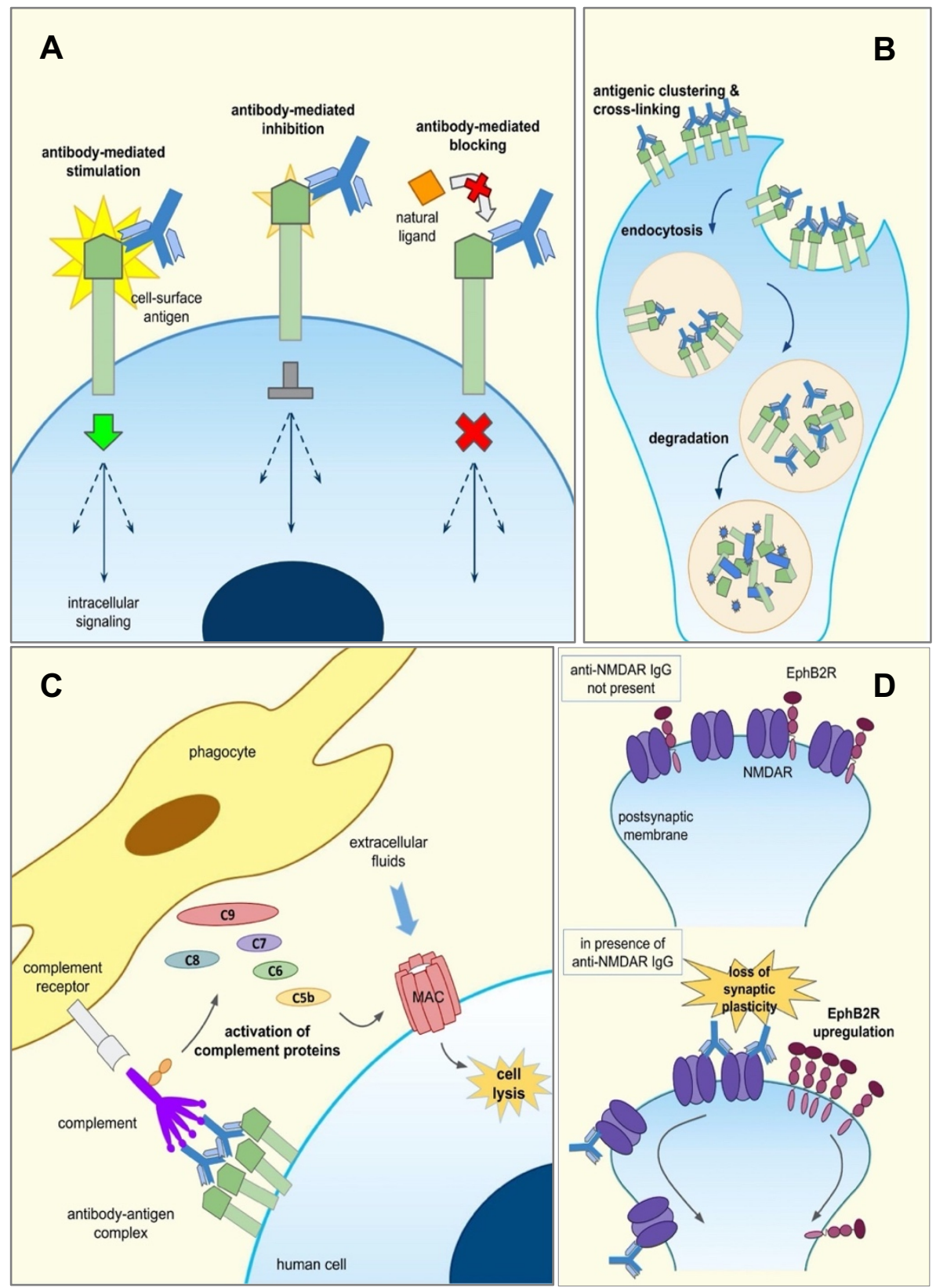

Fig. 3. IgG antibody-mediated disease mechanisms. A) The binding of an antibody to a cell surface antigen can cause either stimulation, inhibition or blocking to the action of agonists on the antigen and its intracellular signaling pathways. B) Cross-linking or clustering of antigens can occur when one antibody binds to 2 antigens. This triggers the removal of the antibody-antigen complexes via endocytosis, after which the complexes are degraded. C) Formation of an antibody-antigen complex can activate the complement system leading to 
chemoattraction of phagocytes, which can bind to complement via specific receptors, initiating opsonization and engulfment. Various other complement proteins are activated as well and assembled into a membrane attack complex (MAC). This creates a pore in the cell membrane through which extracellular fluids enter the cell, eventually inducing cell lysis. D) Antibodies can interfere with the contact between the antigen and its associated membrane proteins, as is the case for NMDA and EphB2 receptors. EphB2 receptors contribute to proper clustering of NMDAR in the postsynaptic membrane, which is crucial for synaptic plasticity. Antibodies can obstruct the contact between EphB2 and NMDAR, causing impaired synaptic retention of both receptors and loss of synaptic plasticity. As compensatory mechanism, EphB2R is upregulated.

\section{Blood-brain-barrier}

After the activation of the immune system, antibody producing cells travel in the blood to reach the organ with the targeted antigen. However, how antibodies or antibody producing cells reach the central nervous system (CNS) is still not well characterized. The blood brain barrier (BBB) unselectively prevents passage of the vast majority of molecules to the brain. The BBB is impermeable to hydrophilic substances and mostly also to large molecules such as proteins, so as to protect the CNS against the potential deleterious actions of these substances. In fact, antibodies can cross the human BBB to a limited extent [62] and reach sites in the CNS to exert pathogenic effects [63]. Diseases in which this is known to occur include paraneoplastic neurological syndromes [64], neuromyelitis optica [65], Stiff-person's syndrome [66], epilepsy with glutamic acid decarboxylase (GAD) antibodies [66,67], narcolepsy [68], dyslexia [69], Morvan's syndrome and limbic encephalitis [55].

Antibodies can be generated on both sides of the BBB, intrathecally [70] or peripherally from where they access the brain by crossing the BBB through different mechanisms. With an intact BBB, antibodies gain access to the CSF with a rate of $0.018 \mathrm{mg} / \mathrm{min}$ and have a turnover rate of five times per day, comparable to the CSF turnover itself of four times per day [62]. This very dynamic equilibrium results in brain IgG levels of around $1 \%$ of the plasma levels. Nonetheless IgG still composes $9.8 \%$ of the total protein in the CSF $[62,71]$, whereas $\lg A$ and $\lg M$ are found only in trace amounts [72]. Following local inflammatory reactions, it is known that the $\mathrm{BBB}$ becomes much more permeable. For instance, in multiple sclerosis, the permeability is increased six fold [71]. Moreover, neuroinflammation may lead to local production of antibodies by B-cells or plasma cells in the brain itself, so that the concentration of antibodies there is strongly increased. A high level of antibodies in the CSF indicates an intrathecal synthesis of antibodies by migrated antibody producing cells in the brain, which is in line with the observation that the level of antibodies in CSF is more closely related with relapses in NMDAR encephalitis than in serum [73]. In psychotic disorders, the CSF analysis presented elevated white cell count as well as total protein levels and albumin quotient in $3.4,42.2$ and $21.8 \%$ respectively, concluding that lgs have been intrathecally produced in $7.2 \%$ of the cases [74]. 
Recent studies have shown that the deep cervical lymph nodes have an important role in the processing and presentation of antigens of the CNS for T-cell mediated responses [75] but not for antibodymediated disorders. However, in NMDAR encephalitis, antibodies seem to occur earlier in CSF than in peripheral blood [76,77]. Moreover NMDAR antibodies have been cloned from CSF-derived cells [78], which indicates an intrathecal synthesis of autoantibodies [70]. This is usually accompanied with inflammatory changes such as pleocytosis and increased protein levels $[73,74,79]$. Furthermore, levels of the $\mathrm{B}$ cell attracting chemokine $\mathrm{C}-\mathrm{X}-\mathrm{C}$ motif chemokine 13 -CXCL13-, associated with plasma cells in the CNS, have been correlated with the intrathecal synthesis of NMDAR antibodies and with limited response to treatments and relapses [80].

It is important to note that in spite of the dynamic turnover of antibodies between the periphery and the brain, well-defined autoantibodies of peripheral diseases, like the Lambert-Eaton myasthenic syndrome and neuromyotonia, do not have central effects. This is remarkable because calcium Cav2.1 (P/Q-type) channels and VGKCC proteins are also present in the brain and could therefore be targeted by these antibodies. Thus, in some cases, CNS autoimmune channelopathies occur only when the integrity of the $B B B$ is disrupted and antibodies gain access to the brain at a higher rate. From this point of view, it might be argued that CASPR2 limbic encephalitis, Morvan's syndrome and acquired neuromyotonia harbor the same or similar disease aspects of pathophysiology and immunological pathogenesis, but that there is a relative difference in permeability of the BBB to the antibodies in these disorders [55].

In line with this, mice immunized with a peptide producing both antibodies to DNA and NMDAR did not show brain pathology unless the integrity of the BBB was challenged [63]. It is unlikely that the BBB is equally permeable to antibodies or antibody-producing cells throughout the brain. Factors affecting the BBB integrity with respect to the transport of antibodies may show regional specificity. This would explain why the "phenotype" of the antibody effect may well depend on the location where the antibody enters the brain and why the same autoantibody might have substantially different pathological effects between different groups of patients. After lipopolysaccharide treatment, NMDAR antibodies derived from systemic lupus erythematosus patients attack channels in hippocampal neurons [81], while the same antibodies damage channels in other regions of the brain, after treatment with adrenaline -which is known to breach BBB integrity [82] (see ref. [63] for a review on BBB and antibodies).

\section{Antibody-mediated channelopathies in neuropsychiatric disorders}

Over two-thirds of patients with autoimmune encephalitis have marked psychotic symptoms that can prevail in periods without obvious neurological manifestations; before onset of encephalitis or as a relapse. Around $45 \%$ of pediatric [83] and $16.5 \%$ of adults with limbic encephalitis [84] and antibodies to 
VGKCC presented with psychotic manifestations [85]. Many patients have their initial presentation at psychiatric services with more than $60 \%$ being first admitted to a psychiatric unit [86-88]. The psychotic manifestations are similar to those seen in schizophrenia including delusional and delirious thinking, anxiety, insomnia, paranoid thoughts, manic and aggressive behaviour, hallucinations and catatonic movement disorder [70,83, 89-92]. In VGKCC antibody-associated encephalopathy, cognitive impairment is an important feature but other neuropsychiatric symptoms occur in various degrees, mainly characterized by personality changes, depression and anxiety (see ref. [85] for review including single case studies). These findings indicate that some cases with underlying encephalitis could be mistaken for a primary psychotic disorder.

\subsection{Incidence of autoantibodies in psychotic disorders}

In the past 10 years, numerous cohorts of patients with mental disorders have been tested for the presence of specific neuronal autoantibodies, with those against the NMDAR and the VGKCC being the most well-described. Outcomes of these studies are variable, as are the detection methods applied. This section summarizes these findings. Details of relevant studies are shown in Table 1. 
Table 1. Studies on the prevalence of neuronal autoantibodies in psychotic disorders

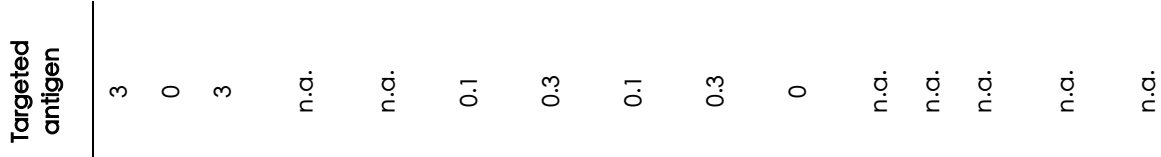

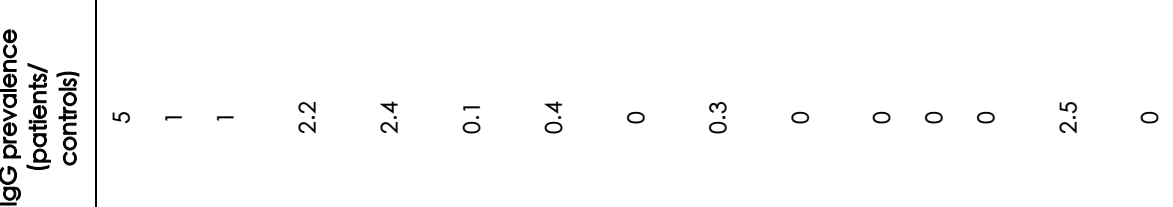

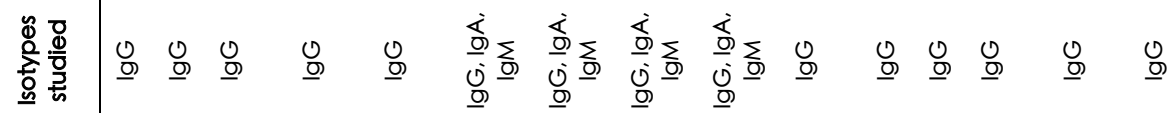

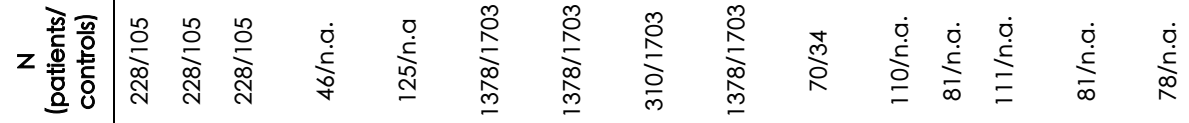

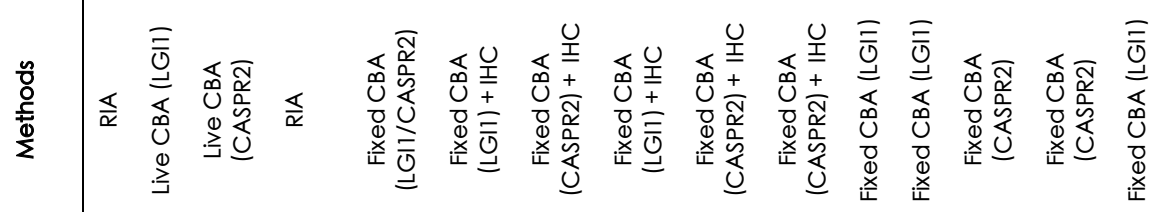

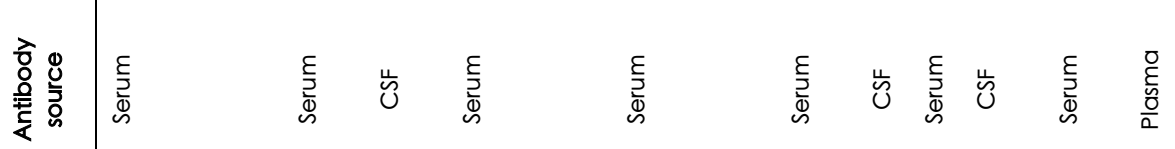

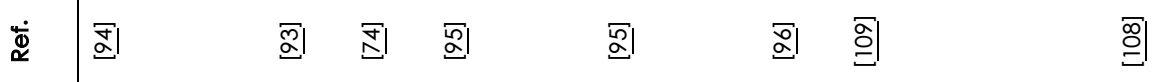

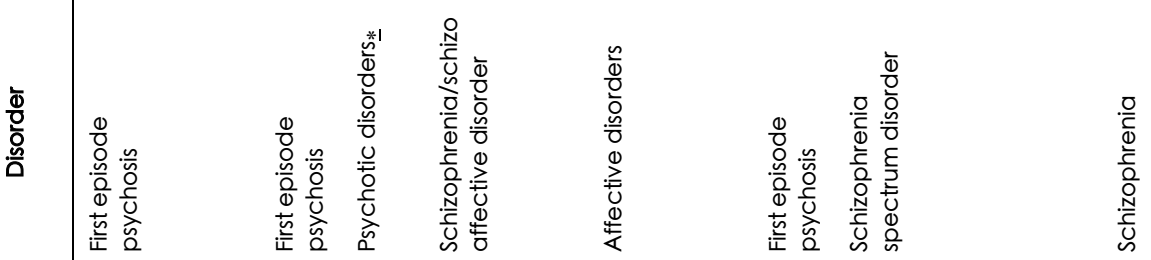

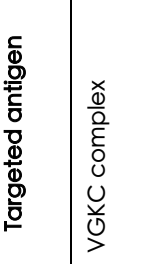




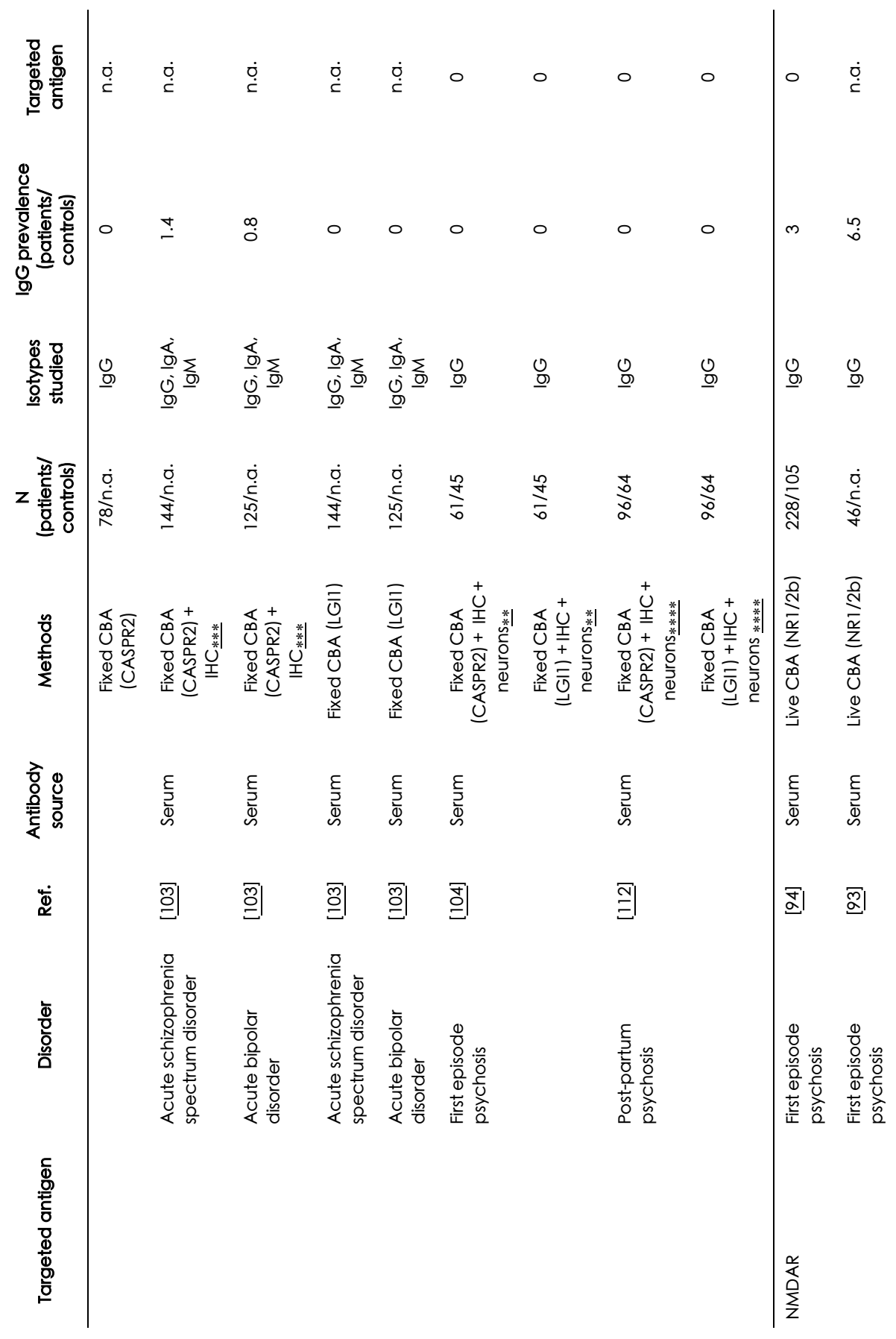




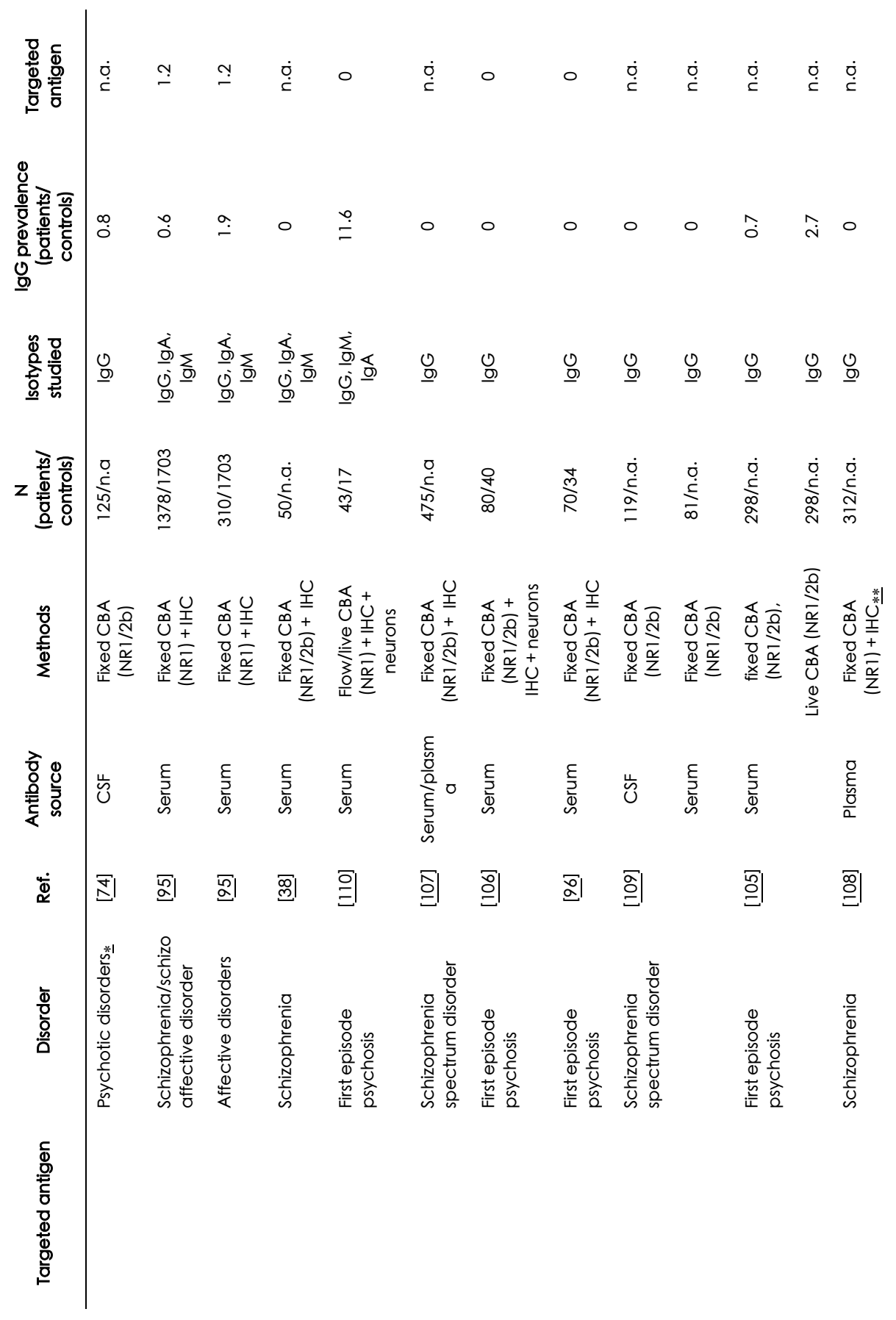




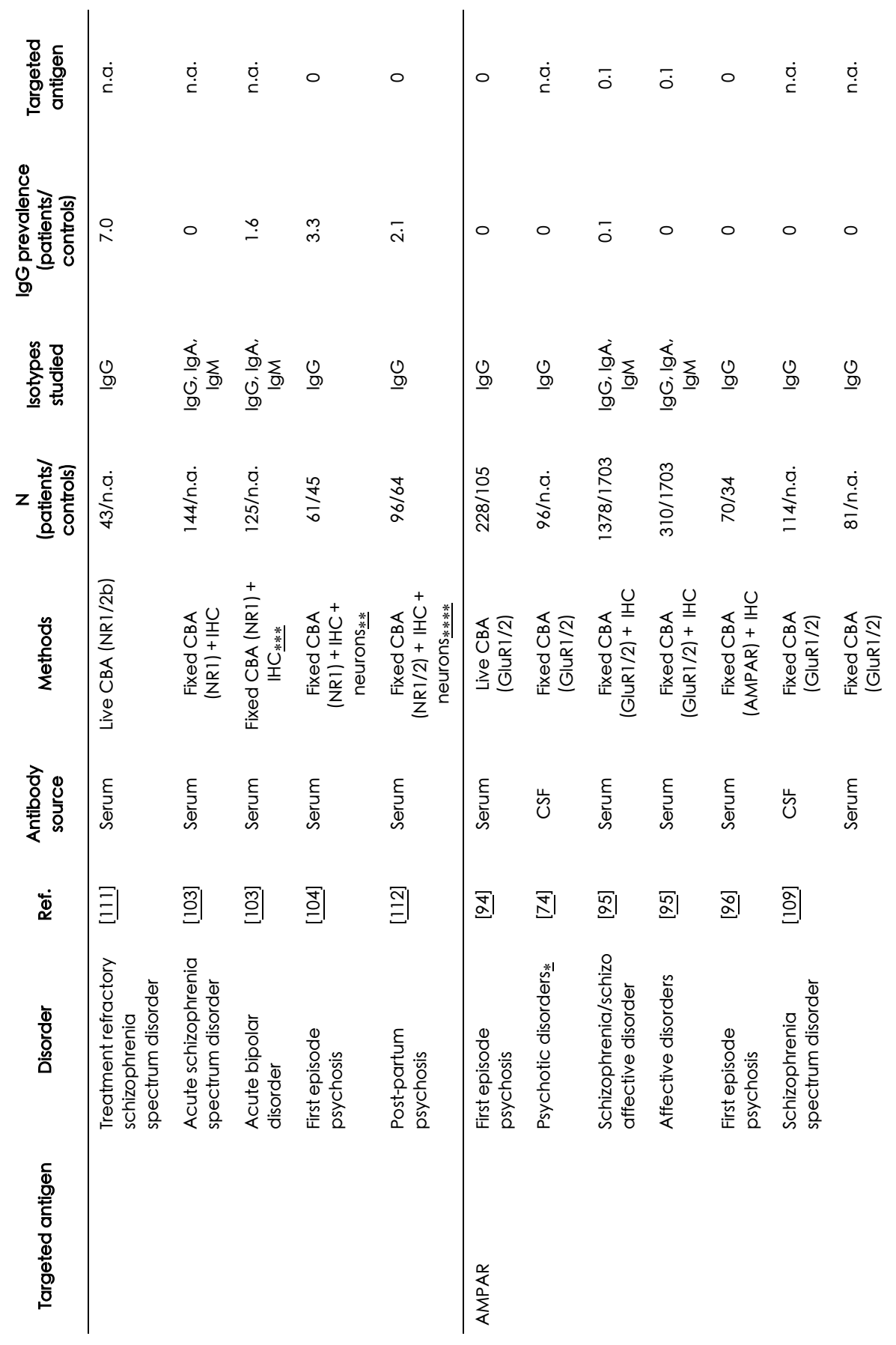




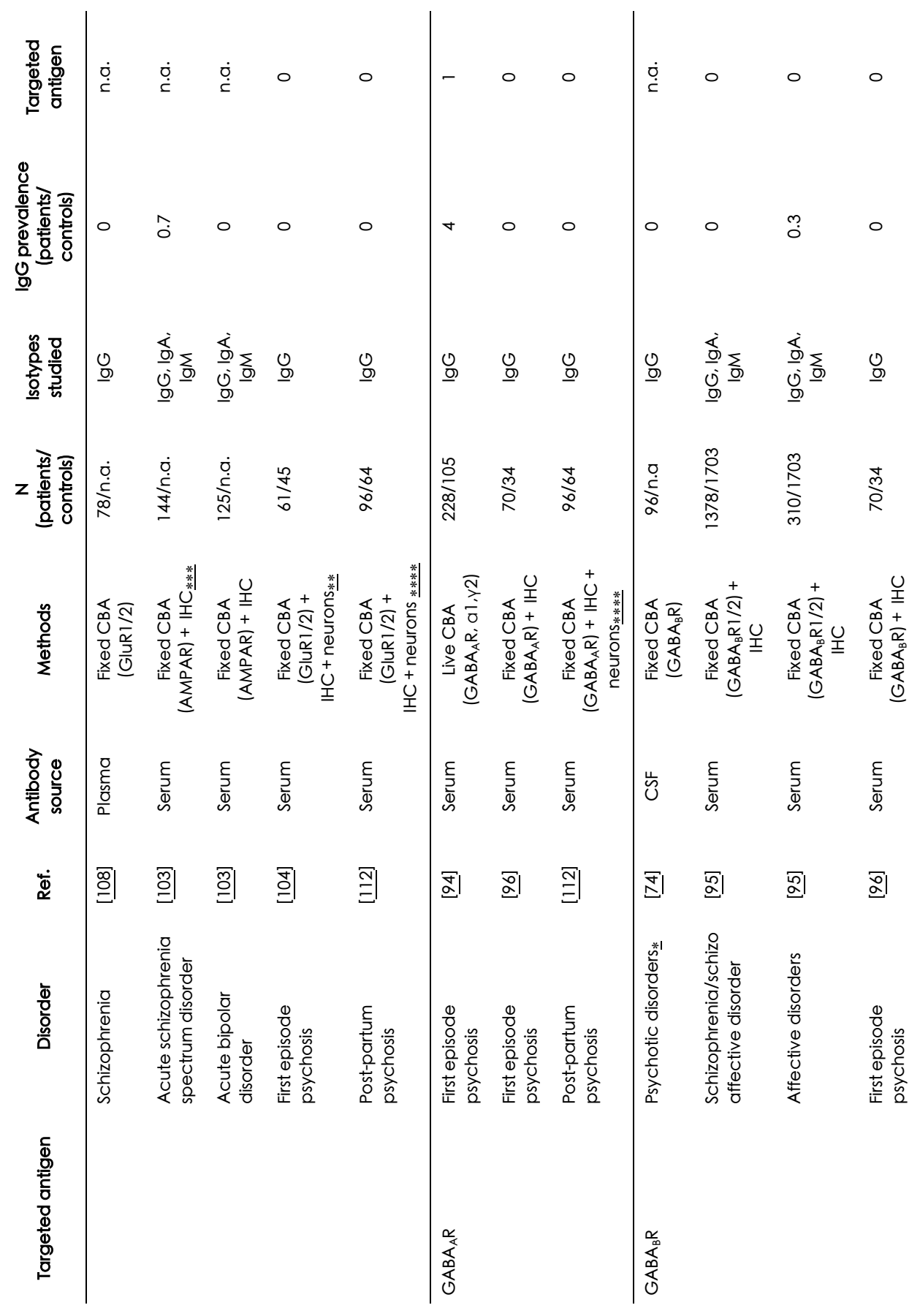




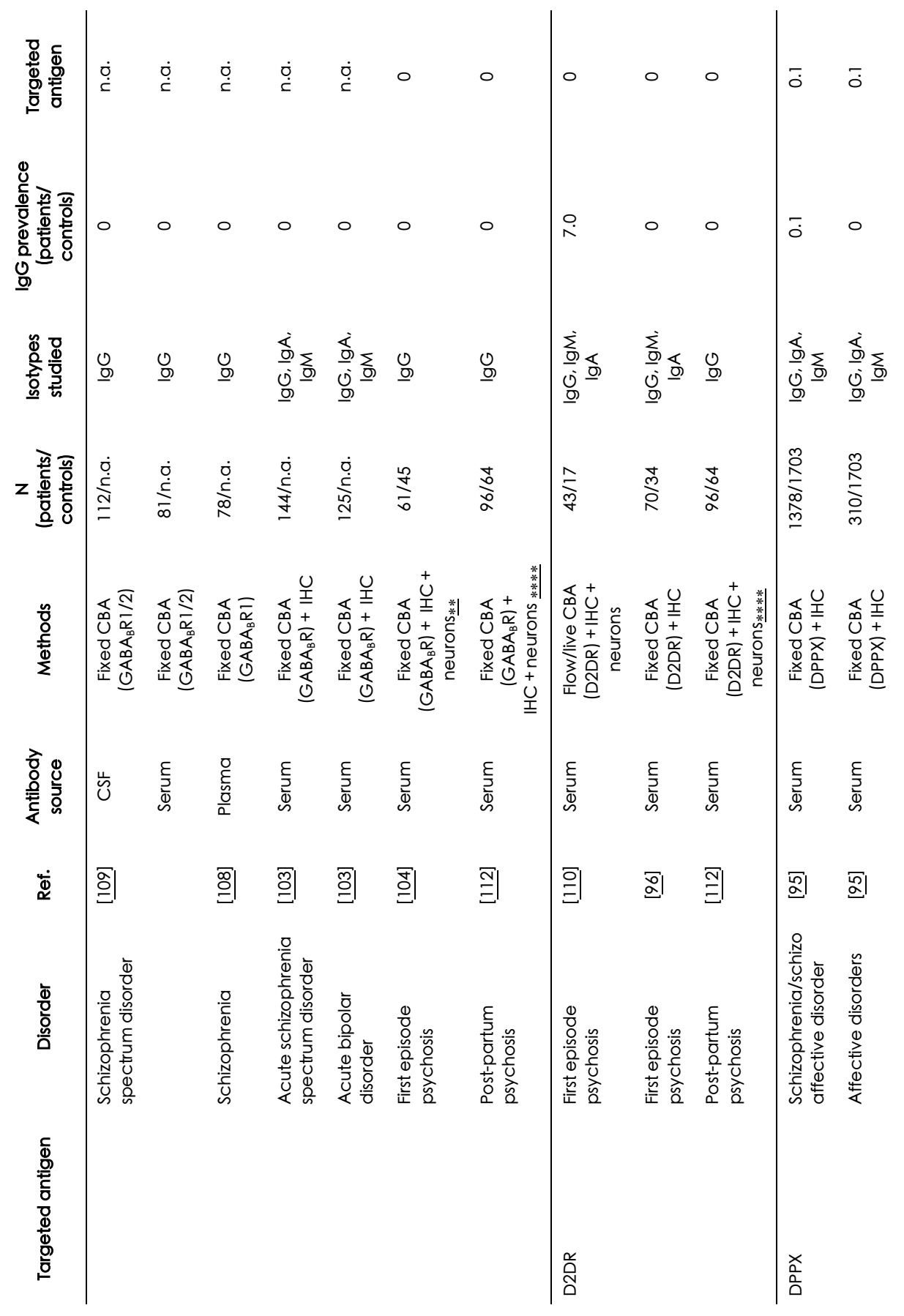




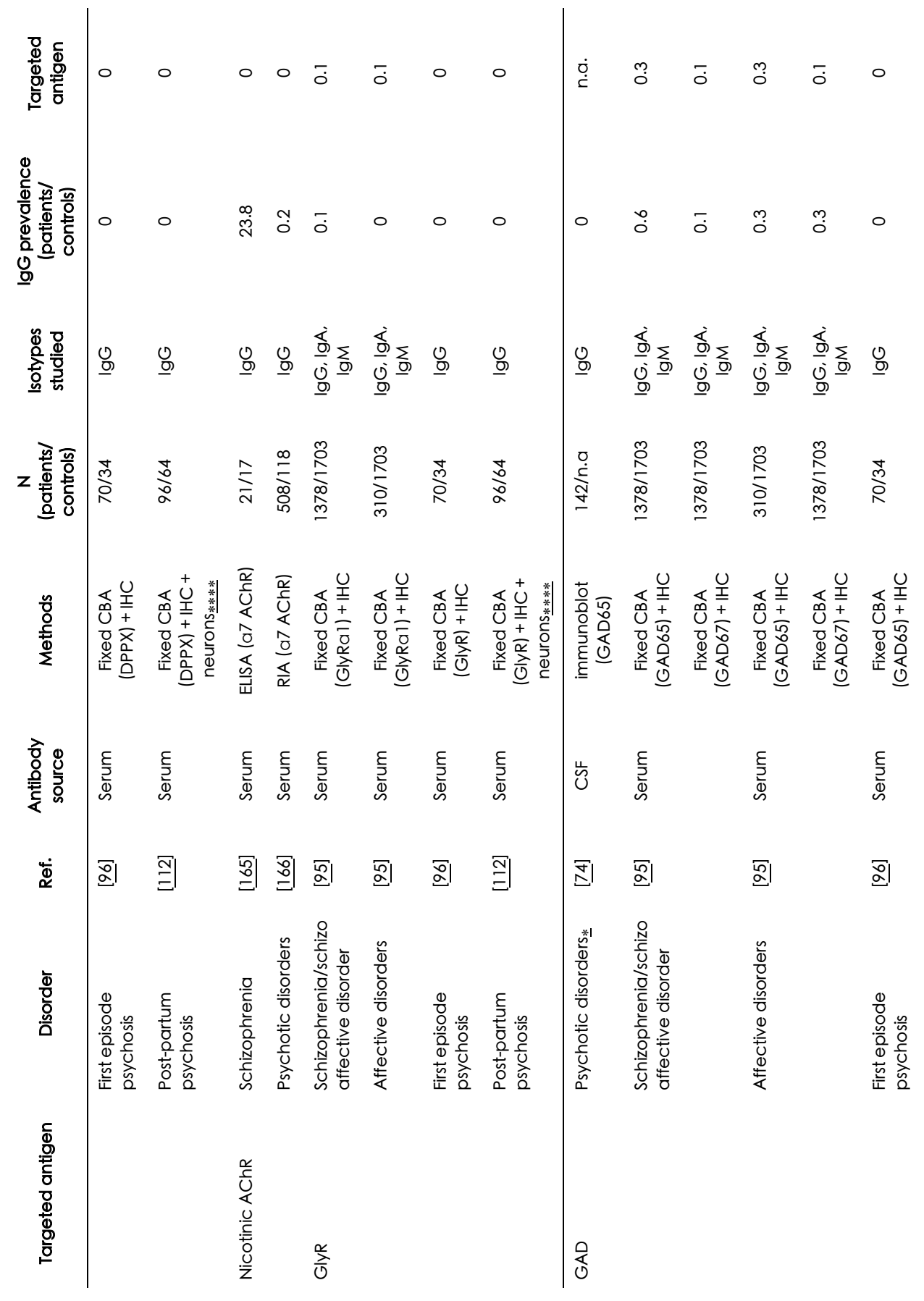




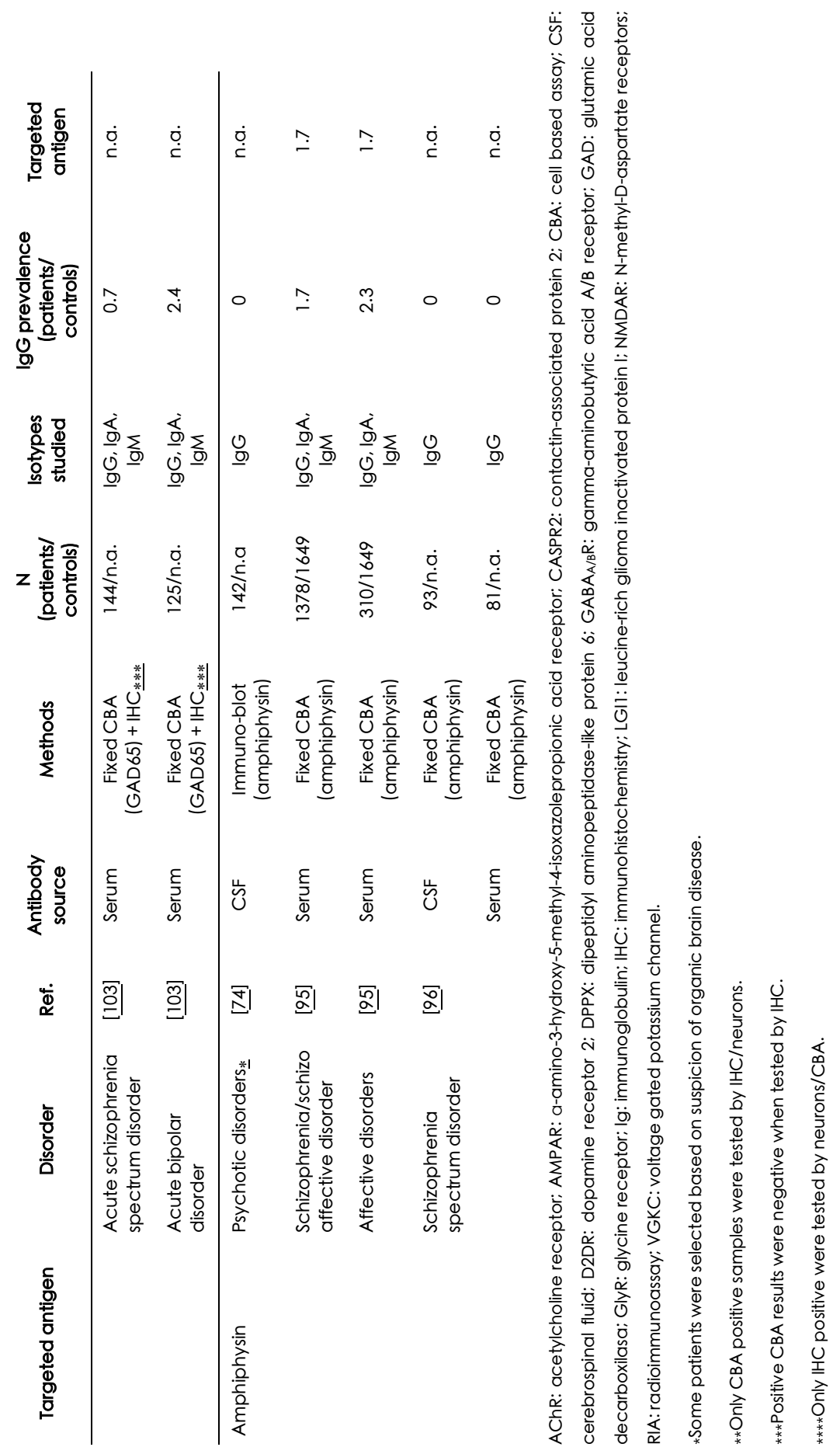


An initial study reported serological prevalence of antibodies to VGKCC in first episode psychosis (2.2\%) [93], tested by radioimmunoassay (RIA), but lacked a control group. A recent study also using VGKCC RIA reported a similar prevalence of autoantibodies both in first episode psychosis (5\%) as well as controls (3\%) [94]. Importantly, the same and other studies find much lower prevalences when studying specific IgG autoantibodies targeting LGI1 and CASPR2 by cell based assay (CBA) (0-1\%) [95-97]. Antibodies to LGI1 but not to CASPR2 were also detected in 2 out of $144(1.4 \%)$ patients with actute schizophrenia disorders and in 1 out of 125 patients $(0.8 \%)$ with acute bipolar disorder in serum by CBA. However this study lacked a control group and CBA positive sera gave negative results by immunohistochemistry (IHC) [103]. However, it is important to keep in mind that autoantibodies against VGKCC but not directed against LGI1 or CASPR2, have no clinical relevance in cases of autoimmune encephalitis [98-100].

Variable results have been reported for the prevalence of autoantibodies to NMDAR in patients with psychotic disorders. Several studies have shown high prevalence $(\sim 10 \%)$ of autoantibodies when including IgG, IgA, and IgM isotypes. However, there were no differences in the distribution of Igs among psychotic patients, other neuropsychiatric disorders and healthy controls; indicating that these isotypes are not disease specific $[95,101,102]$. When studying only the IgG isotype, these and other studies reported much lower NMDAR prevalences in psychotic patients (0.7-3.3\%) [74,94,103-105] or complete absence of these autoantibodies [96,103,106-109]. A recent study also analyzed the three Ig isotypes in serum of different disease cohorts (NMDAR encephalitis, suspected autoimmune encephalitis, schizophrenia, stroke, and dementia), and found that the IgG NMDAR autoantibodies were disease specific for NMDAR encephalitis, with no antibodies present in 50 schizophrenia subjects nor in the other disease groups. In addition, IgG but not IgA or IgM had pathogenic effects in vitro [38].

Higher prevalence of NMDAR IgG autoantibodies have been, however, found in special cohorts of psychotic disorders: The first group included children with first episode of acute psychosis. Using a combination of NR1 and D2DR flow cytometry, CBA and primary neuronal cell culture, Pathmanandavel and colleagues found serum NMDAR IgG antibodies in 5 out of 43 of these children (one of the patients had IgG + IgM autoantibodies targeting NRI, one had IgG to NRI + D2DR IgG autoantibodies, and another one had IgA but not IgG to NR1) [110]. The second group consisted of a cohort of 43 refractory patients with schizophrenia or schizoaffective disorder (with a mean duration of more than 15 years). IgG autoantibodies to NMDAR were found in $7 \%$ of the cases by live CBA. None of the patients had MRI abnormalities, nor neurological signs including seizures [111]. However, the lack of a control group, together with the exclusive use of live CBA, known to give higher detection rates [105], make these results difficult to interpret. The third group consisted of patients with post-partum psychosis. Neuronal surface reactivity was detected by brain IHC in serum in 4 out of 96 post-partum patients with psychosis. Two of 
these patients specifically presented IgG against the NMDAR by CBA. However, all the patients recovered without any immunotherapy [112]. Effects of the maternal antibodies in the offspring have been so far only described in cases of autism spectrum disorder, mental retardation and/or disorders of psychological development [113], specific language difficulties and dyslexia [69, 114-117], all of them disorders wich develop early in life.

The detection of autoantibodies have proven to be more sensitive in CSF compared to serum in cases of NMDAR encephalitis $[73,118,119]$. However, in psychotic disorder cohorts, there is limited access to CSF samples. NMDAR and VGKCC (LGI1 and CASPR2) autoantibodies were detected in CSF (not tested in serum) in $0.8 \%$ for NMDAR antibodies and $2.4 \%$ for VGKCC antibodies in psychotic disorder patients [74]. Another study with a similar cohort showed comparable percentages of VGKCC autoantibodies in CSF (2.5\% positive for CASPR2) but no antibodies were detected for NMDAR. No neuronal autoantibodies were found in the serum from the same patients [109]. The difficulty of interpreting studies where CSF has been analyzed, is that there are no control cohorts available, and the results have not been crossvalidated.

Antibodies against other neuronal antigens have been described for autoimmune encephalitis and are associated with psychotic manifestations. To date autoantibodies to $A M P A R, G A B A_{B} R, G A B A_{A} R, D 2 D R$, GlyR, mGluR1/mGluR5, alpha7 AChR, GAD67/GAD67, amphiphysin, neurexin, etc. have been reported as absent or at low prevalence among psychotic disorders (reviewed by [54]).

Interestingly, some studies have reported presence of autoantibodies against unkonwn neuronal antigens. This is the case of 2 out of 96 post-partum psychosis patients, who showed reactivity by brain immunohistochemistry and immunocytochemistry using live hippocampal neurons [112]. In 17 out of 925 cases, patients admitted to acute psychiatric care, presented immunofluorescence staining on rat and monkey brain sections, without corresponding to a specific antigen [103]. A cohort from the Netherlands Study of Depression and Anxiety (NESDA) revealed that 8 out of 1739 patients but none of the 492 controls, presented with strong hippocampal patterns by rat brain IHC. Five of the positive patients were confirmed by primary hippocampal neurons and all of them shared common clinical manifestations, characterized by anxiety (Zong et al., manuscript in preparation). Similar results have been observed in a cohort of neuropsychiatric disorders, where autoantibodies against neuronal antigens have been detected by brain IHC in 14 out of 621 patients with psychosis, in 1 out of 70 patients with affective disorders and in 5 out of 259 non-disease controls (Hoffmann et al., manuscript in preparation). 


\subsection{Case reports of patients with strong psychotic manifestations}

The increasing awareness of autoimmune encephalitis clinical presentation among clinicians and especially psychiatrists has led to early diagnoses of autoimmune encephalitis with psychotic manifestations. However, there are still a number of case reports with NMDAR autoantibodies predominantly with psychotic symptoms, where a correct diagnosis was complicated. These patients were given provisional diagnoses such as dissociative disorder, or psychotic disorder for several weeks or even years, until the presence of antibodies was finally discovered and treated accordingly with immunosuppression $[90,120,121]$. A recent case reported a misdiagnosed autoimmune encephalitis with VGKCC antibodies in a 16-year old girl, acutely presenting with isolated psychotic symptoms characterized by mania, psychosis and various behavioral and personality changes with no evidence of any neurological abnormality. Psychotropic medication only aggravated some of the symptoms and resulted in a minimal overall improvement. After 2 weeks, high levels of anti-VGKCC antibodies (but not specifically against LGI1 or CASPR2) were detected in serum (methodology not clearly specified). The patient received several courses of intravenous immunoglobulin (IVIG) and methylprednisolone and gradually recovered to normal status, 6-9 months after the psychotic episode [122,123].

Yet, despite the presence of neurological symptoms, an autoimmune condition can be misdiagnosed as psychotic disorder. Especially, after initiation of antipsychotic medication, typical autoimmune symptoms such as dyskinesias are often assumed to be extrapyramidal side effects [5]. Also, epilepsy patients have shown increased risk of psychosis and psychotic illness [124,125], whilst schizophrenic patients are also more likely to suffer from epilepsy [126]. Therefore, it is not surprising that psychotic manifestations are accompanied in many cases by neurological abnormalities, including seizures and therefore the diagnosis of autoimmune encephalitis can be delayed.

A case of a 17-year old male was reported with acute behavioral and mental disturbances characterized by psychosis, agitation, disorganization in behavior and thought processes, hypermetabolism and catatonia, together with seizures. Upon unresponsiveness to antipsychotic agents, the patient underwent electroconvulsive therapy with a remarkable improvement. After a period of four weeks, CSF analysis revealed the presence of anti-NMDAR antibodies (methodology not specified). IVIG immunosuppressant therapy was started, showing a noteworthy improvement [127]. After a long history of alcohol excess consumption, depression and self-harm, a 58-year old male was admitted to the hospital after presenting with seizures, confusion, slurred speech and ataxia. After psychiatric assessment he was diagnosed with paranoid schizophrenia and given antipsychotic medication. Further tests were performed after a deterioration of his symptoms and epileptic onset. Antibodies to VGKCC were detected in serum but not in CSF (detection assay not specified) and the patient underwent plasmapheresis, in combination with 
IVIG and corticosteroids, which caused a substantial improvement of the seizures but with only a minor gain of his cognitive abilities [128].

Post-partum psychosis cases include: i) a 21-year old female presented with psychotic symptoms four weeks after giving birth. After a few weeks, she suffered generalized seizures and had high anti-nuclear antibody levels but no abnormalities in the CSF. A substantial improvement resulted from plasmapheresis and steroids treatment. Later, serum IgGs against VGKCC, specifically targeting LGIl were identified by RIA and live CBA respectively. The patient recovered completely after immunosuppressive treatment [129]; ii) three months after a normal delivery, a 25 year old female developed insomnia, agitation and thanatophobia (fear of death). Antipsychotic treatment, including electroconvulsive therapy, resulted in generalized seizures. After aggravation of the psychotic symptoms and a suicidal attempt, laboratory tests were performed. No abnormalities were detected in serum but in CSF, where antibodies to NMDAR were found (detection assay not specified). Forthwith she was diagnosed with an ovarian teratoma. Repeated IVIG and intravenous methylprednisolone did not show any relieve of symptoms. However, after tumor resection, the patient had a dramatic and stable improvement with minimal behavioural changes at 6 months after surgery [119]; iii) similarly, three women were hospitalized during pregnancy presenting with headache and malaise; followed by bizarre behavior, anxiety, paranoid delusions, seizures and a decreased level of consciousness. Ovarian teratoma was diagnosed in 2 cases (resulted in pregnancy termination in one of the cases). After the identification of NMDAR antibodies in serum and CSF by CBA, the patients were treated with methylprednisolone, plasmapheresis and/or IVIG, together with ovarian teratoma resection in 2 of the cases. The babies showed no abnormalities after birth [130].

Tumor resection and immunotherapy using first line treatment usually results in partial or complete disappearance of the symptoms. However, in some cases, second line immunosuppressive therapies are required. This is also described in two independent case reports of young women, who developed postpartum psychosis followed by typical signs of NMDAR encephalitis. One was diagnosed with ovarian teratoma and both had NMDAR autoantibodies in the CSF. Tumor removal, intravenous methylprednisolone and plasmapheresis resulted in little improvement, but subsequent rituximab therapy improved the clinical manifestations of both women dramatically $[131,132]$.

All in all, autoimmune encephalitis is estimated to have an annual incidence of around 1.2 per 100,000 cases [133]. In many case reports describing patients with pronounced psychotic manifestations, the methodology used to detect autoantibodies is not carefully detailed, making it very difficult to interpret results. Although we do not expect a higher incidence rate in the psychiatric population, we would still like to highlight the importance of considering the diagnosis of autoimmune encephalitis in patients presenting with psychosis and seizures. This is especially vital in those with no previous history of psychotic 
disorders, a rapid progression of the disease, or resistance to antipsychotic medication since the majority of the patients respond well to readily available immunotherapy.

\section{Sensitivity and specificity}

The interpretation of the results in the literature regarding patients with pronounced psychotic manifestations is, unfortunately, difficult. As described through this review, lack of specified methodological strategies and the choice of the different assays, together with the absence of control groups reduces the impact of the findings.

In a group of patients with psychosis, it is likely that the prevalence of neuronal surface antibodies will be below $1 \%$ per specific neuronal antibody, making the reliability of a positive outcome rather small. Thus, the outcome of individual tests would be a poor guidance for counseling immunotherapy and certainly would make simple screening for antibodies in psychosis unfeasible. False results can pose a considerable problem for its interpretation, especially when the probability of specific neuronal antibodies in the test group is low. This is because the reliability of a positive assay outcome is influenced by the prevalence and the number of false positives of the test, as depicted in Fig. 4: the lower the prevalence, the poorer is the reliability with a concomitant increase of the chance of obtaining false positive results. 


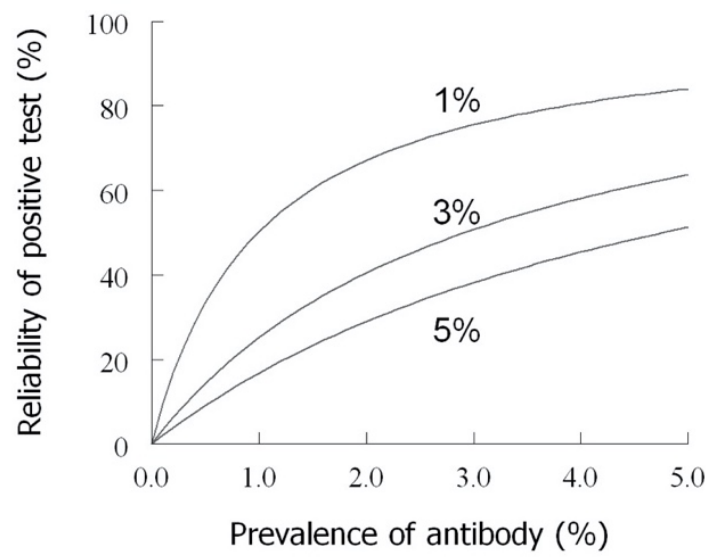

Fig. 4. Relation between reliability of positive outcomes of antibody tests as a function of the prevalence of the antibody within the targeted group with psychosis. The fractions are expressed as percentages. For specificity three conditions are shown, corresponding to $1 \%, 3 \%$ and $5 \%$ false positives assumed for the group of healthy controls. The graph is a hyperbole according to the equation Reliability $=\operatorname{Pr} /(\operatorname{Pr}+(1-S p)(1-\operatorname{Pr}))$, where $\operatorname{Pr}$ is prevalence of the autoantibody within the psychosis group and $\mathrm{Sp}$ the specificity of the antibody assay in the control group. For the equation it is assumed that the likelihood for yielding false positives in the psychosis patients without the antibody is the same as in the healthy control group. The figure shows that the antibody test becomes very unreliable when the prevalence is low in combination with a high percentage of false positives in the human control group. For example, with a prevalence of $1 \%$ and a specificity of $95 \%$, only $17 \%$ of all positive outcomes are expected positive whereas $83 \%$ of them are expected to be false. With $99 \%$ specificity, the outcomes are expected to be $50 \%$ correct and $50 \%$ false positives, respectively.

\subsection{Sensitivity and false negatives}

The fraction of disease cases that an assay correctly predicts, defines the clinical sensitivity of the assay in question [134,135]. A clinical assay should have around $70 \%$ or higher sensitivity to be useful. There are several reasons why an assay could result in negative outcomes for patients genuinely suffering from an autoimmune disease (i.e. with a sensitivity of $70 \%$ this would be $30 \%$ of all cases);

1) Low (undetectable) antibody concentration in blood

2) Low affinity of the antibody to the antigen 
3) High affinity and avidity of the antibody for the antigen in vivo, leading to reduced antibody levels in blood (immunoabsorption effect [136])

4) Interference between the protein in the sample and the assay (i.e. absence of the antibody in the membrane due to antibody internalization and resulting in unclear or ambiguous results)

5) Lack of recognition caused by conformational epitope changes (denaturalization or nonnative conformations) or by absence of receptor-associated proteins, required for the original exposure of the antigen (i.e. anchoring the receptor to the membrane and keeping it in its native conformation) [137]

6) Hook or prozone effect, caused by the excess of antibodies or the lack of agglutination and formation of immunocomplexes

\subsection{Specificity and false positives}

The fraction of individuals with absence of disease that an assay correctly predicts defines the clinical specificity of an immunological assay. Clinical specificity should be preferably $95 \%$ or higher to be useful. However, there are at least three reasons why a test might not be fully specific ( $95 \%$ specificity implies that there are $5 \%$ false positives in the control group). "False positive" outcomes may arise because:

1) The test sample does indeed contain an antibody that is directed to the antigen used in the test; but apparently non-pathogenic (e.g. by not reaching the CNS)

2) The test sample contains an (non-pathogenic) antibody that is directed to a "related" antigen which cross-reacts with the antigen used in the test (e.g. a similar receptor or ion channel)

3) A different protein in the sample interferes with the antigen staining so that an incorrect positive result is read in the laboratory

Is has been reported that positive results for NMDAR antibodies obtained by a commercial kit were not confirmed through cross-validation in two other independent laboratories using commercial and inhouse CBA as well as IHC [107]. This example highlights the importance of considering the variation across tests (including vatiability between different batches of the same test), which will result in differences in sensitivity, specificity, or background signal and supports the need for expert and independent approaches evaluating the results in order to reduce variability and inconsistent results $[105,107,138]$.

Changes in sensitivity and, specifically, in specificity between different laboratories (including companies), variations in the protein homology between species used in the assays and conformational modifications by the pre-treatment such as fixation of the tissue are all possible causes for incoherent or 
false positives/negatives to occur. Although the homology between human and rodent proteins reaches $95 \%$ in most cases, some differences in the extracellular regions can lead to false results, both positive and negative. It has also been observed that embryonic and adult forms of some subunits may differ [139] (i.e. the gamma subunit of the AChR is present in embryonic tissue but is replaced by a homologous epsilon subunit in adult tissue [140]). Different autoantibodies can coexist in the same patient and this phenomenon may occur in up to $10 \%$ of the patients with an autoimmune disease. This raises the possibility that part of the false responses are due to the presence of autoantibodies against a variety of antigens, some of which happen to cross-react with the antigen used in the assay.

\subsection{Considerations for combining diagnostic assays}

Cellular and tissue based techniques are used to diagnose the presence of autoantibodies. However, it is important to mention that when approaching psychotic disorder cohorts where the expected prevalence of autoantibodies is quite low, the methods likely require optimization.

Results from the different assays can be complementary but may not always be comparable. CBA for example is a very specific but not especially sensitive technique [105]. Within this method, variations exist in the experimental conditions, which will highly influence the results. Live CBA is known to better preserve the epitopes which can be damaged when applying fixatives and permeabilizing agents. Live assays, however, not withstanding the technical disadvantage that they can not be prepared as a kit in advance, have higher rates of positivity [105]. Variable results can also be dependent on the species origin from which the cells in the test are derived and also on the expression of the antigens when composed of different subunits (e.g. the NMDAR CBA can be set up with the NR1 or the NR1+NR2a/b or the NR2 subunit alone). The choice of antigen fragments used can also affect the validity of the CBA results e.g. i) the use of synthetic peptides, ii) parts or the complete antigen and iii) the incorporation of carrier proteins to detect secreted proteins that are naturally anchored to the membrane. This is highly relevant, since most of the antibodies have been shown to target the antigen when expressed in the native conformation in situ.

Whether one or another subunit is targeted can matter as this may be translated into different clinical manifestations For example, the NR1 subunit plays a pathogenic role in NMDAR encephalitis [141] whereas the second subunit of the receptor, NR2a/b, has been related with neuropsychiatric systemic lupus erythematosus [142].

A source of confusion has been the detection of different antibody isotypes and their subtypes. Some studies only report the presence of lgs without any distinction of which type and moreover, the 
pathogenic relevance of some of the isotypes is disputed [38,143]. Comparative studies in different disease cohorts showed that IgG was the most prevalent, pathogenic (validated using 3 different methods) and disease specific isotype for NMDAR. Furthermore, the experimental results, due to differences in sample dilution used in the separate assays (i.e. from 1:10 to 1:320 in CBA) are thus of limited comparability across experiments [38].

Some differences could stem from the type of body fluids that are tested, serum, plasma or CSF. Such differences have been reported in the literature, since there is no clear consensus on the most relevant fluid for diagnosis among the different types of encephalitis. Antibodies to $G A B A_{A} R$ were detectable in CSF samples from all patients using live or fixed CBA, while antibodies in serum were mostly visible only with the live version of the CBA [42]. In psychotic disorders where autoimmunity in the CNS could be responsible for the pathology, the analysis of the CSF is a critical point, since a role for lgs in neuropsychiatric disorders is doubtful when autoantibodies cannot be demonstrated in the CSF [144].

A minimum of two different tests in tandem should be used in order to decrease the likelihood of false outcomes. For example, it is recommended to use a combination of CBA' $s$, IHC and/or primary hippocampal cell culture assays or comparing similar tests between different laboratories. At the same time of course, it is also necessary to analyze a group of control samples to confirm that the antibodies are truly disease specific and so the number of "false positives" are reduced to negligible low levels. Screening of autoantibodies in these cases should be done in a panel rather than for individual antigens due to probable coexistence of different target antigens because of the overlap of symptoms in different cohorts [145] and in individual patients [146-148]. Lastly, it is very important to include an exhaustive psychiatric and neurological examination to preselect the patients to be tested, by recognizing particular symptoms that can be associated with specific autoimmune variants of the disease. Discovering such relevant clinical details is therefore the main challenge before we can start treating patients on the basis of individual test assays.

\section{Effect of immunosuppression and new therapeutic approaches}

When it is not too late, immunosuppressive intervention after immuno-diagnosis might avoid possible brain damage as a result of prolonged exposure of the target to the autoantibodies. Based on the evidence from autoimmune encephalitis, psychotic disorders caused by autoimmunity are expected to be similarly treatable by diminishing the level of the autoantibodies. First line immunotherapy may consist of high intravenous steroid (methylprednisolone), high-dose IVIG and/or plasma exchange. A substantial proportion of autoimmune encephalitis patients improve with these treatments. The non-responders have

to follow second line immunotherapies, based on cell therapy, including rituximab and 
cyclophosphamide [149]. Innovative therapies such as proteasome inhibitors, targeting plasma cells involved in the production of antibodies with a secretion of more than 10,000 molecules/cell/second [150] have been used to treat autoimmune diseases such as systemic lupus erythematosus, rheumatoid arthritis and myasthenia gravis [151]. Bortezomib, a first generation proteasome inhibitor, has been used as therapy in a small group of patients with treatment-resistant NMDAR encephalitis, showing a potential therapeutic effect of this drug in refractory patients [85]. A period of 4-8 months is required in most cases to recover completely, starting with a normalization of the autonomic dysfunctions, seizures and abnormal movements, followed by the recovery of the memory and attention deficits and of the behavior and executive impairment functions [73]. The effect of prolonged exposure to the autoantibodies synthesized by plasma cells within the CNS and the effect of these antibodies in the synapse can explain why the recovery in patients with encephalitis is slow. Infiltration of plasma cells and autoantibody production in NMDAR encephalitis [52,152] and the observation of the long white matter tracts degeneration, neuronal loss, antibody deposits and decreased expression of the target antigen, support the notion of an effect of plasma cells within the CNS [36,52].

NMDAR encephalitis cases with first episode isolated psychotic symptoms are treatable by immunotherapy and the majority of patients showed a good response [87], with early treatment predicting a better outcome [149]. However, it should be noted that upon recovery the CSF antibody levels decreased but still tested positive in most cases (i.e. 24 out of 28 patients with NMDAR antibodies) [73]. Plasmapheresis, IVIG and corticosteroids have shown good efficacy in autoimmune encephalitis patients with psychotic symptoms, leading to gradual improvement in all cases $[90,92,120,121,153,154]$. Second line immunosuppressants have been applied in an acute psychotic episode, after NMDAR antibodies were detected. A combination of intravenous steroids and IVIG together with cyclophosphamide and rituximab were administered and showed a slow but almost complete progressive recovery after a period of four months [155]. Immunotherapy in VGKCC antibody-associated encephalopathy, including IVIG or plasma exchange, effectively reduces antibody levels and showed an improvement of cognitive functions, although memory deficits are usually not fully reversible [118,128,129,156-161] which likely implicates some damage to the hippocampus. Complement activation could be responsible for this damage or, alternatively, calcium overload-induced neuronal cell death due to overstimulation, as inhibition of potassium current causes spontaneously high frequency firing. Such firing is observed in neuromyotonia, a peripheral disease with antibodies to VGKCC [162]. Whether or not immunotherapy would be equally beneficial in terms of efficacy and recovery in all autoimmune patients purely with psychotic symptoms is still unclear, since only a few cases (VGKCC and NMDAR positive) have been described up to now (see section on cases report). 


\section{Conclusions}

It is conceivable that an antibody against a neurotransmitter receptor or an ion channel evokes recognizable neurological symptoms in some way. In some cases these symptoms can be subtle and almost insignificant, tending to be overlooked when patients are first seen in psychiatry rather than in neurology departments [5]. It is also possible that a higher level of autoantibodies or a longer exposure time is necessary for neurological symptoms to surface in a patient.

Patients with neuronal autoantibodies diagnosed with a psychotic disorder, although rare, are now recognized primarily due to increasing awareness. However, to date only a few articles have described the presence of these autoantibodies (Table 1). Sample cohorts are usually small and heterogeneous, with an unclear distinction between the different mental disorders and the stage of the disease (especially in psychotic disorders, where the symptoms overlap among the different disorders). It is also clear that in many cases there is a superposition of clinical manifestations between autoimmune encephalitis and psychotic disorders [86]. There is a need to include neurological evaluation and CSF analysis in psychotic patients, since these symptoms can be easily misinterpreted. The use of more sensitive scales for mild symptoms such as the neurological soft signs examination, is intended to detect subtle but observable abnormalities in motor and sensory functions not associated with specific brain regions. Interestingly, several studies have reported lower neurological soft signs scores in healthy controls compared to patients with schizophrenia and bipolar disorder. This makes this scale very promising to identify neurological signs in specific cohorts where these manifestations are not very prominent, such as psychotic disorders $[163,164]$.

The identification of neurological manifestations could serve to better characterize this specific subgroup of autoimmune mediated mental disorder patients where psychotic manifestations are very pronounced, masking the neurological abnormalities. It is also important to mention that several neurological side effects including parkinsonism, akathisia, tardive syndromes, seizures and cerebrovascular events are often observed in patients on antipsychotic drugs. These neurological complaints can overlap with neurological symptoms due to an autoimmune reaction and be mistaken as purely side effects of the drugs.

The methodological differences of the diagnostic assays reviewed are a limiting factor, due to their specificity and sensitivity. There is a need to analyze the prevalence of antibodies targeting novel antigens that are not currently detectable, e.g. those that are not specifically targeting defined antigens, those that are not sufficiently homologous between rodent and human or antigens present on other cell types such as astrocytes and glial cells. 
The study of the autoantibodies using in vivo and in vitro techniques is essential to understand the pathogenic mechanisms underlying these rare autoimmune psychotic cases. This will help to create better diagnostic tools and more specific therapeutic strategies.

In the future, large systematic studies of psychotic patients are needed in order to examine the occurrence of autoimmune-related pathology such as antibody-mediated channelopathies. It is very important to learn how to select clinical phenotypes that help to identify certain patients as a group that runs an increased risk for an autoimmune pathology. Early diagnosis and treatment will reduce the possible sequels generated by the presence of autoantibodies in the target organ and will cut the recovery time of the patients.

\section{Take home message}

To date, pathogenic autoantibodies targeting neuronal surface antigens are very rare in psychotic disorders without any form of neurological manifestation.

It is essential that psychiatrists are aware of the existence of symptoms which overlap between autoimmune encephalitis and psychotic disorders in order to prompt early diagnosis and intervention for cases with an atypical disease course.

\section{Funding}

This work was supported by the Netherlands Organization for Scientific Research (NWO) "Graduate School of Translational Neuroscience Program" (022005019), the Brain Foundation of the Netherlands (KS2012(1)-157) and the ZonMW NWO Program Translationeel onderzoek (40-41200-98-9257); as well as the Veni Fellowship of NWO (916.10.148), a fellowship of the Brain Foundation of the Netherlands (FS2008(1)-28), the Prinses Beatrix Spierfonds (Project WAR08-12) and the China Scholarship Council (201507720015).

\section{Statement of author contributions}

All authors participated in the drafting of the manuscript and provided approval of the final submitted version. 
Declarations of interest

None.

\section{Acknowledgement}

We would also like to thank Ms. Tanya Mohile for providing language and writing assistance. 


\section{References}

1. Vukadinovic, Z. and I. Rosenzweig, Abnormalities in thalamic neurophysiology in schizophrenia: could psychosis be a result of potassium channel dysfunction? Neurosci Biobehav Rev, 2012. 36(2): p. 960-8.

2. Corti, C., et al., Altered levels of glutamatergic receptors and $\mathrm{Na}+/ \mathrm{K}+$ ATPase-alpha1 in the prefrontal cortex of subjects with schizophrenia. Schizophr Res, 2011. 128(1-3): p. 7-14.

3. Stephan, K.E., T. Baldeweg, and K.J. Friston, Synaptic plasticity and dysconnection in schizophrenia. Biol Psychiatry, 2006. 59(10): p. 929-39.

4. Wulff, H., et al., Antibodies and venom peptides: new modalities for ion channels. Nature Reviews Drug Discovery, 2019.

5. Hüfner, K., B. Frajo-Apor, and A. Hofer, Neurology Issues in Schizophrenia. Current Psychiatry Reports, 2015. 17(5): p. 32.

6. Smoller, J.W., et al., Identification of risk loci with shared effects on five major psychiatric disorders: a genome-wide analysis. Lancet, 2013. 381 (9875): p. 1371-9.

7. Gauthier, J., et al., Truncating mutations in NRXN2 and NRXN1 in autism spectrum disorders and schizophrenia. Human genetics, 2011. 130(4): p. 563-573.

8. Rujescu, D., et al., Disruption of the neurexin 1 gene is associated with schizophrenia. Human molecular genetics, 2009. 18(5): p. 988-996.

9. Feng, J., et al., High frequency of neurexin $1 B$ signal peptide structural variants in patients with autism. Neuroscience Letters, 2006. 409(1): p. 10-13.

10. Liu, Y., et al., Mutation analysis of the NRXN1 gene in a Chinese autism cohort. Journal of Psychiatric Research, 2012. 46(5): p. 630-634.

11. Vaags, Andrea K., et al., Rare Deletions at the Neurexin 3 Locus in Autism Spectrum Disorder. American Journal of Human Genetics, 2012. 90(1): p. 133-141.

12. Wright, P., et al., Schizophrenia and HLA: a review. Schizophrenia Research, 2001. 47(1): p. 1-12.

13. Crespi, B.J. and D.L. Thiselton, Comparative immunogenetics of autism and schizophrenia. Genes Brain Behav, 2011 . 10(7): p. 689-701.

14. Dalmau, J., et al., Paraneoplastic anti-N-methyl-D-aspartate receptor encephalitis associated with ovarian teratoma. Ann Neurol, 2007. 61 (1): p. 25-36.

15. Luby, E.D., et al., Study of a new schizophrenomimetic drug一sernyl. A.M.A. Archives of Neurology \& Psychiatry, 1959. 81 (3): p. 363-369.

16. Olney JW, F.N., Glutamate receptor dysfunction and schizophrenia. Arch Gen Psychiatry, 1995. 52(12): p. 998-1007.

17. Malhotra, A.K., et al., NMDA Receptor Function and Human Cognition: The Effects of Ketamine in Healthy Volunteers. Neuropsychopharmacology, 1996. 14: p. 301.

18. Malhotra, A.K., et al., Clozapine Blunts N-Methyl-d-Aspartate Antagonist-Induced Psychosis: A Study with Ketamine. Biological Psychiatry, 1997. 42(8): p. 664-668.

19. Bruna Brands, B.S., Joan Marshman, Drugs \& drug abuse: a reference text. third edition ed, ed. a.D.o.t.A.a.M.H.S.C. Addiction Research Foundation. 1998, Toronto, Ontario M5S 2 S1.

20. Gouzoulis-Mayfrank, E., et al., Psychological Effects of (S)-Ketamine and N,N-Dimethyltryptamine (DMT): A Double-Blind, Cross-Over Study in Healthy Volunteers. Pharmacopsychiatry, 2005. 38(06): p. 301-311. 
21. Cooper, G.S., M.L. Bynum, and E.C. Somers, Recent insights in the epidemiology of autoimmune diseases: improved prevalence estimates and understanding of clustering of diseases. J Autoimmun, 2009. 33(3-4): p. 197-207.

22. Schwartz, R.H., Historical Overview of Immunological Tolerance. Cold Spring Harbor Perspectives in Biology, 2012. 4(4): p. a006908.

23. RamaKrishnan, A.M. and K. Sankaranarayanan, Understanding autoimmunity: The ion channel perspective. Autoimmunity Reviews, 2016. 15(7): p. 585-620.

24. Vincent, A., Developments in autoimmune channelopathies. Autoimmunity Reviews, 2013. 12(6): p. 678-681.

25. Vidarsson, G., G. Dekkers, and T. Rispens, IgG subclasses and allotypes: from structure to effector functions. Frontiers in immunology, 2014. 5: p. 520-520.

26. Guo, J., et al., Recombinant thyroid peroxidase-specific Fab converted to immunoglobulin G (IgG) molecules: evidence for thyroid cell damage by IgG1, but not IgG4, autoantibodies. J Clin Endocrinol Metab, 1997. 82(3): p. 925-31.

27. Nagatomo, Y., et al., Autoantibodies Specifically Against B1 Adrenergic Receptors and Adverse Clinical Outcome in Patients With Chronic Systolic Heart Failure in the B-Blocker Era: The Importance of Immunoglobulin G3 Subclass. Journal of Cardiac Failure, 2016. 22(6): p. 417-422.

28. Phillips, W.D. and A. Vincent, Pathogenesis of myasthenia gravis: update on disease types, models, and mechanisms. F1000Res, 2016. 5.

29. Aalberse, R.C., et al., Immunoglobulin G4: an odd antibody. Clin Exp Allergy, 2009. 39(4): p. $469-77$.

30. van der Neut Kolfschoten, M., et al., Anti-inflammatory activity of human IgG4 antibodies by dynamic Fab arm exchange. Science, 2007. 317(5844): p. 1554-7.

31. Ramaekers, V.T., et al., Autoantibodies to Folate Receptors in the Cerebral Folate Deficiency Syndrome. New England Journal of Medicine, 2005. 352(19): p. 1985-1991.

32. Cox, C.J., et al., Brain Human Monoclonal Autoantibody from Sydenham Chorea Targets Dopaminergic Neurons in Transgenic Mice and Signals Dopamine D2 Receptor: Implications in Human Disease. The Journal of Immunology, 2013. 191 (11): p. 5524-5541.

33. Boronat, A., et al., Encephalitis and antibodies to DPPX, a subunit of Kv4.2 potassium channels. Annals of neurology, 2013. 73(1): p. 120-128.

34. Jain A, L.E., Dalmau J, Balice-Gordon RJ. , Autoantibodies in the CSF of anti-GABA receptor encephalitis patients block activation of GABA receptors in vitro. Ann Neurol, 2015. 78(S77).

35. Lancaster, E., et al., Antibodies to the GABA(B) receptor in limbic encephalitis with seizures: case series and characterisation of the antigen. The Lancet. Neurology, 2010. 9(1): p. 67-76.

36. Hughes, E.G., et al., Cellular and Synaptic Mechanisms of Anti-NMDA Receptor Encephalitis. The Journal of Neuroscience, 2010. 30(17): p. 5866-5875.

37. Mikasova, L., et al., Disrupted surface cross-talk between NMDA and Ephrin-B2 receptors in anti-NMDA encephalitis. Brain, 2012. 135(5): p. 1606-1621.

38. Hara, M., et al., Clinical and pathogenic significance of IgG, IgA, and IgM antibodies against the NMDA receptor. Neurology, 2018. 90(16): p. e1386-e1394.

39. Planagumà, J., et al., Human N-methyl D-aspartate receptor antibodies alter memory and behaviour in mice. Brain, 2015. 138(1): p. 94-109.

40. Lai, M., et al., AMPA receptor antibodies in limbic encephalitis alter synaptic receptor location. Ann Neurol, 2009. 65(4): p. 424-34.

41. Haselmann, H., et al., Human Autoantibodies against the AMPA Receptor Subunit GluA2 Induce Receptor Reorganization and Memory Dysfunction. Neuron, 2018. 100(1): p. 91-105.e9. 
42. Petit-Pedrol, M., et al., Encephalitis with refractory seizures, status epilepticus, and antibodies to the GABAA receptor: a case series, characterisation of the antigen, and analysis of the effects of antibodies. The Lancet. Neurology, 2014. 13(3): p. 276-286.

43. Sabater, L., et al., A novel non-rapid-eye movement and rapid-eye-movement parasomnia with sleep breathing disorder associated with antibodies to IgLON5: a case series, characterisation of the antigen, and post-mortem study. The Lancet Neurology, 2014. 13(6): p. 575-586.

44. Gresa-Arribas, N., et al., Human neurexin-3a antibodies associate with encephalitis and alter synapse development. Neurology, 2016. 86(24): p. 2235-2242.

45. Hutchinson, M., et al., Progressive encephalomyelitis, rigidity, and myoclonus: a novel glycine receptor antibody. Neurology, 2008. 71(16): p. 1291-2.

46. Gomez, A.M., et al., Antibody effector mechanisms in myasthenia gravis-pathogenesis at the neuromuscular junction. Autoimmunity, 2010. 43(5-6): p. 353-70.

47. Martin, F. and A.C. Chan, Pathogenic Roles of B Cells in Human Autoimmunity. Immunity, 2004. 20(5): p. 517-527.

48. Whitney, K.D. and J.O. McNamara, GluR3 Autoantibodies Destroy Neural Cells in a ComplementDependent Manner Modulated by Complement Regulatory Proteins. The Journal of Neuroscience, 2000. 20(19): p. 7307-7316.

49. Carvajal-González, A., et al., Glycine receptor antibodies in PERM and related syndromes: characteristics, clinical features and outcomes. Brain : a journal of neurology, 2014. 137(Pt 8): p. 21782192.

50. Körtvelyessy, P., et al., Complement-associated neuronal loss in a patient with CASPR2 antibodyassociated encephalitis. Neurology(R) neuroimmunology \& neuroinflammation, 2015. 2(2): p. e75-e75.

51. Bien, C.G., et al., Immunopathology of autoantibody-associated encephalitides: clues for pathogenesis. Brain, 2012. 135(5): p. 1622-1638.

52. Martinez-Hernandez, E., et al., Analysis of complement and plasma cells in the brain of patients with anti-NMDAR encephalitis. Neurology, 2011. 77(6): p. 589-593.

53. Tüzün, E., et al., Evidence for antibody-mediated pathogenesis in anti-NMDAR encephalitis associated with ovarian teratoma. Acta neuropathologica, 2009. 118(6): p. 737-743.

54. Dalmau, J., C. Geis, and F. Graus, Autoantibodies to Synaptic Receptors and Neuronal Cell Surface Proteins in Autoimmune Diseases of the Central Nervous System. Physiological Reviews, 2017. 97(2): p. 839-887.

55. Irani, S.R., et al., Antibodies to KV1 potassium channel-complex proteins leucine-rich, glioma inactivated 1 protein and contactin-associated protein-2 in limbic encephalitis, Morvan's syndrome and acquired neuromyotonia. Brain, 2010. 133(9): p. 2734-48.

56. Lai, M., et al., Investigation of LGII as the antigen in limbic encephalitis previously attributed to potassium channels: a case series. Lancet Neurol, 2010. 9(8): p. 776-85.

57. Ohkawa, T., et al., Autoantibodies to Epilepsy-Related LGI1 in Limbic Encephalitis Neutralize LGI1ADAM22 Interaction and Reduce Synaptic AMPA Receptors. The Journal of Neuroscience, 2013. 33(46): p. 18161-18174.

58. Dalva, M.B., et al., EphB Receptors Interact with NMDA Receptors and Regulate Excitatory Synapse Formation. Cell, 2000. 103(6): p. 945-956.

59. Henderson, J.T., et al., The Receptor Tyrosine Kinase EphB2 Regulates NMDA-Dependent Synaptic Function. Neuron, 2001. 32(6): p. 1041-1056.

60. Kullander, K. and R. Klein, Mechanisms and functions of eph and ephrin signalling. Nat Rev Mol Cell Biol, 2002. 3(7): p. 475-486. 
61. Lisabeth, E.M., G. Falivelli, and E.B. Pasquale, Eph Receptor Signaling and Ephrins. Cold Spring Harbor perspectives in biology, 2013. 5(9): p. 10.1101/cshperspect.a009159 a009159.

62. Poduslo, J.F., G.L. Curran, and C.T. Berg, Macromolecular permeability across the blood-nerve and blood-brain barriers. Proc Natl Acad Sci U S A, 1994. 91 (12): p. 5705-9.

63. Diamond, B., et al., Losing your nerves? Maybe it's the antibodies. Nat Rev Immunol, 2009. 9(6): p. 44956.

64. Honnorat, J. and J.C. Antoine, Paraneoplastic neurological syndromes. Orphanet J Rare Dis, 2007. 2: p. 22.

65. Lennon, V.A., et al., A serum autoantibody marker of neuromyelitis optica: distinction from multiple sclerosis. Lancet, 2004. 364(9451): p. 2106-12.

66. Solimena, M., et al., Autoantibodies to glutamic acid decarboxylase in a patient with stiff-man syndrome, epilepsy, and type I diabetes mellitus. N Engl J Med, 1988. 318(16): p. 1012-20.

67. Errichiello, L., et al., Autoantibodies to glutamic acid decarboxylase (GAD) in focal and generalized epilepsy: A study on 233 patients. J Neuroimmunol, 2009. 211 (1-2): p. 120-3.

68. Cvetkovic-Lopes, V., et al., Elevated Tribbles homolog 2-specific antibody levels in narcolepsy patients. J Clin Invest, 2010. 120(3): p. 713-9.

69. Vincent, A., et al., Maternal antibody-mediated dyslexia? Evidence for a pathogenic serum factor in a mother of two dyslexic children shown by transfer to mice using behavioural studies and magnetic resonance spectroscopy. J Neuroimmunol, 2002. 130(1-2): p. 243-7.

70. Dalmau, J., et al., Anti-NMDA-receptor encephalitis: case series and analysis of the effects of antibodies. Lancet Neurol, 2008. 7(12): p. 1091-8.

71. Cutler, R.W., G.V. Watters, and J.P. Hammerstad, The origin and turnover rates of cerebrospinal fluid albumin and gamma-globulin in man. J Neurol Sci, 1970. 10(3): p. 259-68.

72. Delisi, L.E., et al., Quantitative determination of immunoglobulins in CSF and plasma of chronic schizophrenic patients. Br J Psychiatry, 1981. 139: p. 513-8.

73. Gresa-Arribas, N., et al., Antibody titres at diagnosis and during follow-up of anti-NMDA receptor encephalitis: a retrospective study. Lancet Neurol, 2014. 13(2): p. 167-77.

74. Endres, D., et al., Immunological findings in psychotic syndromes: a tertiary care hospital's CSF sample of 180 patients. Frontiers in Human Neuroscience, 2015. 9: p. 476.

75. Louveau, A., et al., Structural and functional features of central nervous system lymphatics. Nature, 2015. 523(7560): p. 337-341.

76. Armangue, T., et al., Herpes Simplex Virus Encephalitis is a Trigger of Brain Autoimmunity. Annals of neurology, 2014. 75(2): p. 317-323.

77. Armangue, T., et al., Autoimmune post-herpes simplex encephalitis of adults and teenagers. Neurology, 2015. 85(20): p. 1736-1743.

78. Kreye, J., et al., Human cerebrospinal fluid monoclonal N -methyl-D-aspartate receptor autoantibodies are sufficient for encephalitis pathogenesis. Brain, 2016. 139(10): p. 2641-2652.

79. Viaccoz, A., et al., Clinical specificities of adult male patients with NMDA receptor antibodies encephalitis. Neurology, 2014. 82(7): p. 556-63.

80. Leypoldt, F., et al., Investigations on CXCL13 in Anti-N-Methyl-D-Aspartate Receptor Encephalitis: A Potential Biomarker of Treatment Response. JAMA neurology, 2015. 72(2): p. 180-186.

81. Kowal, C., et al., Cognition and Immunity: Antibody Impairs Memory. Immunity, 2004. 21 (2): p. $179-188$.

82. Huerta, P.T., et al., Immunity and behavior: antibodies alter emotion. Proceedings of the National Academy of Sciences of the United States of America, 2006. 103(3): p. 678-683. 
83. Hacohen, Y., et al., Paediatric autoimmune encephalopathies: clinical features, laboratory investigations and outcomes in patients with or without antibodies to known central nervous system autoantigens. J Neurol Neurosurg Psychiatry, 2013. 84(7): p. 748-55.

84. Klein, C.J., et al., Insights From LGI1 and CASPR2 Potassium Channel Complex Autoantibody Subtyping. JAMA neurology, 2013. 70(2): p. 229-234.

85. Pruss, H. and B.R. Lennox, Emerging psychiatric syndromes associated with antivoltage-gated potassium channel complex antibodies. J Neurol Neurosurg Psychiatry, 2016. 87(11): p. 1242-1247.

86. Creten, C., et al., Late onset autism and anti-NMDA-receptor encephalitis. Lancet, 201 1. 378(9785): p. 98.

87. Kayser, M.S., et al., Frequency and characteristics of isolated psychiatric episodes in anti-N-methyl-daspartate receptor encephalitis. JAMA Neurol, 2013. 70(9): p. 1133-9.

88. Bost, C., O. Pascual, and J. Honnorat, Autoimmune encephalitis in psychiatric institutions: current perspectives. Neuropsychiatr Dis Treat, 2016. 12: p. 2775-2787.

89. Chapman, M.R. and H.E. Vause, Anti-NMDA Receptor Encephalitis: Diagnosis, Psychiatric Presentation, and Treatment. American Journal of Psychiatry, 2011 . 168(3): p. 245-251.

90. Heekin, R.D., et al., Anti-NMDA Receptor Encephalitis in a Patient with Previous Psychosis and Neurological Abnormalities: A Diagnostic Challenge. Case Reports in Psychiatry, 2015. 2015: p. 253891.

91. Jeffery, O.J., et al., GABA(B) receptor autoantibody frequency in service serologic evaluation. Neurology, 2013. 81 (10): p. 882-887.

92. Sameer Belvi Mangalwedhe, et al., Anti-N-Methyl-d-Aspartate Receptor Encephalitis Presenting With Psychiatric Symptoms. The Journal of Neuropsychiatry and Clinical Neurosciences, 2015. 27(2): p. e152e153.

93. Zandi, M.S., et al., Disease-relevant autoantibodies in first episode schizophrenia. J Neurol, 201 1. 258(4): p. 686-8.

94. Lennox, B.R., et al., Prevalence and clinical characteristics of serum neuronal cell surface antibodies in first-episode psychosis: a case-control study. Lancet Psychiatry, 2017. 4(1): p. 42-48.

95. Dahm, L., et al., Seroprevalence of autoantibodies against brain antigens in health and disease. Ann Neurol, 2014. 76(1): p. 82-94.

96. Mantere, O., et al., Anti-neuronal anti-bodies in patients with early psychosis. Schizophrenia Research, 2017.

97. Chen, C.H., et al., Seroprevalence survey of selective anti-neuronal autoantibodies in patients with first-episode schizophrenia and chronic schizophrenia. Schizophr Res, 2017. 190: p. 28-31.

98. Huda, S., et al., An 11-year retrospective experience of antibodies against the voltage-gated potassium channel (VGKC) complex from a tertiary neurological centre. Journal of Neurology, 2015. 262(2): p. 418-424.

99. Paterson, R.W., et al., Clinical relevance of positive voltage-gated potassium channel (VGKC)complex antibodies: experience from a tertiary referral centre. Journal of Neurology, Neurosurgery \&amp; Psychiatry, 2014. 85(6): p. 625-630.

100. Klein, C.J., et al., Insights From LGI1 and CASPR2 Potassium Channel Complex Autoantibody SubtypingLGI1 and CASPR2 VGKC Complex Autoantibodies. JAMA Neurology, 2013. 70(2): p. $229-234$.

101. Steiner, J., et al., Increased Prevalence of Diverse N -Methyl-D-Aspartate Glutamate Receptor Antibodies in Patients With an Initial Diagnosis of Schizophrenia: Specific Relevance of IgG NRIa Antibodies for Distinction From N -Methyl-D-Aspartate Glutamate Receptor Encephalitis. JAMA Psychiatry, 2013: p. 1-8. 
102. Hammer, C., et al., Neuropsychiatric disease relevance of circulating anti-NMDA receptor autoantibodies depends on blood-brain barrier integrity. Mol Psychiatry, 2013.

103. Schou, M., et al., Prevalence of serum anti-neuronal autoantibodies in patients admitted to acute psychiatric care. Psychological Medicine, 2016. 46(16): p. 3303-3313.

104. Arboleya, S., et al., Anti-NMDAR antibodies in new-onset psychosis. Positive results in an HIV-infected patient. Brain, Behavior, and Immunity, 2016. 56: p. 56-60.

105. Jézéquel, J., et al., Cell- and Single Molecule-Based Methods to Detect Anti-N-Methyl-D-Aspartate Receptor Autoantibodies in Patients With First-Episode Psychosis From the OPTiMiSE Project. Biological Psychiatry, 2017. 82(10): p. 766-772.

106. Masdeu, J.C., et al., Serum IgG antibodies against the NR1 subunit of the NMDA receptor not detected in schizophrenia. Am J Psychiatry, 2012. 169(10): p. 1120-1.

107. de Witte, L.D., et al., Absence of N-Methyl-D-Aspartate Receptor IgG Autoantibodies in Schizophrenia: The Importance of Cross-Validation Studies. JAMA Psychiatry, 2015. 72(7): p. 731-3.

108. Chen, C.-H., et al., Seroprevalence survey of selective anti-neuronal autoantibodies in patients with first-episode schizophrenia and chronic schizophrenia. Schizophrenia Research, 2017. 190: p. 28-31.

109. Oviedo-Salcedo, T., et al., Absence of cerebrospinal fluid antineuronal antibodies in schizophrenia spectrum disorders. The British Journal of Psychiatry, 2018: p. 1-3.

110. Pathmanandavel, K., et al., Antibodies to Surface Dopamine-2 Receptor and N-Methyl-D-Aspartate Receptor in the First Episode of Acute Psychosis in Children. Biological Psychiatry, 2015. 77(6): p. 537547.

111. Beck, K., et al., Prevalence of serum N-methyl-D-aspartate receptor autoantibodies in refractory psychosis. The British journal of psychiatry : the journal of mental science, 2015. 206(2): p. 164-165.

112. Bergink, V., et al., Autoimmune Encephalitis in Postpartum Psychosis. American Journal of Psychiatry, 2015. 172(9): p. 901-908.

113. Coutinho, E., et al., CASPR2 autoantibodies are raised during pregnancy in mothers of children with mental retardation and disorders of psychological development but not autism. Journal of neurology, neurosurgery, and psychiatry, 2017. 88(9): p. 718-721.

114. Warren, R.P., et al., Detection of maternal antibodies in infantile autism. J Am Acad Child Adolesc Psychiatry, 1990. 29(6): p. 873-7.

115. Vincent, A., et al., Antibodies in myasthenia gravis and related disorders. Ann N Y Acad Sci, 2003. 998: p. 324-35.

116. Dalton, P., et al., Maternal neuronal antibodies associated with autism and a language disorder. Ann Neurol, 2003. 53(4): p. 533-7.

117. Martin, L.A., et al., Stereotypies and hyperactivity in rhesus monkeys exposed to lgG from mothers of children with autism. Brain Behav Immun, 2008. 22(6): p. 806-16.

118. Kruse, J.L., et al., Psychiatric Autoimmunity: N-Methyl-d-Aspartate Receptor IgG and Beyond. Psychosomatics, 2015. 56(3): p. 227-241.

119. Keskek, A.K.S.B.B.M.Y.A.A., A case of NMDAR encephalitis misdiagnosed as postpartum psychosis and neuroleptic malignant syndrome. Neurol Sci, 2015. 36: p. 1257-1258.

120. Simabukuro, M.M., C.H.d.A. Freitas, and L.H.M. Castro, A patient with a long history of relapsing psychosis and mania presenting with anti-NMDA receptor encephalitis ten years after first episode. Dementia \& Neuropsychologia, 2015. 9(3): p. 311-314.

121. Hermans, T., et al., Anti-NMDA receptor encephalitis: still unknown and underdiagnosed by physicians and especially by psychiatrists? Acta Clinica Belgica, 2017: p. 1-4. 
122. Kahn, D.A., Voltage-gated Potassium Channel Antibody Autoimmune Encephalopathy Presenting With Isolated Psychosis in an Adolescent. J Psychiatr Pract, 2017. 23(6): p. 441-445.

123. PON, N.C., et al., Voltage-gated Potassium Channel Antibody Autoimmune Encephalopathy Presenting With Isolated Psychosis in an Adolescent. Journal of Psychiatric Practice ${ }^{\circledR}, 2017.23(6): p$. 441-445.

124. Cascella, N.G., D.J. Schretlen, and A. Sawa, Schizophrenia and epilepsy: is there a shared susceptibility? Neuroscience research, 2009. 63(4): p. 227-235.

125. Clancy, M.J., et al., The prevalence of psychosis in epilepsy; a systematic review and meta-analysis. BMC Psychiatry, 2014. 14(1): p. 75.

126. Schoepf, D., et al., Physical comorbidity and its relevance on mortality in schizophrenia: a naturalistic 12-year follow-up in general hospital admissions. European Archives of Psychiatry and Clinical Neuroscience, 2014. 264(1): p. 3-28.

127. Jones, K.C.M.S., Ann C. MD; Hermida, Adriana P. MD; Kahn, David A. MD, A Case of Anti-NMDA Receptor Encephalitis Treated with ECT. Journal of Psychiatric Practice, 2015. 21 (5): p. 374-380.

128. Amitava Ganguli, et al., Voltage-Gated, Potassium-Channel Antibody-Associated Limbic Encephalitis Presenting as Acute Psychosis. The Journal of Neuropsychiatry and Clinical Neurosciences, 201 1. 23(2): p. E32-E34.

129. Gotkine, M., et al., Limbic encephalitis presenting as a post-partum psychiatric condition. Journal of the Neurological Sciences, 2011. 308(1): p. 152-154.

130. Kumar, M.A., et al., Anti-n-methyl-d-aspartate receptor encephalitis during pregnancy. Archives of Neurology, 2010. 67(7): p. 884-887.

131. Hamid Salim Shaaban, H.F.C., John W. Sensakovic, Anti-NMDA-receptor encephalitis presenting as postpartum psychosis in a young woman, treated with rituximab. Ann Saudi Med, 2012. 32(4): p. 421423.

132. Yu, A.Y.X. and F.G.A. Moore, Paraneoplastic Encephalitis Presenting as Postpartum Psychosis. Psychosomatics, 2011. 52(6): p. 568-570.

133. Divyanshu, D., et al., Autoimmune encephalitis epidemiology and a comparison to infectious encephalitis. Annals of Neurology, 2018. 83(1): p. 166-177.

134. Bossuyt, X., Clinical performance characteristics of a laboratory test. A practical approach in the autoimmune laboratory. Autoimmun Rev, 2009. 8(7): p. 543-8.

135. E.K., S., ed. Clinical interpretation of laboratory procedures. Tietz fundamentals of clinical chemistry, ed. A.E.R. Burtis C.A. 1996, W.B. Saunders Company: Philadelphia. 192-199.

136. Castillo-Gomez, E., et al., The brain as immunoprecipitator of serum autoantibodies against N-MethylD-aspartate receptor subunit NR1. Annals of Neurology, 2016. 79(1): p. 144-151.

137. Querol, L., et al., Antibodies to contactin-1 in chronic inflammatory demyelinating polyneuropathy. Annals of Neurology, 2013. 73(3): p. 370-380.

138. Steiner, J. and B. Bogerts, N-Methyl-d-aspartate receptor autoantibodies in schizophrenia and affective disorders. Schizophrenia Research, 2015. 162(1): p. 291.

139. Maddox, F.N., et al., GABAA receptor subunit mRNA expression in cultured embryonic and adult human dorsal root ganglion neurons. Developmental Brain Research, 2004. 149(2): p. 143-151.

140. Protti, M.P., et al., Myasthenia gravis. CD4+ T epitopes on the embryonic gamma subunit of human muscle acetylcholine receptor. Journal of Clinical Investigation, 1992. 90(4): p. 1558-1567.

141. Hughes, E.G., et al., Cellular and synaptic mechanisms of anti-NMDA receptor encephalitis. J Neurosci, 2010. 30(17): p. 5866-75. 
142. Omdal, R., et al., Neuropsychiatric disturbances in SLE are associated with antibodies against NMDA receptors. Eur J Neurol, 2005. 12(5): p. 392-8.

143. Lancaster, E., et al., Immunoglobulin $\mathrm{G}$ antibodies to the N-Methyl-D-aspartate receptor are distinct from immunoglobulin A and immunoglobulin M responses. Ann Neurol, 2015. 77(1): p. 183.

144. Bechter, K., CSF diagnostics in psychiatry - present status - future projects. Neurology, Psychiatry and Brain Research, 2016. 22(2): p. 69-74.

145. Al-Diwani, A., et al., Synaptic and Neuronal Autoantibody-Associated Psychiatric Syndromes: Controversies and Hypotheses. Frontiers in Psychiatry, 2017. 8: p. 13.

146. Gresa-Arribas, N., et al., Antibodies to Inhibitory Synaptic Proteins in Neurological Syndromes Associated with Glutamic Acid Decarboxylase Autoimmunity. PLoS ONE, 2015. 10(3): p. e0121364.

147. Sinmaz, N., et al., Autoantibodies in movement and psychiatric disorders: updated concepts in detection methods, pathogenicity, and CNS entry. Annals of the New York Academy of Sciences, 2015. 1351 (1): p. 22-38.

148. Ohkawa, T., et al., Identification and Characterization of GABA Receptor Autoantibodies in Autoimmune Encephalitis. The Journal of Neuroscience, 2014. 34(24): p. 8151-8163.

149. Dalmau, J., et al., Clinical experience and laboratory investigations in patients with anti-NMDAR encephalitis. Lancet Neurol, 2011. 10(1): p. 63-74.

150. Hibi, T. and H.M. Dosch, Limiting dilution analysis of the B cell compartment in human bone marrow. Eur J Immunol, 1986. 16(2): p. 139-45.

151. Gomez, A.M., et al., Proteasome inhibition with bortezomib depletes plasma cells and specific autoantibody production in primary thymic cell cultures from early-onset myasthenia gravis patients. Journal of immunology (Baltimore, Md. : 1950), 2014. 193(3): p. 1055-1063.

152. Bien, C.G., et al., Immunopathology of autoantibody-associated encephalitides: clues for pathogenesis. Brain, 2012. 135(5): p. 1622-1638.

153. Shimoyama, Y., et al., Anti-NMDA receptor encephalitis presenting as an acute psychotic episode misdiagnosed as dissociative disorder: a case report. Ja Clinical Reports, 2016. 2(1): p. 22.

154. Mariotto, S., et al., Persistence of anti-NMDAR antibodies in CSF after recovery from autoimmune encephalitis. Neurological Sciences, 2017. 38(8): p. 1523-1524.

155. Ryan, S.A.M.C., Daniel J. MD; Cassidy, Eugenie M. MD; Brown, Gemma MD; Harrington, Hugh J. MD; Markx, Sander MD, Anti-NMDA Receptor Encephalitis: A Cause of Acute Psychosis and Catatonia. Journal of Psychiatric Practice., 2013. 19(2): p. 157-161.

156. Buckley, C., et al., Potassium channel antibodies in two patients with reversible limbic encephalitis. Ann Neurol, 2001. 50(1): p. 73-8.

157. Pruss, H., Postviral autoimmune encephalitis: manifestations in children and adults. Curr Opin Neurol, 2017. 30(3): p. 327-333.

158. Schott, J.M., et al., Amnesia, cerebral atrophy, and autoimmunity. Lancet, 2003. 361 (9365): p. 1266.

159. Vincent, A., et al., Potassium channel antibody-associated encephalopathy: a potentially immunotherapy-responsive form of limbic encephalitis. Brain, 2004. 127(Pt 3): p. 701-12.

160. Parthasarathi, U.D., et al., Psychiatric presentation of voltage-gated potassium channel antibodyassociated encephalopathy. The British journal of psychiatry: the journal of mental science, 2006. 189: p. 10.1192/bjp.bp.105.012864.

161. Anand, I., et al., VGKC - complex antibody mediated encephalitis presenting with psychiatric features and neuroleptic malignant syndrome - further expanding the phenotype. Developmental Medicine \& Child Neurology, 2012. 54(6): p. 575-576. 
162. Shillito, P., et al., Acquired neuromyotonia: evidence for autoantibodies directed against $\mathrm{K}+$ channels of peripheral nerves. Ann Neurol, 1995. 38(5): p. 714-22.

163. Prikryl, R., et al., Dynamics of neurological soft signs and its relationship to clinical course in patients with first-episode schizophrenia. Psychiatry Research, 2012. 200(2): p. 67-72.

164. RIGUCCl, S., et al., Neurological Soft Signs Discriminate Schizophrenia from Bipolar Disorder. Journal of Psychiatric Practice $\circledast^{8}, 2014$. 20(2): p. 147-153.

165. Chandley, M.J., et al., Increased antibodies for the alpha7 subunit of the nicotinic receptor in schizophrenia. Schizophr Res, 2009. 109(1-3): p. 98-101.

166. Hoffmann, C., et al., Alpha7 acetylcholine receptor autoantibodies are rare in sera of patients diagnosed with schizophrenia or bipolar disorder. PLOS ONE, 2018. 13(12): p. e02084. 
Autoimmunity in psychotic disorders. Where we stand, challenges and opportunities 


\section{3.}

\section{Unidentified neuronal}

surface IgG autoantibodies in a case of Hashimoto' $s$

\section{encephalopathy}

Marina Mané-Damas ', Anita Vinke 2, Carolin Hoffmann ', Shenghua Zong ', Mario Losen ', Peter Molenaar ' ${ }^{1}$, Jan Damoiseaux ${ }^{3}$, Suzanne Koudijs ${ }^{2}$, Rob P.W. Rouhl ${ }^{2,4}$, Pilar Martinez Martinez ${ }^{1}$

'Department of Psychiatry and Neuropsychology, Maastricht University, Maastricht, the Netherlands

${ }^{2}$ Department of Neurology, Maastricht UMC+, Maastricht, the Netherlands ${ }^{3}$ Central Diagnostic Laboratory, Maastricht UMC+, Maastricht, the Netherlands ${ }^{4}$ Academic Center for Epileptology Kempenhaeghe/MUMC+, Heeze and Maastricht, the Netherlands

Frontiers in Immunology 2020 Jul 7(11):1358. Doi: 10.3389/fimmu.2020.01358. eCollection 2020. 
Unidentified neuronal surface IgG autoantibodies in a case of Hashimoto' s encephalopathy 


\section{Abstract}

Hashimoto' s encephalopathy is an encephalitis of presumed autoimmune origin characterized by the presence of autoantibodies against thyroid proteins. We present a case of a young patient with preexisting Hashimoto's thyroiditis and progressive cognitive complaints, absence-like episodes, and sporadic bilateral epileptiform frontal and frontotemporal activity. No abnormalities were observed during the neurological examination and on MRI. Antibodies to thyroid peroxidase (TPO) were elevated and remained positive while the symptoms were present. Levothyroxine and methylprednisolone did not ameliorate the complaints. Subsequent treatment with high-dose intravenous immunoglobulins (IVIG) led to improved cognitive functions and to the disappearance of the absence-like-episodes. Patient' $s$ serum, but not CSF, gave a characteristic IgG-specific hippocampal pattern in rat brain immunohistochemistry; this immunoreactivity was maintained after specific and complete depletion of TPO antibodies. Serum IgG bound to primary neurons in cell culture, likely targeting a yet unidentified neuronal surface antigen.

The clinical response to IVIG suggests but does not prove that the circulating novel autoantibodies may induce the encephalopathy. It would be of interest to investigate more patients with Hashimoto's encephalopathy for the presence of neuronal surface autoantibodies, to define their role in the disease and their target antigen(s). 


\section{Background}

Autoimmune encephalitides are debilitating disorders characterized by a rapid progression of prominent neuropsychiatric manifestations, associated with autoantibodies against neuronal cell-surface proteins, ion channels or neurotransmitter receptors, and a good response to immunotherapy [1].

Hashimoto' s encephalopathy, also known as steroid-responsive encephalopathy associated with autoimmune thyroiditis (SREAT), is a rare disorder characterized by a variable presentation of neurological and psychiatric manifestations, the presence of anti-thyroid antibodies and by a clinical response to steroids [1]. However, as thyroid antigens are mainly expressed in the thyroid, this would not explain the presence of cognitive decline and neurological manifestations [2]. Recently, pathogenic autoantibodies to neuronal receptors have been identified, co-occurring in some cases with glutamic acid decarboxylase 65 (GAD65) or thyroid peroxidase (TPO) antibodies. The co-occurrence of both autoantibodies may result in misdiagnosis of the patient.

Here we describe a young patient with suspected autoimmune encephalitis presenting with unidentified neuronal surface autoantibodies and concomitant TPO antibodies, who modestly responded to immunosuppressive treatment.

\section{Case presentation}

A 13-year-old boy with a previous history of Hashimoto' s thyroiditis presented with muscle pain, dry skin and subtle memory complaints. A scheme of the clinical events of this case report is shown in Figure 1A. Serological analysis at that time, revealed high levels of creatinine kinase $(5,105 \mathrm{U} / \mathrm{L}$; normal value $<171$ $\mathrm{U} / \mathrm{L}$ ), thyroid-stimulating hormone (TSH) (>100 mU/L; normal value 0.50-3.40 mU/L), anti-TPO (426.2 IU/mL; normal value $<100 \mathrm{IU} / \mathrm{mL}$ ), whereas thyroxine levels were low ( $<5.2 \mathrm{pmol} / \mathrm{L}$; normal value 11.5-17.7 pmol/L). Treatment was started with levothyroxine $100 \mathrm{mcg}$, once daily, after which his thyroxine levels normalized and muscle pain and skin dryness improved. However, six months after the diagnosis, the cognitive complaints worsened and the patient received a five-day course of methylprednisolone, which did not alter his symptoms. Next, his school performance declined in quality, indicating a further worsening in his cognitive abilities. A neuropsychological test showed no remarkable differences beside a subtle decline in his performance intelligence quotient (Figure 1B). One year after his first memory complaints started, the patient was referred to our academic hospital for further investigation with the suspicion of an autoimmune encephalitis. 
Family history was positive for hypothyroidism and high TPO autoantibody levels on the mother' s side. Neurological examination showed no focal deficits or other abnormalities, and brain MRI was unremarkable. At time of admission to our pediatric neurology department, the patient was suffering from amnesia and had long lapses of concentration. Generalized absence seizures were suspected. However, repeated EEG tests, including a 24-hour registration, only revealed sporadic bilateral frontal and frontotemporal activity with some epileptiform features, without clinical correlation (Figure 1C). Therefore, the absence-like episodes were not considered to be of epileptic origin. Repeated serological laboratory tests showed normal levels of TSH $(0.5 \mathrm{mU} / \mathrm{L})$, presence of TPO antibodies $(69 \mathrm{IU} / \mathrm{mL})$ and moderately elevated thyroxine levels (23.4 pmol/L). The lack of response to corticosteroids made a Hashimoto' $\mathrm{s}$ encephalopathy (SREAT) less likely. Because of the ongoing subjective cognitive decline, an alternative cause of this encephalopathy was considered. Further investigation revealed normal cerebrospinal fluid (CSF) cell count, glucose and protein levels, and autoantibodies known to cause autoimmune encephalitis including N-methyl-D-aspartate receptor (NMDAR), a-amino-3 hydroxy-5-methyl-4isoxazolepropionic acid receptor (AMPAR), y-aminobutyric acid receptor subunits B (GABABR), leucinerich glioma-inactivated 1 (LGI1) and contactin-associated protein-like 2 (CASPR2), were undetectable in serum and CSF (autoimmune encephalitis Mosaic 1, Euroimmun). Myelin oligodendrocyte glycoprotein (MOG) autoantibodies were negative in serum (Cell Based FACS assay, Sanquin, Amsterdam). The clinical symptoms in combination with these results, led to a working diagnosis of a possible (seronegative) autoimmune encephalopathy. Therefore, the patient was treated with a 5-day course of high-dose intravenous immunoglobulins (IVIG). After the treatment, the cognitive decline stabilized and the absence-like episodes ceased. He finished secondary school (HAVO) and no further deterioration has been observed since the initial manifestations, 5 years ago. 
A

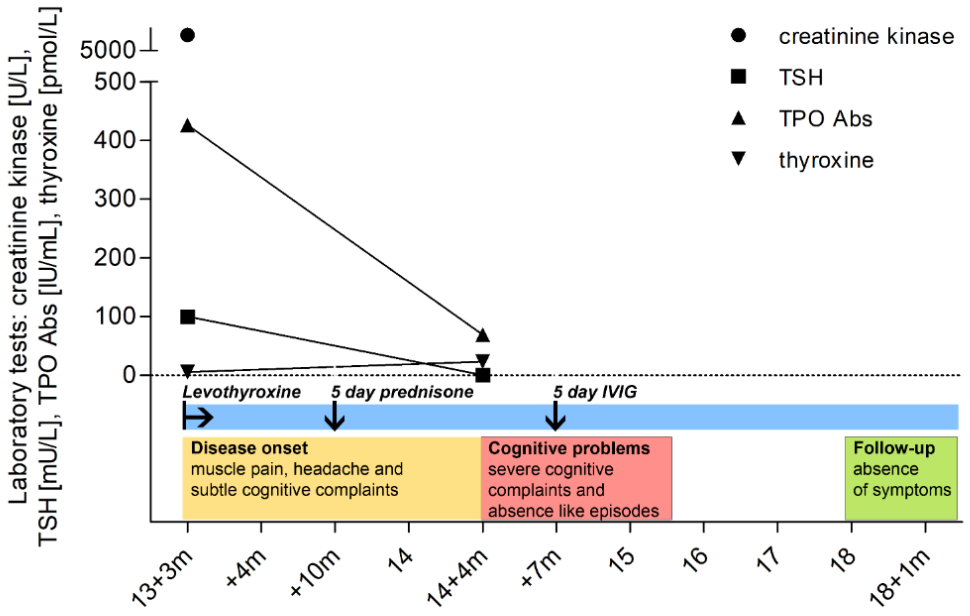

B

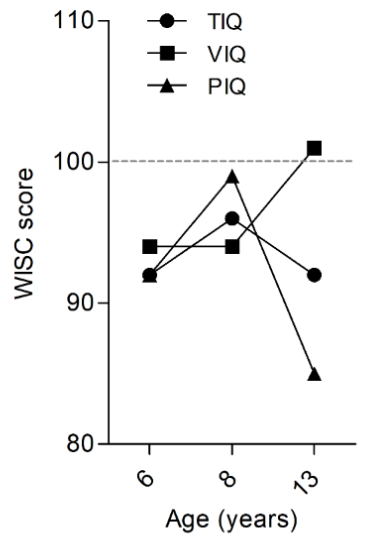

C

Age (years+months)

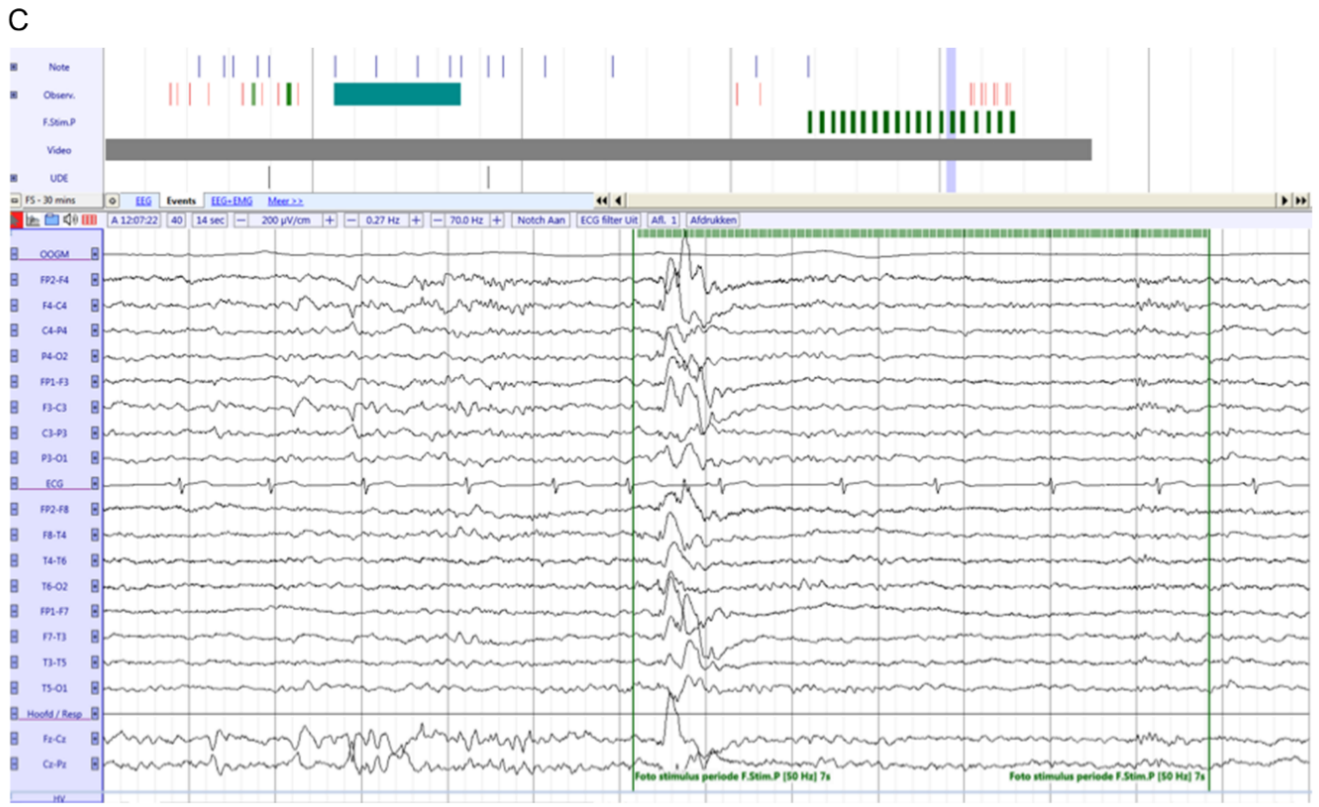

Figure 1. Clinical timeline, IQ and EEG. A) Clinical timeline representing the evolution of serological values of creatinine kinase, thyroid- stimulating hormone (TSH), TPO autoantibodies and thyroxine levels. Treatment intervention is also illustrated as well as qualitative disease progression. B) IQ progression by Wechsler intelligence scale for children. Total IQ (TIQ), verbal IQ (VIQ) and performance IQ (PIQ) at the age of 6,8 and 13 . The average score for the test is 100 , and any score between $90-109$ is considered to be in the average intelligence range. C) EEG showing generalized spike and wave discharge with right frontal dominance during photic stimulation with $50 \mathrm{~Hz}$. 


\section{Antibody and antigen characterization}

Rat brain sections and primary cell cultures from rat embryo hippocampus were used to detect lgG autoantibodies to neuronal antigens [3]. A strong immunoreactivity of serum antibodies to the middle region of the dentate gyrus and the molecular layer of the cerebellum was identified, with a titer of 1:1,600. Pyramidal neurons and GABA-ergic interneurons in the hippocampus were labelled and the hippocampal neuropil-like pattern was present using sera corresponding to different disease time points (Figure 2, A-D). In contrast, rat brain immunoreactivity of sera from a TPO-epilepsy control serum, and a non-disease control, was low (Figure 2, E-F). To quantify the intensity of the rat brain stainings, we selected different areas of the hippocampus including the stratum oriens, the stratum radiatum, the stratum lacunosum-moleculare, the molecular layer of dentate gyrus and the granule cell layer. The optical density of the patient' s serum immunoreactivity at all investigated time points was consistenly high in these hippocampus regions, especially in the molecular layer of the dentage gyrus, the stratum radiatum and the stratum oriens (Figure 2G). Interestingly, this immunoreactivity was highest at the time point corresponding to one year after onset, when the patient was admitted to our neurology department.

Autoantibody reactivity to a surface antigen was confirmed using live rat primary hippocampal neurons (Figure 3). However, live and fixed cell-based assays for NMDA, AMPA, GABA,$G A B A_{B}$ receptors as well as LGI1, and CASPR2 membrane proteins and the intracellular proteins GAD65 and GAD67 were negative. The staining using CSF was negative in cultured live rat hippocampal neurons, in the rat immunohistochemistry and in the abovementioned cell-based assays. 

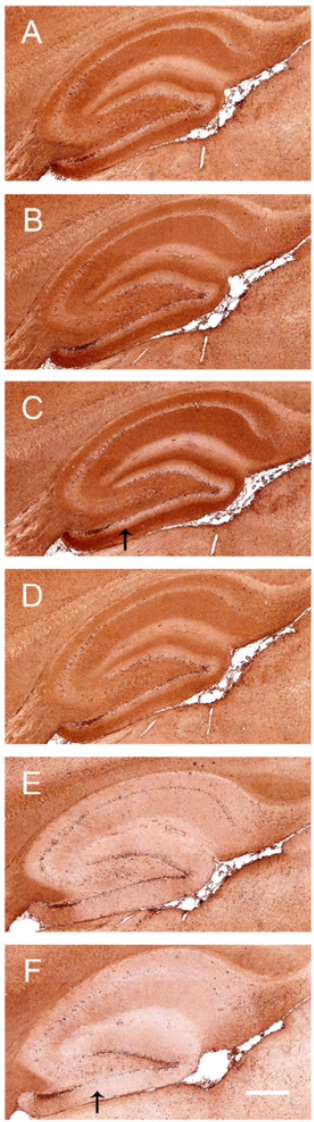
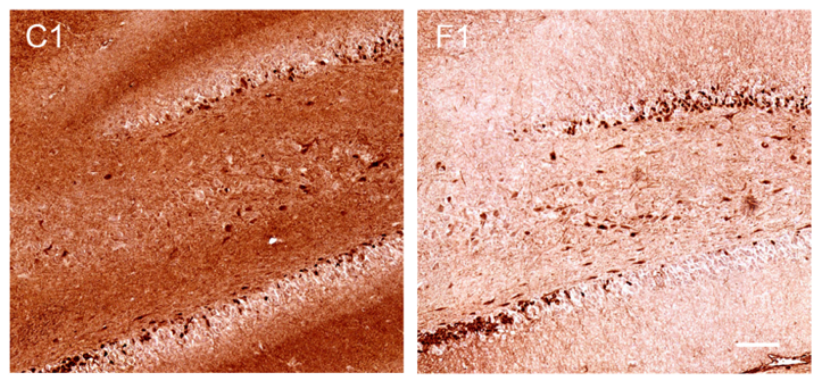

G
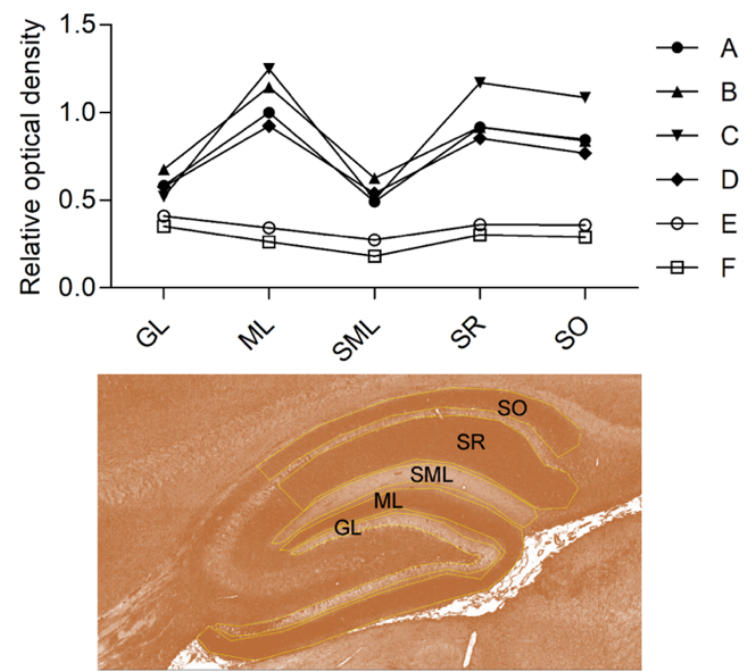

Figure 2. Identification and quantification of a novel neuropil-like hippocampal pattern in rat brain sections. AF) Rat brain immunohistochemistry IgG reactivity of serum. A-D) brain immunoreactivity of sera of the Hashimoto' s encephalopathy patient case at different time points: A) At first presentation B) one month after first presentation, C) one year after first presentation and D) after IVIG infusion. E) brain immunoreactivity of serum from a patient with epilepsy and TPO autoantibodies. F) brain immunoreactivity of serum from a non-disease control. The arrows in $\mathrm{C}$ and $\mathrm{F}$ point at areas shown at higher magnification in $\mathrm{Cl}$ and $\mathrm{Fl}$, respectively. Note the predominance of a neuropil-like pattern in Cl. G) Relative optical denisty quantification in different areas of the hippocampus, outlined in yellow. $\mathrm{SO}=$ stratum oriens, $\mathrm{SR}=$ stratum radiatum, $\mathrm{SML}=$ stratum lacunosum, $\mathrm{ML}=$ molecular layer of dentate gyrus and $\mathrm{GL}=$ granule cell layer. Scale bars are $100 \mu \mathrm{m}$ and $20 \mu \mathrm{m}$. 

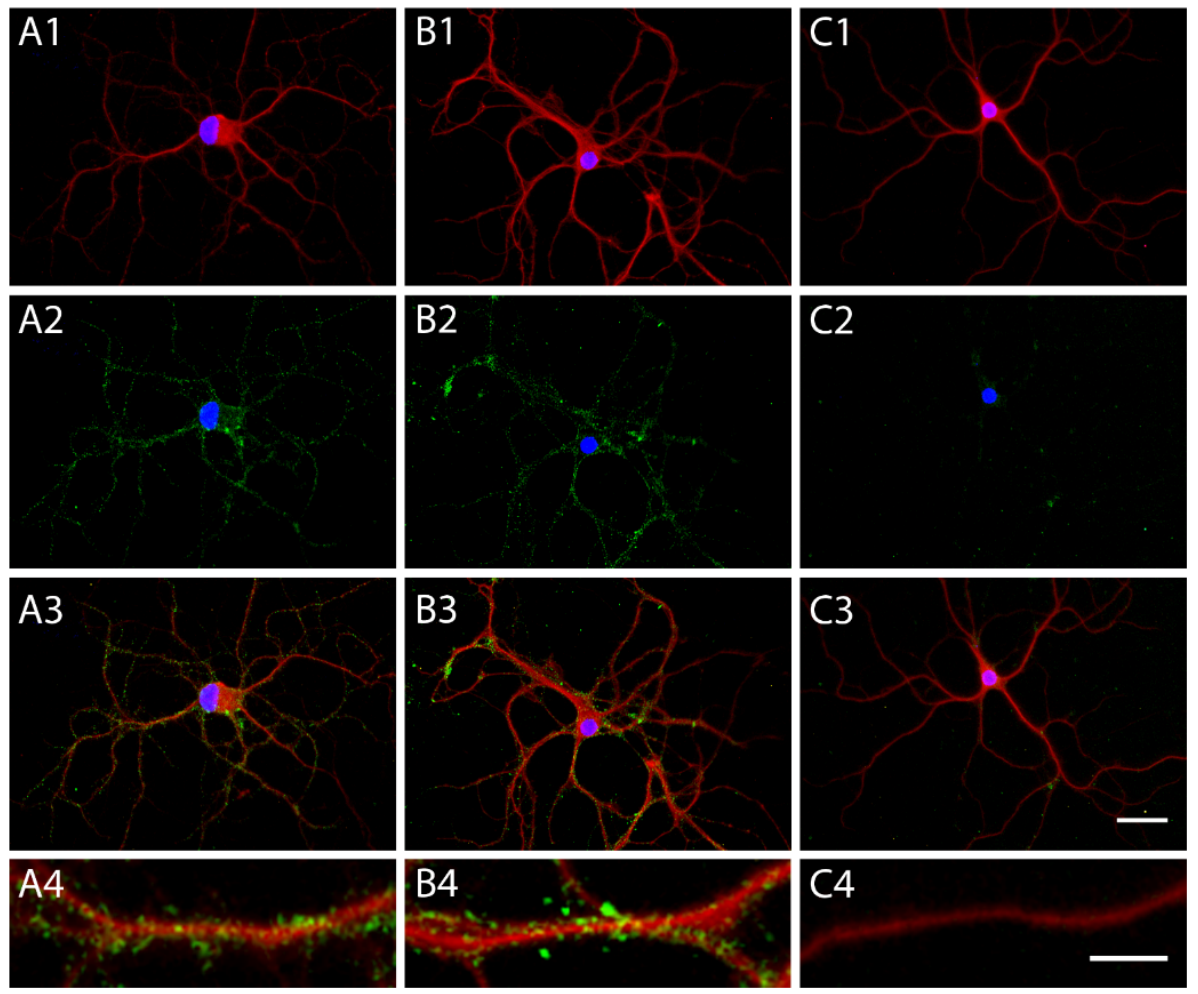

Figure 3. Patient's autoantibodies recognize an unidentified neuronal surface antigen in cultured primary hippocampal neurons. Immunofluorescent photomicrographs of cultured, live primary hippocampal neurons. Human lgGs are stained in green fluorescence, microtubules (MAP2) in red fluorescence, and cell nuclei (Hoechst DNA stain) in blue fluorescence. Serum immunostaining of A) a patient with DPPX antibodies, as a control, B) the Hashimoto' s encephalopathy patient case and C) a non-disease control. Al, B1 and C1 show the merge of nuclear and dendrite staining, A2, B2 and C2 show the merge of nuclear and human IgG staining, A3, B3 and C3 show the merge of all 3 fluorescent stainings. A4 an, B4 and C4 show the immunofluorescence staining of a dendrite at higher magnification. Scale bars are $50 \mu \mathrm{m}$. 
The coexistence of additional autoantibodies in the serum besides anti-TPO was confirmed after six consecutive immune-adsorption steps, using TPO-coated microtiter wells from the anti-TPO ELISA (IgG) kit (Euroimmun; EA 1012-0961 G). Anti-TPO IgG levels were reduced from 87.2 IU/mL to $0 \mathrm{lU} / \mathrm{mL}$. However, the TPO antibody depleted serum retained the same brain IgG immunoreactivity pattern (Figure 4).

All procedures were approved by the medical ethical committee of the Maastricht University Medical Center+.
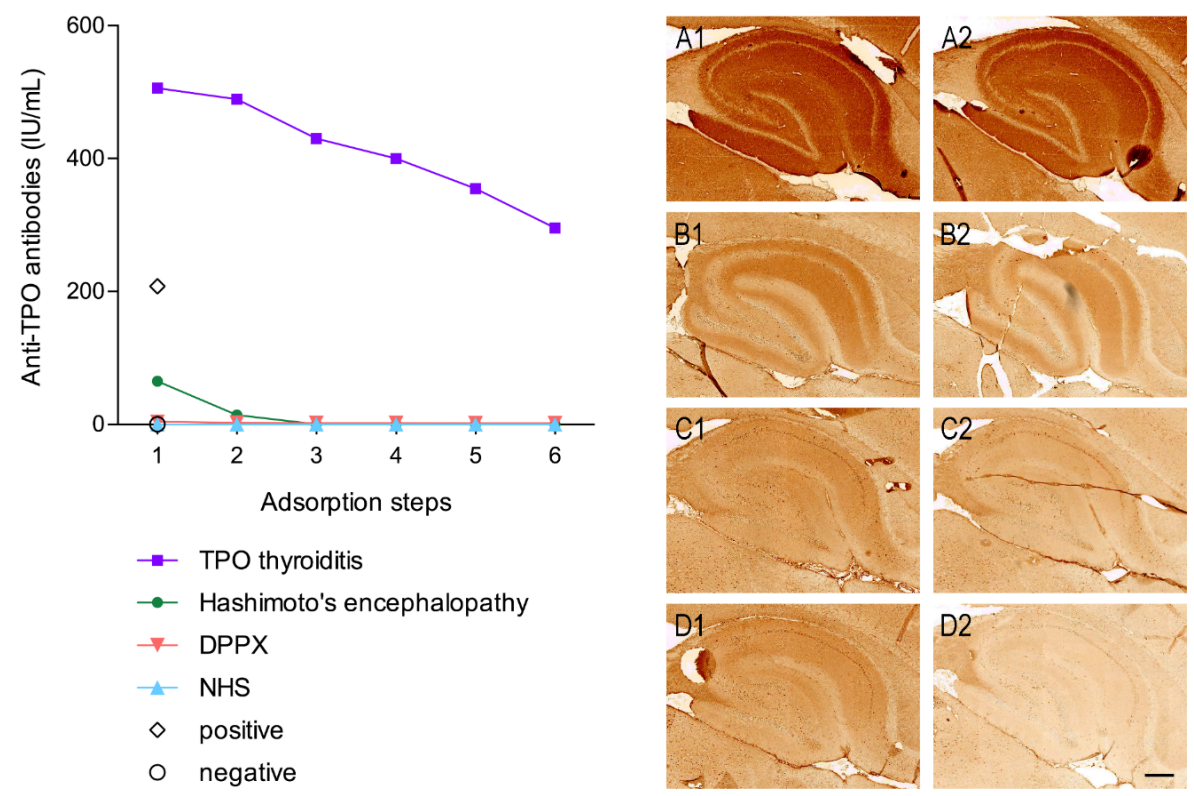

Figure 4. TPO autoantibodies are not responsible for the neuronal reactivity and TPO immuno-adsorption shows co-existence of autoantibodies. Graph on the left panel: TPO antibody levels (IU/mL) at 6 consecutive steps of immune-adsorption using wells coated with recombinant human TPO protein. TPO antibody was depleted from the sera of the following patients: a patient with TPO antibody-positive thyroiditis (blue squares), the Hashimoto' s encephalopathy patient (green closed circles), a patient with autoimmune encephalitis and dipeptidy-peptidase-like protein 6 (DPPX) antibodies (red inverted triangles), and a non- disease human serum control (NHS) (grey triangles). A positive (diamond) and a negative (open circle) calibrator control were included without absorption. Right panel: Rat brain immunohistochemistry using non-immuno-adsorbed sera (A1-D1) and immune-adsorbed sera (A2-D2) from A) a patient with DPPX antibodies, B) the Hashimoto's encephalopathy patient, C) a patient with TPO positive antibody thyroiditis and D) a non-disease control. Scale bar is $100 \mu \mathrm{m}$. 


\section{Discussion}

The presence of serum autoantibodies against thyroid proteins, including TPO, is one of the key diagnostic criteria for Hashimoto' s encephalopathy [1]. Clinically, patients can present with a broad range of symptoms, including seizures, myoclonus, stroke-like episodes with focal neurological and psychiatric manifestations such as hallucinations, impaired cognition or even dementia. In this particular case, there was a subjective cognitive decline and absence-like episodes, which persisted after adequate supplementation of thyroid hormone and treatment with methylprednisolone.

Hashimoto' s encephalopathy is known as steroid-responsive encephalopathy associated with autoimmune thyroiditis (SREAT) due to the high rate of response to steroids [1]. Even though more than $95 \%$ of patients show a good response to steroids [4], some patients require additional immunosuppressive therapies including IVIG, cyclosporine, cyclophosphamide and rituximab [5].

TPO is a membrane-bound glycoprotein, mainly expressed in the thyroid. Thyroid autoantibodies are present in more than $10 \%$ of the healthy population, as well as in patients with autoimmune encephalopathies, questioning their causative role in the pathology [6]. A study showed that approximately $16 \%$ of autoimmune encephalitis patients with $G A B A_{A} R$ antibodies have coexisting TPO autoantibodies [5]. Furthermore, cognitive impairment and other neuropsychiatric manifestations in these patients did not correlate with the presence of TPO antibodies as the fluctuations of the autoantibody levels did not correlate with the clinical manifestations [7].

The presence of TPO autoantibodies in CSF is not included in the diagnostic criteria for Hashimoto' $s$ encephalopathy. Hence, CSF of our patient was not initially tested for autoantibodies against thyroid antigens. Only a few studies have analyzed thyroid autoantibodies and circulating immune complexes in the CSF, which were reported in a small cohort of Hashimoto' s encephalopathy patients but not in a control group [8]. Furthermore, we did not find nor identify known autoantibodies associated with autoimmune encephalitis in the CSF; moreover, no reactivity of CSF against neuronal antigens was detected by rat brain immunohistochemistry. Undetectable autoantibody levels in the CSF of patients with neuro-psychiatric manifestations could result from an immune adsorption effect within the brain where the autoantigen is expressed [9]. Other factors that could contribute are low autoantibody levels crossing the blood brain barrier, in combination with the use of techniques with high detection limit. Nevertheless, low autoantibody levels in the brain could have an effect when they have high affinity and a wide range of effector functions.

Co-occurrence of TPO autoantibodies with AMPAR, NMDAR, GABA $A$ R, GABA $R$, LGII and MOG autoantibodies has been described in patients with very diverse clinical phenotypes, with a 
predominance of epilepsy [5, 10-12]. These findings are supported by this patient' s case report, where the TPO autoantibodies were not responsible for the brain-specific lgG (immuno) reactivity, implying the presence of other autoantibodies targeting a neuronal antigen. Lack of reactivity against the currently known neuronal antigens targeted in autoimmune brain disorders and the lack of similarity in the known hippocampal patterns preclude at present the identification of the pathogenic target [1].

Tuzun and colleagues described the presence of autoantibodies against novel targets in two out of eight patients with limbic encephalitis and co-occurring thyroid autoantibodies [10]. Presence of IgG reactivity was also identified in Hashimoto' s encephalopathy patient serum using human and mouse brain sections while the results from patients with Hashimoto' $s$ thyroiditis were negative [13]. Various studies have described the presence of unidentified autoantibodies against neuronal (surface) antigens with a potential pathogenic role in other pathologies [14] (S. Zong, unpublished results).

The clinical manifestations displayed by the patient described in this case report and the conspicuous hippocampal immunorectivity pattern of the patient' s sera, are novel to the best of our knowledge.

All-in all, TPO autoantibodies in our patient seem to be mere bystanders rather than having a causative, pathogenic role in Hashimoto's encephalopathy. The diagnosis of this encephalopathy remains controversial, since some patients do not meet all diagnostic criteria nor respond to steroids. It would be desirable to study the presence of neuronal surface autoantibodies in both serum and CSF in additional cases of suspected Hashimoto' s encephalopathy in order to analyze their putative contribution to the pathology. A better understanding of the pathogenic mechanisms and co-occurrence of autoantibodies will contribute to aiming therapy at the right targets.

\section{Acknowledgements}

We would like to thank Dr. Dalmau and Dr. Leypoldt for their advice in the methodology for the detection of autoantibodies causing autoimmune encephalitis and especially Prof. Dalmau for the validation and discussions on the interpretation of the results. We further acknowledge Prof. Zur Hausen for providing access to the facilities of the Pathology department and use of the VENTANA iScan. Additionally, we would like to thank Dr. Brilot, Dr. Waters, Prof. Tuzun, Dr. Faivre-Sarrailh and Prof. Graus for generous gifts of plasmid DNA for antigen expression and Dr. Hampe for kindly sharing the GAD antibodies with us. 


\section{Funding disclosure}

This study has been supported by the Netherlands Organization for Scientific Research (NWO) "Graduate School of Translational Neuroscience Program" (022005019), the Brain Foundation of the Netherlands (KS2012(1)-157) and the ZonMW NWO Program Translationeel onderzoek (40-127 41200-989257) and the China Scholarship Council (201507720015).

\section{Author Contributions Statement}

AV, SK and RPWR provided clinical information. JD provided the samples. MMD, CH, SZ ML and PMM designed the experiments and interpreted the data. MMD performed the research. MMD, AV and PMM drafted the manuscript. All authors revised the manuscript and gave critical feedback.

\section{Conflicts of Interest}

The authors declare that the research was conducted in the absence of any commercial or financial relationships that could be construed as a potential conflict of interest.

\section{Ethics statement}

The Hashimoto' s encephalopathy patient' s samples, data and permit for the publication of this case report were collected with written informed consent by the parents, according to the national and institutional ethical guidelines, in accordance with the Declaration of Helsinki. Additionally, the use of other human material reported within this case report was approved by the medical ethical committee of the Maastricht University Medical Center+ (METC 14-4-157). 


\section{References}

1. Graus, F., et al., A clinical approach to diagnosis of autoimmune encephalitis. The Lancet. Neurology, 2016. 15(4): p. 391-404.

2. Laurent, C., et al., Steroid-responsive encephalopathy associated with autoimmune thyroiditis (SREAT): Characteristics, treatment and outcome in 251 cases from the literature. Autoimmunity Reviews, 2016. 15(12): p. $1129-1133$.

3. Hoffmann, C., et al., Absence of Autoantibodies Against Neuronal Surface Antigens in Sera of Patients With Psychotic Disorders. JAMA Psychiatry, 2019.

4. Chong, J.Y., L.P. Rowland, and R.D. Utiger, Hashimoto Encephalopathy: Syndrome or Myth? JAMA Neurology, 2003. 60(2): p. 164-171.

5. Petit-Pedrol, M., et al., Encephalitis with refractory seizures, status epilepticus, and antibodies to the GABAA receptor: a case series, characterisation of the antigen, and analysis of the effects of antibodies. The Lancet. Neurology, 2014. 13(3): p. 276-286.

6. Hollowell, J.G., et al., Serum TSH, T4, and Thyroid Antibodies in the United States Population (1988 to 1994): National Health and Nutrition Examination Survey (NHANES III). The Journal of Clinical Endocrinology \& Metabolism, 2002. 87(2): p. 489-499.

7. Napthali, K., et al., Thyroid antibodies, autoimmunity and cognitive decline: is there a populationbased link? Dementia and geriatric cognitive disorders extra, 2014. 4(2): p. 140-146.

8. Ferracci, F., et al., Antithyroid antibodies in the CSF. Their role in the pathogenesis of Hashimoto' $s$ encephalopathy, 2003. 60(4): p. 712-714.

9. Castillo-Gomez, E., et al., The brain as immunoprecipitator of serum autoantibodies against N-MethylD-aspartate receptor subunit NR1. Annals of Neurology, 2016. 79(1): p. 144-151.

10. Tuzun E, E.E., Durmus H, Brenner T, Turkoglu R, Kurtuncu M, Lang B, Akman-Demir G, Eraksoy M, Vincent A, Autoantibodies to neuronal surface antigens in thyroid antibody-positive and -negative limbic encephalitis. Neurol India 2011. 59: p. 47-50.

11. Chen, K.-A., et al., Hashimoto's encephalopathy and anti-MOG antibody encephalitis: 50 years after Lord Brain's description. European Journal of Paediatric Neurology, 2017. 21 (6): p. 898-901.

12. Armangue, T., et al., Associations of paediatric demyelinating and encephalitic syndromes with myelin oligodendrocyte glycoprotein antibodies: a multicentre observational study. The Lancet Neurology, 2020. 19(3): p. 234-246.

13. Oide, T., et al., Anti-neuronal autoantibody in Hashimoto's encephalopathy: neuropathological, immunohistochemical, and biochemical analysis of two patients. Journal of the Neurological Sciences, 2004. 217(1): p. 7-12.

14. Mané-Damas, M., et al., Autoimmunity in psychotic disorders. Where we stand, challenges and opportunities. Autoimmunity Reviews, 2019. 18(9): p. 102348 


\section{4.}

\section{Prevalence of neuronal antibodies in a cohort of ealy- onset psychotic disor ders.the PSYANIB study}

Marina Mané-Damas ', Anita Vinke ${ }^{2}$, Anna lané-- ntacana ${ }^{3}$, Nikita van de Burgt

', Bea Campfort ', Carolin Hoffmann', Sh nghara z hg ', Peter Molenaar ', Mario Losen ', Rob Rouhl ${ }^{2}$, Theres nn nelsv ort ${ }^{1,4}$, Pilar Martinez-Martinez ${ }^{1}$

'Department of Psychiatry and opsyonology, School of Mental Health and Neuroscierse, Mad richt University, Maastricht, the Netherlands

${ }^{2}$ Department of Neurology, Man wich. University Medical Center, Maastricht, the Netherlands Jep ytme tof Psychiatry, Hospital del Mar, Barcelona, Spain

${ }^{4}$ Department of $\mathrm{A}, \mathrm{b}$, ary, Madricht University Medical Center, Maastricht, the Netherlands 


\section{5.}

Novel treatment strategies for myasthenia grgus with autoantibodies asoins the

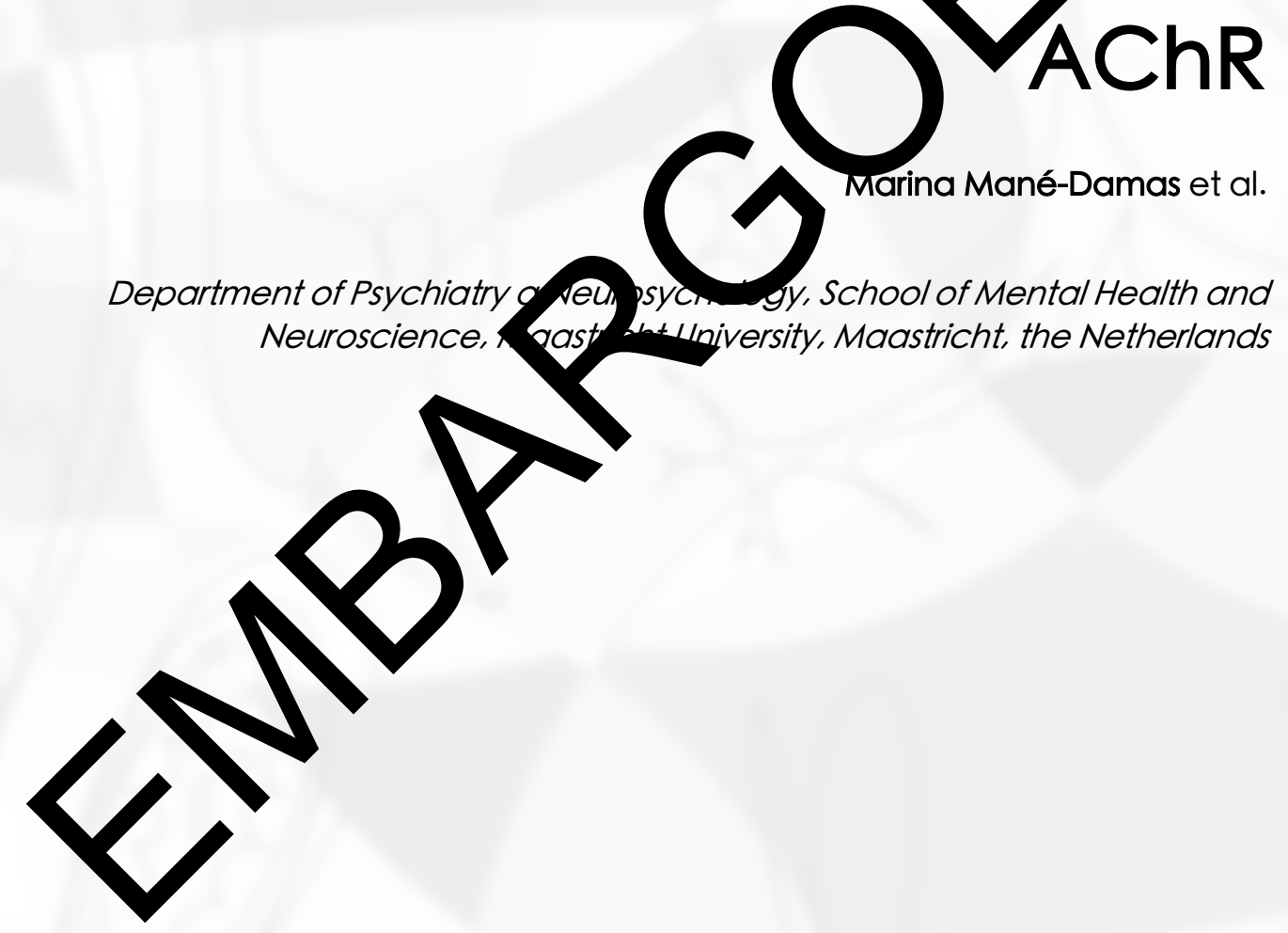




\section{6.}

\section{Silencing of Dok-7 in adult rat muscle increases susceptibility to passive transfer myasthenia gravis}

Alejandro M. Gomez ' ', Marina Mané-Damas ', Jo Stevens ' , Peter Molenaar ' , Hans Duimel $^{2}$, Fons Verheyen 2 , Judith Cossins ${ }^{3}$, David Beeson ${ }^{3}$, Marc H. De Baets ${ }^{\text {, }}$ Mario Losen ', Pilar Martinez-Martinez ${ }^{1}$

${ }^{\prime}$ Neuroimmunology Group, Division of Neuroscience, School for Mental Health and Neuroscience, Maastricht University, the Netherlands

${ }^{2}$ Electron Microscopy Unit, Department of Molecular Cell Biology, Maastricht University, Maastricht, the Netherlands

${ }^{3}$ Neurosciences Group, Nuffield Department of Clinical Neurosciences, University of Oxford, Oxford, United Kingdom

American Journal of Pathology.

2016 Oct;186(10):2559-68 .

Doi: 10.1016/j.ajpath.2016.05.025. 
Silencing of Dok-7 in adult rat muscle increases susceptibility to passive transfer myasthenia gravis 


\section{Abstract}

Myasthenia gravis (MG) is an autoimmune disease mediated by autoantibodies that target proteins at the neuromuscular junction, primarily the acetylcholine receptor (AChR) and the muscle-specific kinase. Because downstream of kinase 7 (Dok-7) is essential for the full activation of muscle-specific kinase and consequently for dense clustering of AChRs, we hypothesized that reduced levels of Dok-7 increase the susceptibility to passive transfer MG. To test this hypothesis, Dok-7 expression was reduced by transfecting shRNA-coding plasmids into the tibialis anterior muscle of adult rats by in vivo electroporation. Subclinical MG was subsequently induced with a low dose of anti-AChR monoclonal antibody 35. Neuromuscular transmission was significantly impaired in Dok-7-siRNA-electroporated legs compared with the contralateral control legs, which correlated with a reduction of $A C h R$ protein levels at the neuromuscular junction (approximately 25\%) in Dok-7-siRNA-electroporated muscles, compared with contralateral control muscles. These results suggest that a reduced expression of Dok-7 may play a role in the susceptibility to passive transfer MG, by rendering AChR clusters less resistant to the autoantibody attack. 
The neuromuscular junction (NMJ) is the synaptic connection between a motor nerve terminal and the skeletal muscle membrane. For efficient neuromuscular transmission to occur, acetylcholine receptors (AChRs) must be densely clustered on the top of postsynaptic membrane folds facing the nerve terminal, in a process primarily mediated by the activation of muscle-specific kinase (MUSK). To be activated, MuSK requires two signals: one from nerve-derived agrin and one from the muscle cytoplasmic protein downstream of kinase 7 (Dok-7) [1,2]. Once released from the nerve terminal, agrin binds to its receptor, the low-density lipoprotein receptor-related protein 4 , and this, in association with basal activation by Dok-7, activates MUSK at the muscle' s postsynaptic membrane. This ultimately leads to dense AChR clustering by the receptor associated protein of the synapse (rapsyn). In mouse models in which one of the main AChR-clustering proteins (rapsyn, MuSK, Dok-7, or low-density lipoprotein receptor-related protein 4) is knocked down, pups die at birth due to an absence of mature NMJs that results in respiratory failure, [2-5] demonstrating the crucial role of each of these proteins during embryonic synaptogenesis $[2,6,7]$.

During embryonic development, the agrin-MuSK-Dok-7 triad is widely recognized as the main organizer of neuromuscular synapses $[2,6,8,9]$ and, in adulthood, is fundamental for the maintenance and stability of AChR clusters at the NMJ. The latter has been demonstrated by both siRNA down-regulation [10] and conditional inactivation [11] of MUSK expression and, more extensively, by the effects of anti- MuSK antibodies at the NMJ [12-15]. In such studies, the most consistently reported finding was a significant reduction of AChR clustering that follows the decrease in MUSK levels at the endplate, in addition to increased nerve branching, disassembly of endplates, and formation of aberrant NMJs.

Recessive mutations in the DOK7 gene are a frequent cause of congenital myasthenic syndromes [16,17]. Patients with such mutations develop a limb girdle pattern of muscle weakness at an early age. Simplified endplates with reduced postsynaptic folding and impaired neuromuscular transmission are found in muscle biopsies of these patients [18-20]. These observations suggest the possibility that Dok-7 could also have an important role in the pathophysiology (and treatment) of conditions that affect the NMJ in adulthood, such as in the autoimmune disease myasthenia gravis (MG).

In AChR-MG, autoantibodies cause complement-mediated damage at the NMJ, leading to loss of AChR and AChR-associated proteins [21]. Loss of synaptic proteins may impair the clustering of newly synthesized AChR, thus contributing to the severity of symptoms in MG. In this regard, silencing the expression of rapsyn in adult muscles with siRNAs impaired neuromuscular transmission [22], whereas its overexpression protected the NMJ from antibody-mediated damage in the passive transfer MG (PTMG) model induced by injections of anti-AChR monoclonal antibody 35 (mAb35) [23]. 
To evaluate the role of Dok-7 in adult NMJs, we studied the effects of Dok-7 down-regulation by siRNAs in control and PTMG muscles. Muscles of adult rats were transfected by electroporation with the PSUPER vector, which encodes shRNAs. Our results suggest that reduced Dok-7 expression in the muscle potentiates the susceptibility of the NMJ to the damage caused by PTMG.

\section{Materials and Methods}

\section{shRNA Constructs and Evaluation of Silencing Efficiency}

Dok-7-siRNA sequence selection was performed using the siRNA design interface from the University of Hong Kong (http://i.cs.hku.hk/wsirna/software/sirna.php, last accessed April 30, 2016). A total of five siRNAs targeting rat DOK7 (NM 001 130062), plus one scrambled siRNA, were cloned in the PSUPER vector [24] as described [22].

Dok-7 silencing efficiency was measured in vitro by cotransfecting the shRNAs or the scrambled constructs with a rat DOK7-green fluorescent protein (GFP) expression vector (rat DOK7, NM 001130062 in a pEGFP-N1 vector, cloned by Geneart AG, Regensburg, Germany) in human embryonic kidney (HEK) 293 cells. HEK cells were transfected with $2.5 \mu \mathrm{g}$ of each plasmid using the polyethylenimine transfection method [25], in the presence of D-glucose $(6.5 \% \mathrm{w} / \mathrm{v})$. Dok-7 silencing efficiency in transfected cells was estimated by quantification of Dok-7 protein levels in cell extracts by Western blot analysis (see Immunoblot Analysis); each condition was analyzed in triplicate.

In addition, we cotransfected $\mathrm{C} 2 \mathrm{C} 12$ myoblasts with Dok-7 shRNAs and DOK7-GFP using a NEON transfection system (Invitrogen, Paisley, UK), and we cultured them in Dulbecco' s modified Eagle' $s$ medium plus $15 \%$ inactivated fetal bovine serum until confluent. Cells were then switched to Dulbecco's modified Eagle' s medium plus $5 \%$ inactivated fetal bovine serum for differentiation and, once myotubes were formed, AChR clusters were stained with a-bungarotoxin Alexa 594 (B-13423; dilution 1:1000; Invitrogen), as described [17]. A total surface of $4.25 \mathrm{~mm}^{2}$ was imaged per condition (in triplicate) with an Olympus IX71 fluorescence microscope (Olympus, Tokyo, Japan), and the average AChR cluster length was estimated with ImageJ version 1.48a ( $\mathrm{NIH}$, Bethesda, MD; https://imagej.nih.gov/ij). A minimum length of $3 \mu \mathrm{m}$ was considered for defining an AChR cluster. From their in vitro silencing efficiency, we selected two of the five shRNAs (S-1 and S-5), in addition to the scrambled-shRNA, for muscle electroporation in vivo: 
S1-forward， 5' -GATCCCCGCAGATCAGCTTCCTGTTtTCAAGAGAAAACAGGAAGCTGATCTGCTTtTGGAAA-3' ; S1-reverse,

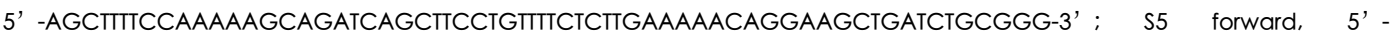
GATCCCCGATCAGCTTCCTGTTTGACTTCAAGAG -AGTCAAACAGGAAGCTGATCTTTTTGGAAA-3' ; S5-reverse, 5' AGCTTTCCAAAAAGATCAGCTTCCTGTTTGACTCTCTTGAAGTCAAACAGGAAGCTGATCGGG-3' ; scrambled shRNA-forward, 5' - GATCCCCGAGATGGTCCCTGTTTGACAGTTCAAGAGACTGTCAAACAGGGA - CCATCTCTTTTA-3' ; and scrambled shRNAreverse, 5' -AGCTTAAAAAGAGATGGTCCCTGTTTGACAGTCTCTTGA ACTGTCAAACAGGGACCATCTCGGG-3' .

\section{Immunoblot Analysis}

Protein extracts from transfected HEK cells were separated by SDS-PAGE, transferred into nitrocellulose membranes, and incubated with rabbit anti-Dok-7 (H-77; dilution 1:400; Santa Cruz Biotechnology, Santa Cruz, CA) and mouse anti-glyceraldehyde-3-phosphate dehydrogenase (10R-G109a; dilution 1:3,000,000; Fitzgerald, Acton, MA;) antibodies. Secondary antibodies were donkey anti-mouse IgG IRDye 680 and goat anti-rabbit IgG IRDye 800 (926-32222 and 926-32211, respectively; LI-COR Biosciences, Lincoln, NE), diluted 1:10,000. Stained membranes were imaged with the Odyssey Imaging System (LICOR Biosciences), and bands were quantified with the ImageJ software version 1.48a (NIH), normalizing for glyceraldehyde-3-phosphate dehydrogenase expression.

\section{Animal and tissue processing}

Seven-week-old female Lewis rats were obtained from Charles River Laboratories (Cologne, Germany), with permission from the Committee on Animal Welfare, according to Dutch governmental rules. Statistical power analyses were performed to calculate the minimum number of animals required to achieve statistically significant results, based on statistical parameters obtained from previous animal studies in our laboratory [22,23,26]. For electroporation, induction of PTMG, and electromyography (EMG), animals were anesthetized and later euthanized as described [22]. Frozen tibialis anterior muscles were cut in a cryostat (CM3050 S; Leica Biosystems, Wetzlar, Germany) in $10 \mu \mathrm{m}$ sections. For electron microscopy (EM) analysis, animals were euthanized as described [23,26], and fixed muscles were sectioned at $500 \mu \mathrm{m}$ with a VT1200S vibratome (Leica Biosystems).

\section{In Vivo Muscle Electroporation}

Dok-7 shRNA plasmids were prepared with the Gigaprep DNA purification kit (catalog no. 12191; Qiagen, Hilden, Germany), according to the manufacturer's manual, and dissolved at a concentration of 2 $\mu \mathrm{g} / \mu \mathrm{L}$ in $0.9 \% \mathrm{NaCl}$. For the PTMG experiments, we injected muscles with a combination of $50 \mu \mathrm{g}$ of each of the two shRNA vectors (S-1 and S-5) and, for the contralateral control leg, $100 \mathrm{\mu g}$ of the scrambledshRNA vector, in a final volume of $50 \mu \mathrm{L}$, followed by electroporation. Electroporation of the tibialis anterior 
muscle was performed as previously described $[22,23]$ using the Electro Square Porator ECM 830 (BTX, San Diego, CA).

\section{Induction of PTMG and Experimental Setup}

Tibialis anterior muscles of adult rats were electroporated with shRNA plasmids on days 0,2 , and 4 , and PTMG was induced by i.p. injection of mAb35 [27] on day 35, whereas control animals received saline solution. PTMG animals received $5 \mathrm{pmol} / 100 \mathrm{~g}$ body weight of mAb35 (subclinical dose) (Supplemental Figure S1) and were sacrificed 48 hours later (five PTMG and three control rats). Day 35 after electroporation was chosen for induction of PTMG because it has been demonstrated that there is a time-lag between reduced MUSK levels, the main effector protein activated by Dok-7, and a reduction in AChR levels at the NMJ. It has been shown, for instance, that the passive transfer of anti-MuSK antibodies in mice is followed by a reduction of endplate AChR content not earlier than 14 days after the injection of anti-MUSK IgGs [12]. In addition, Cre-Lox conditional inactivation of MuSK in muscle fibers of adult mice requires at least 27 days for inducing a $50 \%$ reduction in junctional AChR levels [11].

\section{$E M G$}

Decrement of compound muscle action potentials (CMAPs) was measured simultaneously in both tibialis anterior muscles of five PTMG and three control rats at the day of sacrifice, as described [22,23,28]. Decrement was defined as $>10 \%$ decrease of the amplitude and area of the CMAPs during $3-\mathrm{Hz}$ stimulation. If no decrement was observed initially, neuromuscular transmission was challenged by a continuous i.p. infusion of a $20 \mathrm{\mu g} / \mathrm{mL}$ solution of curare [(+)-tubocurarine, T2379; Sigma-Aldrich, St. Louis, $\mathrm{MO}$, at a rate of $1 \mathrm{~mL} / \mathrm{h}(0.33 \mu \mathrm{g}$ curare/min) with a syringe pump. During curare infusion, CMAP measurements were repeated at intervals of 1 minute (measuring one leg at a time, with 30 seconds between a measurement in one leg and a measurement in the other leg), until a reproducible decrement was observed in both muscles, for all animals. The time at which a decrement is observed is directly correlated to the dose of curare injected and to the amount of functional AChR at the NMJ.

\section{Immunofluorescence}

Muscle cryosections of $10 \mu \mathrm{m}$ were stained for b-galactosidase activity as described [22], dehydrated in a series of ethanol dilutions (70\% to 100\%), immersed in Ultraclear (J.T. Baker, Deventer, the Netherlands), and mounted with Pertex (Histolab Products AB, Gothenburg, Sweden). To ensure evaluation of the whole muscle tissue, we analyzed three different sets of 10- $\mu \mathrm{m}$ sections spaced $500 \mu \mathrm{m}$ in between, and quantified the number of transfected fibers/total number of fibers per muscle cryosection to define the 
percentage of transfection. Images were acquired with an Olympus BX50 microscope and the Stereo Investigator software version 10.40 (MicroBrightField Bioscience, Williston, VT).

To visualize NMJs, 10- $\mu \mathrm{m}$ frozen muscle sections were fluorescently stained. Cryosections were fixed in cold acetone for 15 minutes at $4{ }^{\circ} \mathrm{C}$ and blocked for 30 minutes with donkey serum [1:500 in 0.05\% trisbuffered saline (TBS)-Triton]. Sections were also blocked with an endogenous streptavidin/biotin blocking kit (SP-2002; Vector Laboratories, Burlingame, CA), according to the manufacturer's instructions. Slides were incubated for 1 hour with the following primary antibodies: rabbit anti-MuSK (dilution 1:1000; kind gift from Steven J. Burden, New York University, New York, NY) and mouse anti-SV2 (against synaptic vesicle protein 2; dilution 1:2000; DS Hybridoma Bank, lowa City, IA). Alexa 647-conjugated abungarotoxin (dilution 1:300; B35450; Invitrogen, Breda, the Netherlands) was used for detection of AChRs. Subsequently, slides were incubated 1 hour with the following secondary antibodies: biotinconjugated goat anti-rabbit IgG (dilution 1:1000; 11 1- 065-144; Jackson ImmunoResearch, West Grove, PA) and Alexa 594 donkey anti-mouse IgG (dilution 1:300; A21203; Invitrogen), followed by incubation with Alexa 488 streptavidin (dilution 1:2000; S11223; Invitrogen) for another hour at room temperature. Finally, slides were mounted in $80 \%$ glycerol-TBS. All antibodies and reagents were diluted in $2 \%$ bovine serum albumin in TBS, and all washing steps were performed with TBS-Triton. Because of technical limitations with the currently available antibodies against rat Dok-7, we were unable to stain NMJs of transfected muscles for this protein (data not shown).

\section{Quantitative Immunofluorescence Analysis}

The relative concentrations of AChR and MuSK at the NMJ were analyzed as described [22,23] Muscle sections from five PTMG and three control rats (16 muscles in total) were stained for immunofluorescence as described. For each muscle, two sets of sections from two different regions of the tissue were stained, each set containing three muscle sections of $10 \mu \mathrm{m}$. Endplate regions were identified based on their morphologic structure and positive staining for SV2, and they were imaged for the quantification of SV2, AChR, and MUSK intensities with an Olympus Provis AX70 fluorescence microscope. Approximately 50 images per muscle (with 3 to 10 endplates each) were acquired, and the fluorescence intensities were quantified using Image J version 1.48a (NIH), in a blinded fashion (A.M.G.). For each endplate, both AChR and MUSK mean intensities were normalized to the SV2 mean intensity. The average of the normalized intensities from all endplates in a set of muscle sections was used for comparison between conditions. 


\section{$E M$}

Electron micrographs were obtained from endplate regions of the Dok-7-siRNA-electroporated muscles of five subclinical PTMG rats ( 48 hours after induction of PTMG) and their respective control animals ( $n=$ 3). Sections of glutaraldehyde-perfused muscles $(500 \mu \mathrm{m})$ were processed for EM imaging as described $[23,26]$. Ultra-thin sections $(80 \mathrm{~nm})$ were viewed with a Philips CM 100 electron microscope (Philips, Amsterdam, the Netherlands). At least 15 endplate regions (including one to three endplates each) were imaged from each muscle, and the morphometric analysis of each micrograph was performed using the Image J version 1.48 a in a blinded fashion (A.M.G.), as described $[23,26,29,30]$.

\section{Statistical Analysis}

GraphPad Prism 4 (GraphPad Software, La Jolla, CA) was used to perform statistical analyses. Normally distributed values were compared using either one- or two-way analysis of variance and Bonferroni post hoc tests. $P<0.05$ was considered significant. Values are expressed as means \pm SEM, unless stated otherwise.

\section{Results}

Dok-7 shRNAs Reduce Dok-7 Levels and Induce Smaller and Simplified AChR Clusters in Vitro

To reduce the expression of Dok-7, we designed and cloned shRNAs into the PSUPER expression vector and tested them in vitro by cotransfection with DOK7-GFP in HEK 293 cells. After transfection, two PSUPER constructs (S-1 and S-5) efficiently reduced the levels of Dok-7-GFP (between $40 \%$ and $90 \%$ ) compared with DOK7-GFP cotransfected with the scrambled pSUPER vector (negative shRNA control), as quantified by Western blot analysis $(\mathrm{P}<0.001$ ) (Figure 1, A and B). The combination of these two shRNAs had a minor additive effect (95\% reduction in Dok-7-GFP levels compared with the scrambled vector; $P<0.001$ ) (Figure $1, \mathrm{~A}$ and $\mathrm{B}$ ). 
A

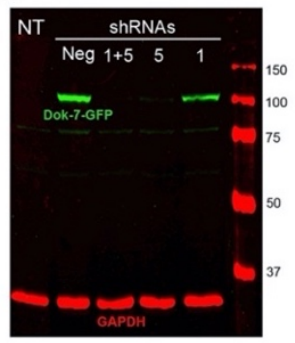

C
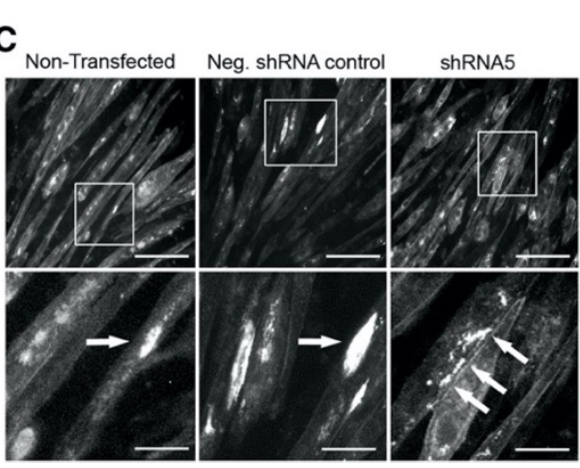

B

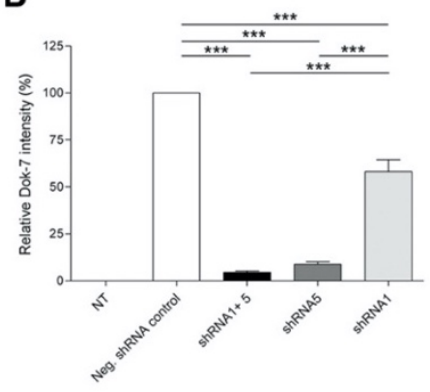

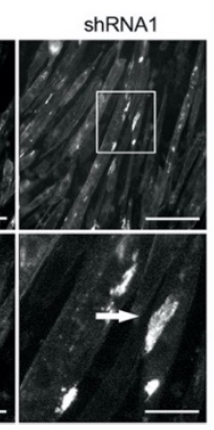

D

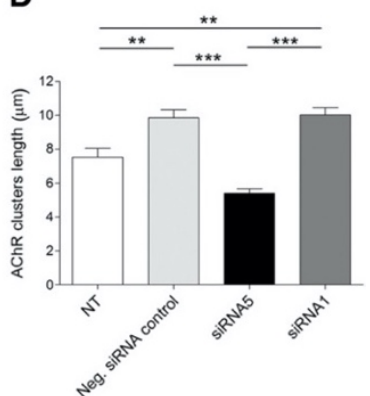

Figure 1. In vitro analysis of shRNA silencing efficiency. A: HEK 293 cells were cotransfected with plasmids for the expression of Dok-7-GFP (MW Z 91 kDa), and Dok-7 shRNAs (S-1, S-5, and S-1 + S-5), or a scrambled-shRNA plasmid (negative shRNA control). Forty-eight hours later, cells were harvested, and protein extracts were separated by SDS-PAGE, followed by immunoblotting for Dok-7 (green band) and GAPDH (red band). B: Western blot analysis quantification of Dok-7-siRNA silencing efficiency. Cotransfection of DOK7-GFP with Dok-7 shRNAs (S-1, S-5, and their combination) strongly reduced Dok-7 expression compared with cells transfected with the scrambledshRNA plasmid. Dok-7 band intensities were measured using Image J densitometry software version 1.48a and normalized for GAPDH intensity. C: In vitro analysis of Dok-7-shRNA silencing efficiency in $\mathrm{C} 2 \mathrm{C} 12$ cells. $\mathrm{C} 2 \mathrm{C} 12$ myoblasts were cotransfected with a plasmid for the expression of Dok-7-GFP, and either Dok-7 shRNAs (S-1 or S5) or the scrambled-shRNA expression plasmid. On myotube differentiation, DOK7-GFP-transfected cells have large AChR clusters when no Dok-7 shRNA was cotransfected. AChR clusters in S-5-cotransfected myotubes are small and disperse, and even smaller than in NT cells. Boxed areas in the top row delineate the region enlarged in the bottom row, arrows in the bottom row point to AChR clusters. D: The average AChR cluster length increases after cotransfection of DOK7-GFP with the scrambled shRNA or shRNA S-1, but it significantly reduces when DOK7-GFP is cotransfected with shRNA S-5. Cells were stained with Alexa 594-conjugated a-bungarotoxin, and Image J densitometry software was used for quantification of cluster length. Data are expressed as the means \pm SEM percentage of Dok-7 intensity compared with the negative control shRNA (scrambled). $n=3$ independent experiments (B). ${ }^{* * P}<0.01,{ }^{* * *} \mathrm{P}<0.001$, one-way analysis of variance. Scale bars: $100 \mu \mathrm{m}$ (C, top row); $30 \mu \mathrm{m}$ (C, bottom row). AChR, acetylcholine receptor; Dok-7, downstream of kinase 7; GAPDH, glyceraldehyde-3- 
phosphate dehydrogenase; GFP, green fluorescent protein; HEK, human embryonic kidney; Neg, negative; NT. nontransfected.

Because overexpression of Dok-7 leads to increased AChR clustering in muscle cells [2], we tested if Dok7 shRNAs affected clustering of AChRs in differentiated myotubes of the mouse muscle cell line $\mathrm{C} 2 \mathrm{C} 12$ cotransfected with a DOK7-GFP plasmid. Cotransfection of DOK7 with S-5 impaired the Dok-7-induced clustering of AChRs and led to smaller and simplified AChR clusters ( $45 \%$ smaller than in scrambled-shRNA transfected cells; $\mathrm{P}<0.001$ ) (Figure 1, C and D). In contrast, cotransfection of DOK7 with the scrambledShRNA or S-1 promoted the formation of larger AChR clusters (32\% larger than in nontransfected cells; $\mathrm{P}<$ 0.01 ) (Figure 1, C and D). Interestingly, clusters in S-5-transfected $C 2 \mathrm{C} 12$ cells were even smaller than those in cells nontransfected with DOK7 (28\%) (Figure 1, C and D), albeit not significantly.

\section{Effects of in Vivo Dok-7-siRNA Electroporation in Neuromuscular Transmission}

To estimate the in vivo transfection efficiency of Dok-7 shRNAs, tibialis anterior muscles of 18 rats were injected with a DNA solution containing $100 \mu \mathrm{g}$ of S-1 or S-5, plus $50 \mu \mathrm{g}$ of the reporter plasmid pVAX1LacZ and electroporated. These rats were later sacrificed at 7, 14, or 28 days after electroporation ( $n=3$ per time point). For both shRNAs, B-galactosidase was highly expressed 7 days after electroporation in approximately $60 \%$ of the muscle fibers, and it was still clearly detectable at day 28 after electroporation (Figure 2A).

A

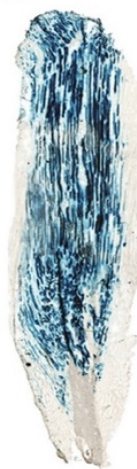

Day 7

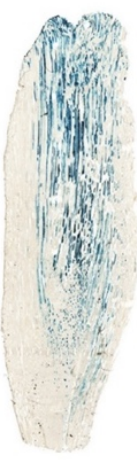

Day 14

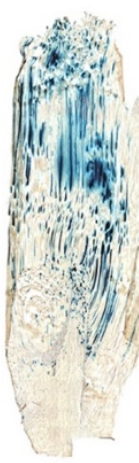

Day 28

B

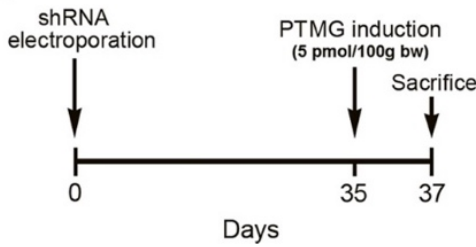

Figure 2. In vivo electroporation of shRNA plasmids (S-1 and S-5). $A$ : The overall transfection efficiency was analyzed using $X$-gal as a substrate for the reporter gene product B-galactosidase in $10 \mu \mathrm{m}$ thick muscle sections. To ensure evaluation of the whole muscle, we analyzed three different sets of sections spaced 500 $\mu \mathrm{m}$ in between. For both shRNA constructs, B-galactosidase expression was observed in muscle fibers at all analyzed time points (7, 14, and 28 days after electroporation), and in the majority of the tissue (approximately $60 \%$ of muscle fibers), indicating stable plasmid expression. Here we show a representative set of sections of an S-5 transfected muscle at days 7, 14, and 28 after electroporation. B: Scheme of the experimental set up for investigating the effects of in vivo Dok7-siRNA electroporation in the susceptibility to PTMG. bw, body weight; Dok-7, downstream of kinase 7; PTMG, passive transfer myasthenia gravis. 
To evaluate the importance of Dok-7 for the susceptibility to PTMG, we electroporated tibialis anterior muscles with Dok-7 shRNAs, subsequently induced PTMG in some animals by injection of 5 pmol mAb35/100 g body weight (subclinical dose), and sacrificed them and their respective controls 2 days later (Figure 2B). Dok-7-siRNA electroporation in muscles of control animals did not impair neuromuscular transmission, as measured by the resistance to curare with EMG $(n=3)$ (Figure 3, A and B). However, Dok7-siRNA-electroporated muscles in subclinical PTMG animals were less resistant to curare (26\% less) compared with the control contralateral leg $(n=5 ; P<0.05)$ (Figure $3, A$ and B). These results imply that Dok-7 levels are important for the resistance of the NMJ to an autoantibody attack.

A

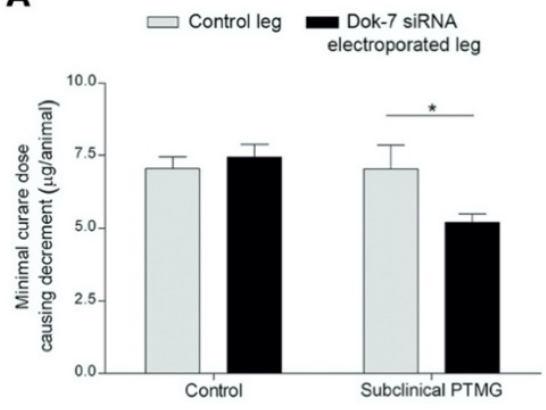

B

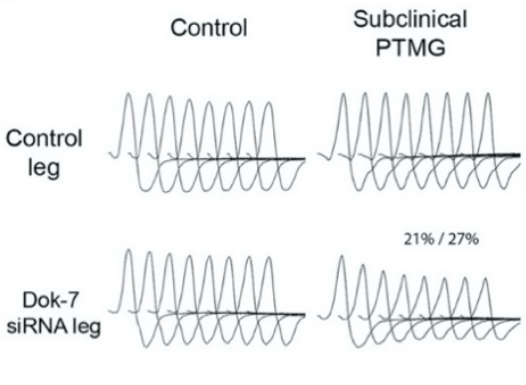

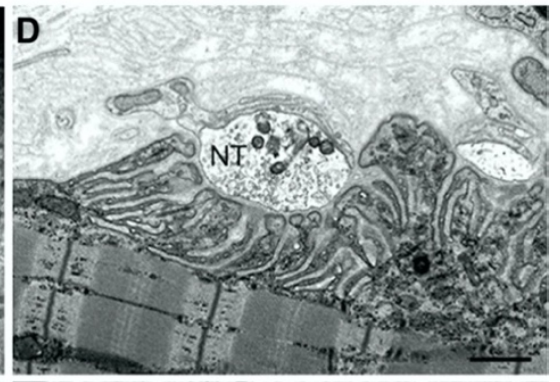
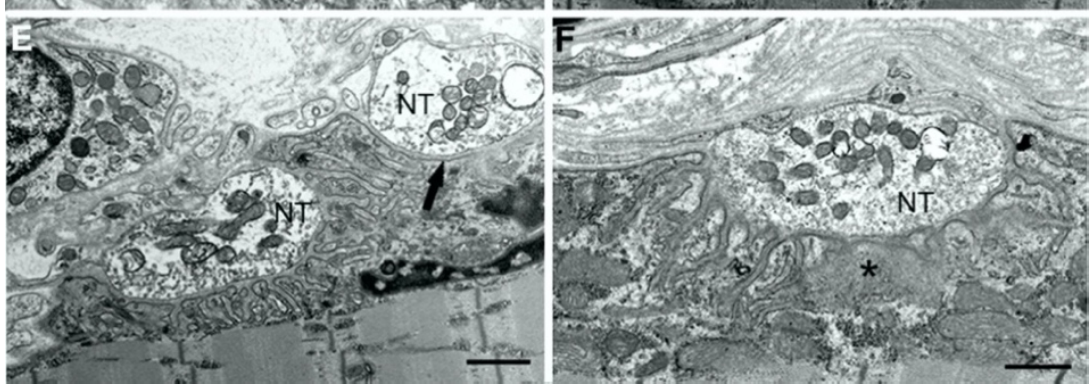

Figure 3. Dok-7-siRNA electroporation impairs neuromuscular transmission in subclinical PTMG (induced with 5 pmol mAb35/100 g bw), and it does not affect the ultrastructure of the NMJ. A: CMAP was measured bilaterally in transfected muscles by EMG, in the presence of continuous curare i.p. infusion. Dok- 7-siRNA electroporation 
does not affect the resistance to curare of control animals, but it significantly decreases curare resistance in subclinical PTMG animals. B: Representative decrement measurements in a control (left) and a subclinical PTMG (right) animal. CMAP measurements during repetitive supramaximal nerve stimulation at $3 \mathrm{~Hz}$ were performed on control (top) and Dok-7-siRNA-electroporated (bottom) tibialis anterior muscles. Decrement was defined as $>10 \%$ decrease of both the CMAP amplitude and area and indicated above the measurement when positive (amplitude decrement \%/area decrement \%). Representative EMG traces of a control and a PTMG rat (for both legs) at a dose of $6.5 \mathrm{\mu g}$ of curare are shown. Curare resistance decreases in the Dok-7- siRNA-electroporated leg but not in the control leg of the PTMG rat. C-F: Electron microscopy analysis of endplate morphologic structure. C: Normal endplate region in a control muscle, with an elaborate postsynaptic folding facing the NT. D: Normal endplate region in a Dok-7-siRNA-electroporated control muscle. No particular morphologic alterations were observed in most Dok-7-siRNA-electroporated endplates, in both control and subclinical PTMG animals. E and F: Subclinical PTMG muscles contain both normal endplate regions and endplate regions showing reduction of postsynaptic folding ( $E$, arrow) and widening of the synaptic cleft ( $F$, asterisk). Ultrathin muscle sections from PTMG and control animals were imaged with an electron microscope (at least 15 endplate regions per muscle). $n=3$ control animals; $n=5$ PTMG animals. ${ }^{*}<<0.05$, two-way analysis of variance for comparisons. Scale bars $=1 \mu \mathrm{m}$ (C-F). bw, body weight; CMAP, compound muscle action potential; Dok-7, downstream of kinase 7; EMG, electromyography; mAb35, monoclonal antibody 35; NMJ, neuromuscular junction; NT, nerve terminal; PTMG, passive transfer myasthenia gravis.

\section{Effects of Dok-7-siRNA Electroporation in NMJ Ultrastructure}

In addition, we examined the ultrastructure of the NMJ by EM in control and PTMG animals 37 days after electroporation with Dok-7 shRNAs. Control animals had morphologically normal NMJs in both Dok-7siRNA-electroporated and control muscles (Figure 3, C and D). Resembling control animals, most endplates in subclinical PTMG rats also had a normal NMJ morphologic structure in both Dok-7- siRNAelectroporated and control legs. However, some endplates were clearly disrupted at the postsynaptic membrane, with wider junctional folds and enlarged synaptic clefts or simplified postsynaptic folds, which are typical signs of complement-mediated damage (Figure 3, E and F). Such endplates were equally observed in both Dok-7- siRNA-electroporated and control legs. For statistical comparisons between conditions, we performed quantitative morphometric analysis of the folding index (ratio between the postsynaptic and presynaptic membrane length [31]) in control and subclinical PTMG animals ( $n=3$ and $\mathrm{n}=5$, respectively; approximately 25 endplates per muscle were analyzed). The folding index was not significantly different either between these two conditions $(P=0.064$; averages per group: control = 7; PTMG $=6.1)$ or between Dok-7- siRNA-electroporated and control legs $(P=0.12$; averages per group: PTMG control Z 6.1; PTMG Dok-7- siRNA-electroporated $=5.5$ ). These results suggest that Dok-7-siRNA electroporation does not significantly modify the ultrastructure of the NMJ. 
A

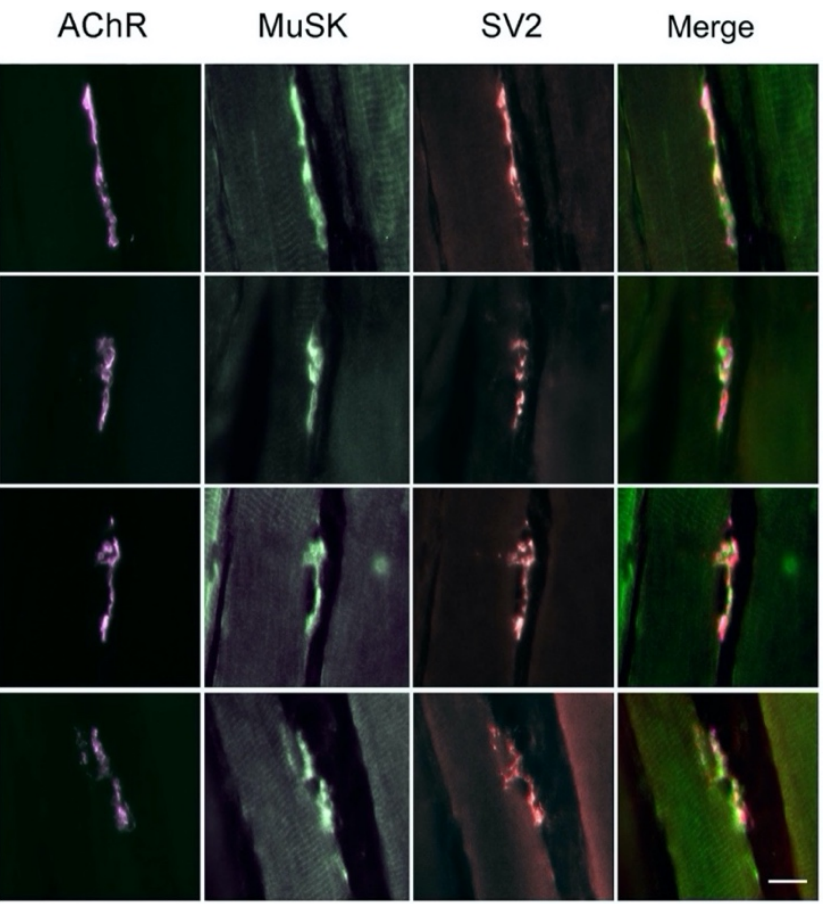

B

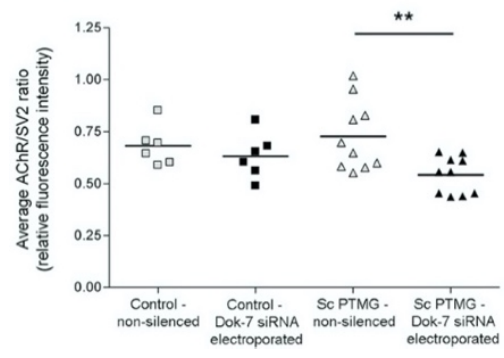

C

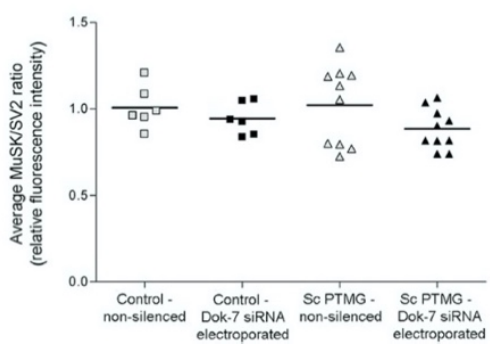

Figure 4. Fluorescence microscopy images of representative endplates and quantitative immunofluorescence analysis. Muscle sections were triple stained for AChR (magenta), MuSK (green), and the presynaptic marker SV2 (red) as a reference. A: Representative images of endplates from control and subclinical PTMG muscles. No evident differences in morphologic structure or AChR cluster size are observed between Dok-7-siRNAelectroporated and control legs in control animals. Most endplates are normal in subclinical PTMG muscles, although in Dok-7-siRNA-electroporated legs some endplates are disrupted and have lower AChR intensity (as representatively shown in the panel). B and C: Quantification of the relative intensity of AChR (B) and MuSK (C), normalized for SV2 intensity. The average AChR/SV2 ratio is significantly lower in Dok-7-siRNA-electroporated legs, compared with the contralateral control legs, in SC PTMG animals but not in control animals. MUSK levels are not significantly affected by Dok-7-siRNA electroporation. $n=$ approximately 300 endplates per muscle; $n=$ 5 PTMG animals; $n=3$ control animals. ${ }^{*} \mathrm{P}<0.01$, two-way analysis of variance for comparisons. Scale bar $=10$ 
$\mu \mathrm{m}$. AChR, acetylcholine receptor; Dok-7, downstream of kinase 7; MUSK, muscle-specific kinase; Sc, subclinical; PTMG, passive transfer myasthenia gravis; SV2, synaptic vesicle protein 2.

\section{Dok-7-siRNA Electroporation Reduces AChR Protein Levels in PTMG Rat Muscle}

To further characterize the effects of Dok-7-siRNA electroporation on AChR and AChR-associated proteins, we stained for AChR, MUSK, and SV2 in muscles of subclinical PTMG rats $(n=5)$ and untreated animals (control, $n=3$ ). We estimated their relative density at the NMJ by quantitative immunofluorescence 48 hours after induction of PTMG. Most endplates in subclinical PTMG rats had a normal morphologic structure in both Dok-7-siRNA-electroporated and control legs (Figure 4A). The intensities of AChR and MuSK were quantified in approximately 300 endplates per muscle and normalized for their corresponding presynaptic SV2 intensity [22]. In control animals, both AChR/SV2 and MuSK/SV2 ratios were not affected by Dok-7-siRNA electroporation, and they were not significantly different from those in subclinical PTMG ( $P=0.66$ and $P=0.72$, respectively) (Figure $4, B$ and $C$ ). By contrast, Dok-7- siRNAelectroporated legs in subclinical PTMG animals had a significantly lower AChR/SV2 ratio at their NMJs compared with control legs ( $25 \%$ less; $\mathrm{P}<0.01$ ) (Figure 4B), whereas MuSK levels were not significantly affected $(P=0.09)$ (Figure $4 C$ ). These findings are consistent with the impaired neuromuscular transmission observed by EMG in Dok-7-siRNA-electroporated legs of subclinical PTMG animals but not controls. Altogether, they suggest that functional AChR molecules are more likely to be reduced by the relatively low amount of autoantibodies in subclinical PTMG when there is less Dok-7 available in the muscle.

\section{Discussion}

In this study, we have examined the effects of Dok-7 down- regulation to obtain further insight into the function of Dok-7 in the adult NMJ and its possible involvement in the pathophysiology of MG. The main finding is that electroporation with our Dok-7 silencer constructs leads to increased susceptibility to mAb35 in the PTMG model, whereas it does not seem to affect the safety factor for neuromuscular transmission in control animals.

The efficiency of neuromuscular transmission is directly related to the number and degree of clustering of AChRs at the surface of the postsynaptic membrane. The NMJ has a large safety factor because the endplate potential caused by the released ACh is much larger than the threshold potential where the muscle membrane starts firing the action potential [21,32]. Because in rodents the safety factor is about five [33], it is likely that the effects of reduced Dok-7 expression would only become visible when neuromuscular transmission is compromised after challenge by an autoimmune attack or a neuromuscular toxin. Indeed, in our experiment we observed a significant impairment in neuromuscular 
transmission due to Dok-7-siRNA electroporation, as judged by the curare test, only after challenge by injection with 5 pmol of mab35 (subclinical PTMG).

Our EMG findings are in good correlation with the quantification of AChRs at the endplate by immunofluorescence. We observed a significant reduction in AChR content in Dok-7-siRNAelectroporated legs of subclinical PTMG animals, further supporting the importance of Dok-7 in the stabilization of AChR clusters at the NMJ. In this regard, previous studies have demonstrated that Dok-7 is particularly relevant for the prepatterning of AChR clusters during development [6,34] and Dok-7 knockdown zebrafish generated fewer and smaller AChR clusters [34]. In addition, our ultrastructural analysis by EM did not reveal morphologic abnormalities at the endplates of Dok-7-siRNA-electroporated muscles. Thus, it seems that Dok-7 does not play a crucial role in maintaining the ultrastructure of the mature NMJ; therefore, morphologic changes are probably not responsible for the increased sensitivity to curare of Dok-7-siRNA-electroporated legs. However, a limitation of this study is that we were unable to properly measure the silencing efficiency of our Dok-7 siRNAs in vivo, which was probably less efficient than in cell cultures, due to technical limitations in the quantification of Dok-7 protein levels (data not shown). Taking into account that the overall transfection efficiency in muscles was around $60 \%$, we can speculate that, if we would have either restricted our analysis to the Dok-7-siRNA-transfected fibers, or if we would have achieved a higher transfection efficiency, particularly at later time points, we would have probably observed more pronounced effects on the AChR content and/or NMJ morphologic structure.

A link between Dok-7 and MuSK expression has been demonstrated by several studies. For instance, both proteins share the transcription factor Spl [35], and Dok-7 is the limiting factor for the formation of AChR clusters when MUSK is overexpressed in muscle fibers [36]. Furthermore, the two proteins increase their expression on denervation [36,37]. Nevertheless, we did not find significantly altered MuSK levels at the NMJ as a result of Dok-7-siRNA electroporation. Because Dok-7 is required for full activation of MuSK, it seems likely that the additional loss of AChR clusters in Dok-7-siRNA-electroporated muscles of PTMG rats was a result of reduced MUSK activation rather than of reduced MUSK levels.

\section{Conclusions}

Our results indicate a relevant role for Dok-7 in the susceptibility to damage at the NMJ and, therefore, implicate it in the maintenance of a functional adult NMJ. Taking into account that several wellcharacterized mutations of the DOK7 gene in humans have been involved in the development of congenital myasthenic syndromes [17-19], it is tempting to speculate that, in the general population, minor variations in the sequence of DOK7 or its promoter could also mildly impair the levels or activity of Dok-7. Such carriers would then be more susceptible to damage at the NMJ; therefore, Dok-7 could be 
a promising marker to predict the severity of conditions that challenge neuromuscular transmission, such as MG.

\section{Acknowledgments}

We thank Jochen De Vry for help with the cloning of shRNAs; Marjan Philippens for technical assistance in immunofluorescence; Steven J. Burden (New York University) for rabbit anti-MuSK antibodies; and Laura Van Dam, Sonny Sliepen, and Christian Paylor-Smith for processing muscle samples.

\section{Grant support}

Supported by the Prinses Beatrix Fonds project WAR08-12, a Marie-Curie fellowship by the European Union (A.M.G.), a grant from the Association Française contre les Myopathies (P.M.-M.), the Netherlands Organization for Scientific Research Veni fellowship 916.10.148 (M.L.), and the Brain Foundation of the Netherlands fellowship FS2008(1)-28 (M.L.).

\section{Author contribution}

J.A.A.S. and M.M.-D. contributed equally to this work.

\section{Declaration of interest}

Disclosures: None declared. 


\section{Supplemental data}

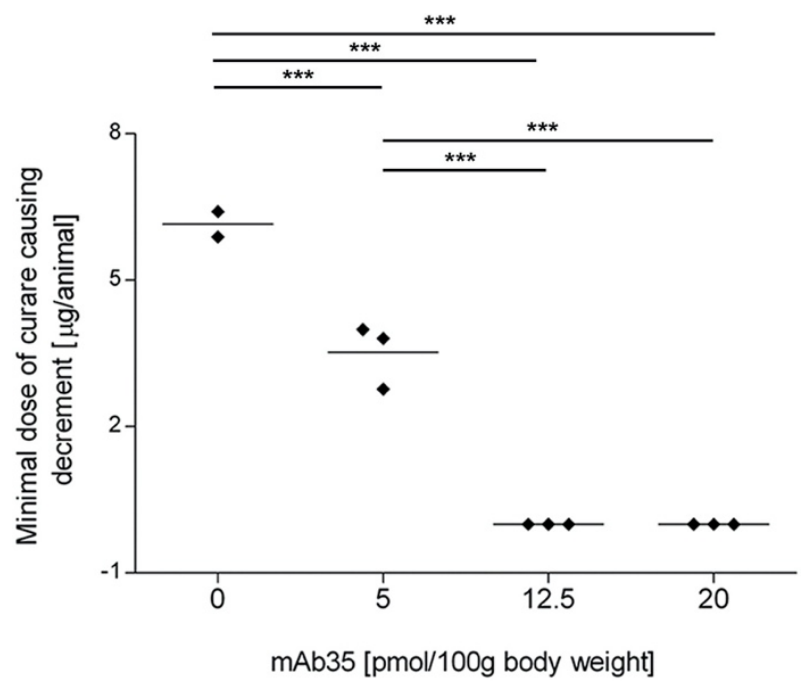

Supplemental figure 1. Assessment of the minimal dose of mAb35 that induces decrement of the CMAP, as measured by EMG, without noticeable clinical effects (subclinical PTMG). Non-electroporated rats were injected with $5,12.5$ or $20 \mathrm{pmol} / 100 \mathrm{~g}$ bw mAb35 ( $\mathrm{n}=3$ per dose), and neuromuscular transmission was assessed by EMG 2 days later, in the presence of continuous i.p. injections of curare. Animals that received either 12.5 or $20 \mathrm{pmol} / 100 \mathrm{~g}$ bw mAb35 already had a decrement before the injection of curare solution, while those injected with $5 \mathrm{pmol} / 100 \mathrm{~g}$ bw required approximately $3.5 \mu \mathrm{g}$ curare to show a decremental response. This was significantly less curare than what was needed to induce decrement in control animals $(5 \mu \mathrm{g})$, indicating that injection of $5 \mathrm{pmol} / 100 \mathrm{~g}$ bw mAb35 significantly impaired neuromuscular transmission, though to a lesser extent than injection of 12.5 or $20 \mathrm{pmol} / 100 \mathrm{~g}$ bw mAb35. Additionally, at 2 days after induction of PTMG, animals that received 12.5 or $20 \mathrm{pmol} / 100 \mathrm{~g}$ bw mAb35 had clinical scores ranging from 0 to 2 , while control animals and animals injected with $5 \mathrm{pmol} / 100 \mathrm{~g}$ bw mAb35 had no clinical signs of muscle weakness (score 0 , data not shown). Clinical scoring was assessed with the paw-grip test, as described [28]. $n=3$ rats per dose of mAb35. ${ }^{* *} P<0.001$, one-way analysis of variance. bw, body weight; CMAP, compound muscle action potential; EMG, electromyography; mAb35, monoclonal antibody 35; PTMG, passive transfer myasthenia gravis. ${ }^{* * *} \mathrm{p}<$ 0.001 ; 1-way ANOVA. 


\section{References}

1. Bergamin, E., et al., The cytoplasmic adaptor protein Dok7 activates the receptor tyrosine kinase MuSK via dimerization. Mol Cell, 2010.39(1): p. 100-9.

2. Okada, K., et al., The muscle protein Dok-7 is essential for neuromuscular synaptogenesis. Science, 2006. 312(5781): p. 1802-5.

3. Gautam, M., et al., Failure of postsynaptic specialization to develop at neuromuscular junctions of rapsyn-deficient mice. Nature, 1995. 377(6546): p. 232-6.

4. DeChiara, T.M., et al., The receptor tyrosine kinase MuSK is required for neuromuscular junction formation in vivo. Cell, 1996. 85(4): p. 501-12

5. Weatherbee, S.D., K.V. Anderson, and L.A. Niswander, LDL-receptor-related protein 4 is crucial for formation of the neuromuscular junction. Development, 2006. 133(24): p. 4993-5000.

6. Inoue, A., et al., Dok-7 activates the muscle receptor kinase MuSK and shapes synapse formation. Sci Signal, 2009. 2(59): p. ra7.

7. Yamanashi, Y., T. Tezuka, and K. Yokoyama, Activation of receptor protein-tyrosine kinases from the cytoplasmic compartment. J Biochem, 2012. 151 (4): p. 353-9.

8. Misgeld, T., et al., Agrin promotes synaptic differentiation by counteracting an inhibitory effect of neurotransmitter. Proc Natl Acad Sci U S A, 2005. 102(31): p. 11088-93.

9. Kim, N. and S.J. Burden, MuSK controls where motor axons grow and form synapses. Nat Neurosci, 2008. $11(1)$ : p. 19-27.

10. Kong, X.C., P. Barzaghi, and M.A. Ruegg, Inhibition of synapse assembly in mammalian muscle in vivo by RNA interference. EMBO Rep, 2004. 5(2): p. 183-8.

11. Hesser, B.A., O. Henschel, and V. Witzemann, Synapse disassembly and formation of new synapses in postnatal muscle upon conditional inactivation of MuSK. Mol Cell Neurosci, 2006. 31 (3): p. 470-80.

12. Cole, R.N., et al., Patient autoantibodies deplete postsynaptic muscle-specific kinase leading to disassembly of the ACh receptor scaffold and myasthenia gravis in mice. J Physiol, 2010. 588(Pt 17): p. 3217-29.

13. Klooster, R., et al., Muscle-specific kinase myasthenia gravis IgG4 autoantibodies cause severe neuromuscular junction dysfunction in mice. Brain, 2012. 135(Pt 4): p. 1081-101.

14. ter Beek, W.P., et al., The effect of plasma from muscle-specific tyrosine kinase myasthenia patients on regenerating endplates. Am J Pathol, 2009. 175(4): p. 1536-44.

15. Punga, A.R., et al., Muscle-selective synaptic disassembly and reorganization in MuSK antibody positive MG mice. Exp Neurol, 2011. 230(2): p. 207-17.

16. Engel, A.G., Current status of the congenital myasthenic syndromes. Neuromuscul Disord, 2011. 22(2): p. 99-111.

17. Cossins, J., et al., The spectrum of mutations that underlie the neuromuscular junction synaptopathy in DOK7 congenital myasthenic syndrome. Hum Mol Genet, 2012. 21 (17): p. 3765-75.

18. Beeson, D., et al., Dok-7 mutations underlie a neuromuscular junction synaptopathy. Science, 2006. 313(5795): p. 1975-8.

19. Muller, J.S., et al., Phenotypical spectrum of DOK7 mutations in congenital myasthenic syndromes. Brain, 2007. 130(Pt 6): p. 1497-506.

20. Selcen, D., et al., Dok-7 myasthenia: phenotypic and molecular genetic studies in 16 patients. Ann Neurol, 2008. 64(1): p. 71-87. 
21. Gomez, A.M., et al., Antibody effector mechanisms in myasthenia gravis-pathogenesis at the neuromuscular junction. Autoimmunity, 2010. 43(5-6): p. 353-70.

22. Martinez-Martinez, P., et al., Silencing rapsyn in vivo decreases acetylcholine receptors and augments sodium channels and secondary postsynaptic membrane folding. Neurobiol Dis, 2009. 35(1): p. 14-23.

23. Losen, M., et al., Increased expression of rapsyn in muscles prevents acetylcholine receptor loss in experimental autoimmune myasthenia gravis. Brain, 2005. 128(Pt 10): p. 2327-37.

24. Brummelkamp, T.R., R. Bernards, and R. Agami, A system for stable expression of short interfering RNAs in mammalian cells. Science, 2002. 296(5567): p. 550-3.

25. Boussif, O., et al., A versatile vector for gene and oligonucleotide transfer into cells in culture and in vivo: polyethylenimine. Proc Natl Acad Sci U S A, 1995. 92(16): p. 7297-301.

26. Martinez-Martinez, P., et al., Overexpression of rapsyn in rat muscle increases acetylcholine receptor levels in chronic experimental autoimmune myasthenia gravis. Am J Pathol, 2007. 170(2): p. 644-57.

27. Tzartos, S., et al., Passive transfer of experimental autoimmune myasthenia gravis by monoclonal antibodies to the main immunogenic region of the acetylcholine receptor. J Neuroimmunol, 1987. 15(2): p. 185-94.

28. Gomez, A.M., Vrolix, K., Martinez-Martinez, P., Molenaar, P.C., Phernambucq, M., van der Esch, E., Duimel, H., Verheyen, F., Voll, R.E., Manz, R.A., De Baets, M.H., and Losen, M. Proteasome inhibition with bortezomib depletes plasma cells and autoantibodies in experimental autoimmune myasthenia gravis. J Immunol. 2011; 186: p. 2503-2513

29. Lindstrom, J.M., et al., Pathological mechanisms in experimental autoimmune myasthenia gravis. II. Passive transfer of experimental autoimmune myasthenia gravis in rats with anti-acetylcholine recepotr antibodies. J Exp Med, 1976. 144(3): p. 739-53.

30. Engel, A.G., et al., Passively transferred experimental autoimmune myasthenia gravis. Sequential and quantitative study of the motor end-plate fine structure and ultrastructural localization of immune complexes (IgG and C3), and of the acetylcholine receptor. Neurology, 1979. 29(2): p. 179-88.

31. Slater, C.R., et al., Structure and function of neuromuscular junctions in the vastus lateralis of man. A motor point biopsy study of two groups of patients. Brain, 1992. 115 ( Pt 2): p. 451-78.

32. Wood, S.J. and C.R. Slater, Safety factor at the neuromuscular junction. Prog Neurobiol, 2001. 64(4): p. 393-429.

33. Wood, S.J. and C.R. Slater, The contribution of postsynaptic folds to the safety factor for neuromuscular transmission in rat fast- and slow-twitch muscles. J Physiol, 1997. 500 ( Pt 1): p. 165-76.

34. Muller, J.S., et al., Dok-7 promotes slow muscle integrity as well as neuromuscular junction formation in a zebrafish model of congenital myasthenic syndromes. Hum Mol Genet, 2010. 19(9): p. 1726-40.

35. Hamuro, J., et al., The transcription factor Spl plays a crucial role in dok-7 gene expression. Biochem Biophys Res Commun, 2011 . 408(2): p. 293-9.

36. Punga, A.R., et al., MuSK levels differ between adult skeletal muscles and influence postsynaptic plasticity. Eur J Neurosci, 2011. 33(5): p. 890-8.

37. Valenzuela, D.M., et al., Receptor tyrosine kinase specific for the skeletal muscle lineage: expression in embryonic muscle, at the neuromuscular junction, and after injury. Neuron, 1995. 15(3): p. 573-84 


\section{7.}

\section{Therapeutic efficacy of MLN9708 (ixazorib) in experimental aut unnmane myasthenia gravis no primary thymic cegrayitures from myastheprogrvis patients} Marina Mané-Dquas ${ }^{1}$, Alo ishek Saxena ${ }^{1,2}$, Gisela Nogales-Gadea ${ }^{1,3}$, Nick Wilcox ${ }^{4}$, Shanne Vi,ckat ', Hans Duimel ${ }^{5}$, Jos G Maessen ${ }^{6}$, Peter C. Molenaar ${ }^{1}$, N AC De B Eets ', Pilar Martinez-Martinez ${ }^{1 \$}$ and Mario Losen ${ }^{1 \$}$

'School for Me "He " and Neuroscience, Maastricht University, Maastricht, the Netherlands

curn tam ytion: Shanghai Institute for Advanced Immunochemical Studies, Pudongxin District, Shanghai, China

rent filiation: Neuromuscular and Neuropediatric Diseases Research Group, Neuro ci ice department, Institut d' Investigació en Ciencies de la Salut Germans Trias i Pujol, Universitat Autónoma de Barcelona, Badalona, Spain

${ }^{4}$ Department of Clinical Neurology, University of Oxford, UK

${ }^{5}$ ELMI Unit-CRISP, Department of Molecular Cell Biology, Maastricht University, Maastricht, the Netherlands

${ }^{6}$ Department of Cardiothoracic Surgery, Maastricht UMC+, Maastricht, the Netherlands 


\section{General discussion, limitations}

and conclusions 
General discussion, limitations and conclusions 
Antibody-mediated autoimmune diseases are, in many cases, chronic debilitating illnesses that affect more than $2.5 \%$ of the general population, contributing substantially to morbidity, mortality, and annual health care cost [1-3]. Over the past decades, this percentage has increased worldwide.

The disruption of balance within the immune system results in the production of antibodies that recognize and attack self-antigens. Autoimmune diseases present a wide variability of clinical manifestations, targets and pathogenic processes [4, 5]. Symptoms are usually associated and directly correlated with the presence of autoantibodies. However, the damage generated by these autoantibodies and the concomitant inflammatory response can have long term sequelae. As a consequence, rapid diagnosis and early treatment are important $[5,6]$. Traditional therapies aim to control the overreaction of the immune system and to reduce the inflammation. While they are highly efficient, around $10 \%$ of the patients do not achieve complete remission or have a poor response to these therapies. The benefit of many of immunosuppressive drugs is counterbalanced by their toxicity and serious side effects following long term/chronic administration and also because of the lack of specificity.

This thesis addresses the study of well-known as well as novel, antigens that drive human autoimmune diseases. Furthermore, it aims to identify the inherent limitations to current therapies and to elucidate the disease mechanisms in order to develop more specific targeted strategies with special focus on enhancement of efficacy and tolerability.

After a brief introduction, in CHAPTER 2 we address the matter of autoimmunity in psychotic disorders. Besides the strong economic burden, mental disorders have a devastating societal impact as a result of the high dependency of the sick and the low rate of re-integration of the patients in society. Therapeutic options aim to ameliorate the symptoms, but they have often a poor response, or no response for some of the symptoms such as cognitive decline or serious side effects. Unfortunately, despite the great efforts of the scientific community, little is known about the aetiology of these disorders. There is evidence which shows the involvement of the immune system in mental disorders. A decade ago, a novel disease named NMDAR encephalitis was discovered to be caused by autoantibodies against neuronal antigens having neurological as well as psychotic manifestations. Neurological abnormalities can be subtle, however, or absent in some cases, leading to underdiagnosis. Awareness of psychiatrists of the existence of autoimmune encephalitis and the overlapping symptoms is essential to guarantee a prompt diagnosis and adequate therapeutic intervention. In our review, we summarize the results of several studies addressing the question whether in some patients, psychosis could have an autoimmune origin. At the starting point of our research, variations of specificity and sensitivity in the screening methods had led to controversial results in the field. We recommend the use of combined standardized assays to validate the results so as to reduce the number of false positive or negative outcomes. Further, it should be realised 
that cerebrospinal fluid (CSF) analysis is essential for a definitive diagnosis of psychotic disorders of autoimmune origin. Cross-validated results confirmed that pathogenic autoantibodies targeting neuronal surface antigens are very rare in psychotic disorders without any form of neurological manifestation. The number of cases with isolated psychosis of autoimmune origin is apparently very limited. To have a clear vision of the potential role of autoimmunity in psychotic disorders, larger, homogeneous and systematically described cohorts need to be studied, with paired analysis of both plasma and CSF.

Subsequently, we continued contributing to the aforementioned research question and investigated the presence of neuronal autoantibodies in patients with neuropsychiatric manifestations. In CHAPTER 3 we describe the case of a young patient with Hashimoto' $s$ thyroiditis with thyroid peroxidase (TPO) autoantibodies, progressive cognitive complaints and absence-like episodes. The persistence of the symptoms after levothyroxine and methylprednisolone raised the suspicion of an autoimmune encephalopathy. We discovered a novel IgG-specific hippocampal pattern by rat brain immunohistochemistry. This conspicuous pattern was maintained after the depletion of TPO autoantibodies. Binding to primary neurons in cell culture, indicated that the coexisting autoantibodies target a yet unidentified neuronal surface antigen. Finally, the clinical response to IVIG suggested that the circulating novel autoantibodies may be responsible for the encephalopathy. With this case report, we underline the importance of investigating additional patients with Hashimoto' s encephalopathy for the presence of neuronal surface autoantibodies. Moreover, it is important to characterize the autoantibody pathophysiology and their target antigen(s).

CHAPTER 4 describes the preliminary results on the presence of hippocampal autoantibodies in patients with psychotic disorders. While this is not the first study to address this research question, some aspects have been paid little or no attention previously such as the characteristics of the recruited patients, the detailed neuropsychiatric characterization, the neurological examination and the CSF analysis. Rat brain immunohistochemistry revealed immunoreactivity, lgG specific, in the serum of $7 \%$ of the patients. Novel hippocampal patterns have been found in 7 of the 8 positive samples. An anti-Hu -like pattern, with strong immunoreactivity in the stratum oriens connecting to the stratum lacidum and in the granule cell was observed in the last sample. All the positive samples belonged to patients with severe psychotic manifestations, strong degree of functioning impairment and shorter duration of the disease. In a sub analysis, including only patients with first episode psychosis and strong disease manifestations (cohort 2), the percentage of brain immunoreactive patients is significantly higher: $15.4 \%$. The number of positive samples becomes then relatively higher than previously reported studies and control/non-disease individuals. However, most of these studies included patients with a longer duration of the disease and mild psychotic manifestations, without neurological examination and no CSF analysis. In the few studies 
that included patients with a severe phenotype, the reduced cohort size, the lack of assays crossvalidation and the lack of reproducibility makes it difficult to establish a conclusion. With our preliminary results, we would like to make a case for continuing investigations of the presence of (novel) neuronal autoantibodies in patients with severe psychotic manifestations, soon after their first episode, who may experience a poor response to antipsychotics. We thus encourage the use of standardized validated screening assays, including the analysis of CSF and recommend the confirmation of the results with other methods or other laboratories. Patients with psychotic disorders with an autoimmune origin could possibly directly benefit from an early diagnosis and treatment.

Limitations of the previously mentioned studies include the relatively small cohort size. In the case report, the identification of a single patient with a novel hippocampal pattern gives an opportunity for other researchers and physicians to find similarities with their patients thereby encouraging a collaborative effort to unveil potential disease mechanisms. For the diagnosis of autoimmune encephalitis it is recommended that abnormalities in the CSF are identified [6]. Moreover, autoimmune encephalitis is unlikely in view of the lack of antibody activity in the CSF of the patient and the potential pathogenicity of autoantibodies found in his serum is questionable. However, pleocytosis or protein/lgG levels were not measured in the single sample of CSF. In this case, it is possible that the level of autoantibodies in the CSF at that time point was low or that autoantibodies were immunoadsorbed by an antigen present in the brain [7]. Unfortunately, the lack of identification of the antigen precludes any speculation regarding the pathogenicity of these autoantibodies. In the PSYANTIB study, the broad inclusion criteria might be "diluting" the prevalence of autoantibodies in psychotic patients. As matter of fact, preliminary results indicate that patients with characteristics of strong psychotic manifestations, high functioning impairment and a short duration of the disease have more autoantibodies detected by rat brain immunohistochemistry. Narrowing the inclusion criteria would probably help to identify these patients. In addition, neuronal surface autoantibodies in chronically ill patients have been found to be very rare. Besides that, not all patients had donated CSF, since it was optional in our protocol due to the ethical restrictions. Differences in the neurological and psychiatric examination between both centers could also be a source of variability of interpretation. Imaging techniques like MRI or EEG that could help to identify other abnormalities for follow up and treatment response would significantly promote the relevance of the study.

In conclusion, we think it important to stress the value of screening in mental disorder patients for the presence of autoantibodies against known but also unknown antigens. Acquiring more knowledge on the pathophysiology of psychotic disorders with an autoimmune origin will help to understand the disease mechanisms, guarantee an accurate diagnosis and eventually to design and develop specific treatment strategies. This concept links to the following chapters of this thesis, which focuses on one of 
the best-characterized antibody-mediated autoimmune diseases, namely myasthenia gravis (MG). In MG, the study of the disease mechanisms has been shown most helpful to design and to develop novel treatment strategies and to repurpose the use of drugs with similar disease mechanisms.

CHAPTER 5 describes novel treatment strategies for MG with autoantibodies against the AChR. After a brief overview on the established treatments, we reveal the need of innovative-targeted immunotherapies and symptomatic therapies for antibody-mediated disorders. Symptomatic relief therapies, antibody competition, complement modulation, FCRN antagonisms and cell therapies are approached in detail. We highlight the relevance of understanding the different disease mechanisms, which might translate in the efficacy of certain therapeutic strategies but lack of response in others. A clear example of it are plasma cell targeting therapies, specifically the use of proteasome inhibitors, shown to have beneficial effects in a subgroup of patients with AChR-MG but not MuSK-MG, where B cell targeting therapies seems to be more suitable. Additionally, after the extensive description of the mechanisms of action and the rationale behind these novel therapies we speculate on the changes of autoreactive antibody levels following different therapeutic strategies. Even though the review focuses on AChR-MG, the rationale behind it applies also to many other antibody-mediated autoimmune disorders.

In CHAPTER 6, we describe the consequences of down-regulating Dok-7, a protein required for the correct activation of muscle-specific kinase (MUSK) and consequently the dense clustering of AChRs, essential for successful neuromuscular transmission. Using a passive transfer animal model for MG, the silencing of Dok-7 significantly reduced the number of AChRs available at the neuromuscular junction. This reduction made the neuromuscular transmission weaker and more susceptible to the attack of the pathogenic autoantibodies. Mutations in the Dok-7 sequence of promotors, altering the expression of the protein could increase the susceptibility to damage at the neuromuscular junction. All together, these results could serve as a proof of principle for the development of novel therapeutic strategies aiming to upregulate the expression of Dok-7 at the neuromuscular junction. Agrin is a protein that contributes to the assembling and aggregation of AChRs by binding to LRP4 and activating MuSK/Dok-7. NT-1654, a new agrin agonist, improved in an animal model of $M G$ neuromuscular transmission, promoted the clustering of AChRs and reduced the MuSK loss at the neuromuscular junction, which all resulted in improved muscle force and diminished fatigue in the animals [8].

A serious limitation of the Dok-7 study was that we could not properly measure the silencing efficiency of our Dok-7 siRNAs in vivo, which was likely to be less efficient that in vitro. Taking into account that the overall transfection efficiency was around $60 \%$, we can speculate that, if we could have either restricted our analysis to the Dok-7 siRNA-transfected fibers or if we could have achieved a higher transfection 
efficiency, particularly at later time-points, we would have probably obtained more pronounced effects on the morphology and the AChR content of the neuromuscular junction. It would be interesting as a next step also to study the effect of silencing Dok-7 in an animal model for MuSK-MG.

Understanding the role of plasma cells in antibody-mediated autoimmune disorders and the capacity of proteasome inhibitors to deplete not only malignant but also normal plasma cells, resulted in the following research. In CHAPTER 7, we describe the efficacy of the proteasome inhibitor MLN9708, also known as ixazomib, for treatment in AChR MG. Ixazomib has been demonstrated to have less side effects in multiple myeloma patients compared to first generation proteasome inhibitors $[9,10]$. In primary thymic cell cultures from MG patients, ixazomib led to an almost complete elimination of plasma cells and halted IgG and AChR antibody production. In experimental autoimmune myasthenia gravis (EAMG), the administration of ixazomib resulted in a reduction of $75 \%$ total plasma lgG levels and in a $94 \%$ reduction of AChR antibody levels. No differences were found between preventive and therapeutic treatment strategies and no signs of neurotoxicity were observed. Treatment with ixazomib resulted in a protective effect against weight loss, which is as a result of muscle weakness and fatigue in EAMG. These results have also been observed in another antibody-mediated animal model for systemic lupus erythematosus [11]. This study provides the basis for a possible short-term clinical trial in AChR-MG patients. In addition to MGFA scores, such a study should include the quantitative analyses of autoantibody levels and single fiber electromyography of patients.

The lack of electrophysiological studies as well as curare resistance, limits the comparability with previously reported drug efficacy studies for MG [12]. Definitive studies on the effect of the complete Freund' $s$ adjuvant (CFA) in animal models will help to subtract the effect of such a reagent from the potential neurotoxic effect of the studied drugs.

In summary, elucidating the pathogenic mechanisms underlying autoimmune neuromuscular diseases is clearly of great importance. Our knowledge, together with the inherent limitations of the current therapies provide the basis for novel or repurposed therapies, with increased specificity, circumventing the effects of systemic immune suppression and increasing tolerability. In addition, combination therapies should be explored to identify synergistic responses that will exploit the therapeutic effects of the administered drugs, limiting their side effects. Tailor-made therapeutic approaches will most likely have a therapeutic benefit in different disease settings. We are on the cusp of translating this new knowledge to treat antibody-mediated human diseases. 
Lastly, the perspectives and future directions of the studies conducted during this thesis are recapitulated as follows:

More studies including severely ill psychotic patients, using a robust screening strategy encompassing different detection methods, CFA analysis, and neurological examination will help to describe the presence or absence of neuronal surface autoantibodies in these disorders.

- It is important to study known but also novel antigenic targets, which may play a role in neuropsychiatric disorders. Currently, commercially available tests include such a possibility. However, in practice, antigen-specific tests are more commonly used in the clinic for diagnostic purposes. For this reason, the use of different techniques including antigen unspecific assays will help to avoid underdiagnosis of patients with novel autoantibodies.

- After the identification of novel as well as known autoantibodies with distinctive clinical presentation in patients with neuropsychiatric disorders, it is essential to confirm the pathogenicity and study their mechanisms of action.

- Using classical animal models for autoimmune disorders such as myasthenia gravis is very valuable for the study of the mechanisms of action of the pathogenic autoantibodies.

- Gaining perspective into the pathophysiology of autoimmune disorders will help to understand the disease mechanisms and to identify potential novel therapeutic targets.

- In vitro and in vivo studies on the safety and tolerability and the therapeutic efficacy of novel and repurposed drugs provide the basis for future "proof of principle" human clinical trials.

- Lastly, in-depth characterization of different drugs and its therapeutic outcome in patients will allow us to understand whether combination therapies could have a synergic effect with reduced side effects. These findings could then be further optimized towards a tailor-made treatment. 


\section{References}

1. Eaton, W.W., et al., Epidemiology of autoimmune diseases in Denmark. Journal of autoimmunity, 2007. 29(1): p. 1-9.

2. Cooper, G.S., M.L.K. Bynum, and E.C. Somers. Recent insights in the epidemiology of autoimmune diseases: improved prevalence estimates and understanding of clustering of diseases. Journal of autoimmunity, 2009. 33(3-4): p. 197-207.

3. Bach, J.-F., et al., The Effect of Infections on Susceptibility to Autoimmune and Allergic Diseases. New England Journal of Medicine, 2002. 347(12): p. 911-920.

4. Gomez, A.M., et al., Antibody effector mechanisms in myasthenia gravis-Pathogenesis at the neuromuscular junction. Autoimmunity, 2010. 43(5-6): p. 353-370.

5. Mané-Damas, M., et al., Autoimmunity in psychotic disorders. Where we stand, challenges and opportunities. Autoimmunity Reviews, 2019. 18(9): p. 102348.

6. Graus, F., et al., A clinical approach to diagnosis of autoimmune encephalitis. The Lancet. Neurology, 2016. 15(4): p. 391-404.

7. Castillo-Gomez, E., et al., The brain as immunoprecipitator of serum autoantibodies against N-MethylD-aspartate receptor subunit NR1. Annals of Neurology, 2016. 79(1): p. 144-151.

8. $\quad L i, Z$., et al., Engineered agrin attenuates the severity of experimental autoimmune myasthenia gravis. Muscle \& nerve, 2018. 57(5): p. 814-820.

9. Kumar, S.K., et al., Phase 2 trial of ixazomib in patients with relapsed multiple myeloma not refractory to bortezomib. Blood cancer journal, 2015. 5(8): p. e338-e338.

10. Richardson, P.G., et al., Phase 1 study of twice-weekly ixazomib, an oral proteasome inhibitor, in relapsed/refractory multiple myeloma patients. Blood, 2014. 124(7): p. 1038-1046.

11. Itomi, Y., et al., Ixazomib, an oral proteasome inhibitor, depletes plasma cells reducing autoantibodies and pdcs in pre-clinical model of systemic lupus erythematosus. Lupus Science \&amp; Medicine, 2017. 4(Suppl 1): p. A37-A37.

12. Gomez, A.M., et al., Proteasome Inhibition with Bortezomib Depletes Plasma Cells and Autoantibodies in Experimental Autoimmune Myasthenia Gravis. The Journal of Immunology, 2011. 186(4): p. 25032513. 
General discussion, limitations and conclusions 
09.

Valorization 
Valorization 
Chronic disorders are defined as persistent lifelong health conditions that usually require ongoing clinical support. They significantly affect the activity and daily life of the patients and their families. Examples of the most common chronic diseases in the world include Alzheimer' s disease, cancer, coronary heart disease, autoimmune diseases such as diabetes, rheumatoid arthritis, multiple sclerosis, and mental disorders. These diseases usually affect different parts of the body and develop in waves, with periods of remission and relapse that can vary in intensity. Enormous progress has been made in the diagnostics, monitorization and treatment of these disorders. While symptoms can partially be suppressed and sometimes even eliminated, no cure exists to date. Besides the consequences of the disability experienced by the patients and the societal burden, chronic disorders represent a stunning economic affliction on society and health care resources.

Importantly, the immune system plays a crucial role in a significant number of chronic disorders, while in many others its contribution is still under investigation. The studies described in this dissertation have mainly focused on the potential role of the immune system in psychotic disorders, the pathogenic mechanisms and the efficacy of novel therapeutic strategies in myasthenia gravis.

It is estimated that 1 in 5 adults is suffering from a mental illness, and a total cumulative of $43 \%$ of the population experience a form of mental illness at least once in their lifetime $[1,2]$. The spectrum of mental disorders is extremely diverse and the underlying pathogenic mechanisms remain a mystery, making the diagnosis and treatment extremely difficult. Antipsychotics and mood stabilizers focus on the suppression of the symptoms but are not efficient at reducing the cognitive decline experienced by many patients or at stagnating disease progression. Besides long-term periods where medication is required, sometimes for life, the treatment-associated side effects and the lack of treatment efficacy which in some cases leads to institutionalization is very common in the active phases of the disease. The public stigmatization and the negative connotation associated to these disorders challenges the integration of these individuals into society, meaning that they can experience difficulties finding and maintaining a job and and also struggle to live an independent life.

It has been demonstrated that there is a clear link between the immune system and mental disorders [3]. Its exact role, however, is not yet well-defined. In autoimmune encephalitis antibodies against neuronal surface channels and receptors trigger neuropsychiatric manifestations which could, in some cases, be incorrectly diagnosed as schizophrenia or bipolar disorder.

Lately, the prevalence of antibody-mediated autoimmune disorders, those caused by antibodies that mistakenly recognize and attack organs, tissues and cells of the body, is increasing significantly [4, 5]. Nowadays, $2.5 \%$ of the global population suffer from an antibody-mediated autoimmune disease [6]. 
Some of the most common are multiple sclerosis, diabetes, systemic lupus erythematous, celiac disease, psoriasis and myasthenia gravis. Myasthenia gravis is a neuromuscular disorder characterized by fluctuating muscle weakness and fatigue. Antibodies against different proteins of the neuromuscular junction are the direct cause of the disease, and the underlying pathogenic mechanisms have been intensively studied.

In this dissertation, I have reviewed the literature on psychotic disorders (including schizophrenia and bipolar disorder) and the potential role of the immune system in the development of these disorders. Interestingly, the methodological differences among the different screening assays raised a controversial variability in the prevalence of these autoantibodies in psychotic disorders. Thanks to the dissemination of scientific studies, patients with a subtle and uncommon disease course, treatment resistance or relapses and/or subtle neurological abnormalities, where the probability of autoimmunity is enhanced, are nowadays diagnosed in most of the cases. The use of standardized detection assays, and the analysis of cerebrospinal fluid, along with an extensive neurological examination indicate that the percentage of patients with pure psychosis and an autoimmune origin is very low. Early diagnosis and treatment are essential for a complete and fast recovery of the patients. However, it is important to be critical when it comes to the analysis of the results, since treatment administration could also have severe consequences for the patient when the disease is not correctly diagnosed.

Including different detection assays, I was able to identify novel autoantibodies in a young adult with Hashimoto' s thyroiditis, progressive cognitive complaints and subtle neurological abnormalities. After testing negative for neuronal surface autoantibodies by the commercial kit, I revealed the presence of coexistent autoantibodies against a protein expressed in the brain, specifically, in the membrane of pyramidal hippocampal neurons. Although I have not been able to identify the target yet, the clinical response to immunosuppressive IVIG treatment suggests but does not prove that these novel autoantibodies may induce the encephalopathy. Even though this is a single case report and the expected prevalence of autoimmunity in these patients is very low, reporting our findings could help other researchers to identify similar cases. In an extended cohort of newly recruited patients with a recent onset of psychosis, $7 \%$ of the patients presented neuronal autoantibodies. Thanks to the extensive neuropsychiatric description, I was able to identify the phenotype of these patients, characterized by severe manifestations and impairment of cognitive functioning and, interestingly, a shorter time between the last psychotic episode and the moment of the visit. This will help to narrow the characteristics of these patients with higher probabilities to have an underlying autoimmune cause and facilitate their diagnosis and further treatment. 
Insight into the pathogenic mechanisms of psychotic disorders will help to understand the role of the different components involved in the disease. Autoantibodies could then be used as biomarkers that could serve not only for diagnosis but also to monitor the disease progression and might be instrumental in developing specific therapies that will not only mask the symptoms but treat the disease at the source. If successful, this will cause a true landslide in psychiatry with genuine healing effects on patients. The impact on patients, their families, society and economy would be substantial.

Even though antibody-mediated autoimmune disorders, especially myasthenia gravis, are better characterized and we know more about the disease mechanisms, important gaps remain in our understanding of the disease.

Using an animal model for myasthenia gravis, I showed that changes in the expression of Dok7, involved in the clustering of the acetylcholine receptors (AChRs), essential for the correct muscle contraction, directly affects the disease susceptibility. Elucidating the role of the different proteins involved in the disease not only answers a basic research question about the pathogenic mechanisms, but also would be most helpful for designing new therapies. In the case of agrin, a protein involved in the upstream activation of MUSK via its interaction with LRP4, the administration of an agrin fragment has shown binding to LRP4 and stimulation of the neuromuscular junction. Together with Dok7 and rapsyn, they assure the correct anchoring and dense clustering of the AChRs at the membrane, essential for a correct neuromuscular transmission. Manipulating the signalling path of these proteins by enhancing MuSK activation, one could improve the motor function and correct neuromuscular defects not only in myasthenia gravis but also in many other disorders of the neuromuscular junction such as amyotrophic lateral sclerosis, spinal muscular atrophy, nerve injury and sarcopenia. In combination with other diseasemodifying therapies, they can help to reduce the damage at the neuromuscular junction and accelerate its recovery.

Antibody-mediated autoimmune diseases are in most cases successfully treated with broad-spectrum immunosuppressive drugs, known as first line therapeutic strategies. However, the lack of complete remission, the presence or development of treatment-resistance and the high incidence of unwanted side effects reinforce the unmet medical need to find and design novel therapeutic strategies. Using myasthenia gravis as a template, I described the novelties in the field of pharmacological intervention and highlight the relevance of treatment combination. Interlacing different drugs can enhance the effect or reduce the side effects. An additional value comes from the bivalency aspect of the newly developed therapies, which could also apply to other disorders where the immune system is involved such as cancer. Treatment strategies are moving towards personalized treatment, i.e. an exhaustive study of the disease mechanisms developed in each patient and the subsequent selection of the most 
efficient therapies that alone or in combination, following a specific timeline, will help patients to reach disease remission that will be maintained over their lifetime.

Besides the design of novel drugs, this knowledge gives new opportunities to use drugs already available on the market, whose effects can be beneficial for other pathologies. Proteasome inhibitors, initially developed to treat multiple myeloma, a plasma cell malignancy, not only eliminate malignant plasma cells but all plasma cells. Plasma cells produce high amounts of antibodies and are significantly involved in antibody-mediated autoimmune disorders. However, they are rather insensitive to regular immunosuppressant therapies. I proved the therapeutic effect of ixazomib, a second generation proteasome inhibitor, in various models of myasthenia gravis. Additionally, no signs of neurotoxicity were observed, which was one of the bottlenecks of previous proteasome inhibitors. Animal research is essential for the application of novel or repurposed human therapies as they provide mechanistic information and give evidence of the safety and effectiveness in different diseases. These results are the proof of principle used to develop a clinical trial with ixazomib in patients with myasthenia gravis. Eliminating the plasma cells is a step further towards the cure of not only myasthenia gravis, but many other antibody-mediated autoimmune diseases since these cells are responsible for the antibody production and in consequence are responsible for the development of the disease.

All in all, the studies described in this dissertation are relevant for a substantial proportion of society considering the patients who currently have or will develop mental illnesses or autoimmune disorders which also have impact on members of their family. The results presented will influence the diagnostics and treatment of these patients with a direct impact in health care costs and new opportunities for pharmaceutical industries. 


\section{References}

1. Steel, Z., et al., The global prevalence of common mental disorders: a systematic review and metaanalysis 1980-2013. International Journal of Epidemiology, 2014. 43(2): p. 476-493.

2. Trimbos instituut. Focus on Mental Health. 2015.

3. Bennett, F.C. and A.V. Molofsky, The immune system and psychiatric disease: a basic science perspective. Clinical \& Experimental Immunology, 2019. 197(3): p. 294-307.

4. Lerner, A., P. Jeremias, and T. Matthias, The World Incidence and Prevalence of Autoimmune Diseases is Increasing. International Journal of Celiac Disease, 2015. 3(4): p. 151-155.

5. Vento, S. and F. Cainelli, Autommune Diseases in Low and Middle Income Countries: A Neglected Issue in Global Health. Isr Med Assoc J, 2016. 18(1): p. 54-5.

6. Eaton, W.W., et al., Epidemiology of autoimmune diseases in Denmark. J Autoimmun, 2007. 29(1): p. 19. 
Valorization 


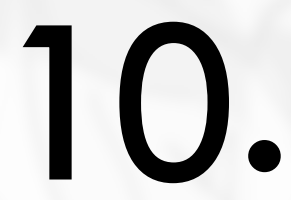

Curriculum vitae 
Curriculum vitae 
Marina Mané Damas was born on March the 15th in 1990 in Tarragona, Spain. She enrolled in the Bachelor degree programme in Biotechnology at the Universitat Rovira i Virgili (2008) in Tarragona, Spain. During her Bachelor internship, she joined the team of Prof. Dr Isabel Illa, Sendra at the Experimental Neurology laboratory at the Research Institute at the Hospital de la Santa Creu I Sant Pau. Under the supervision of Dr Gisela Nogales-Gadea she studied the presence of autoantibodies against neuronal surface receptors in rare neuromuscular disorders. During this period she got fascinated by the nuts and bolts of the laboratory assays, as well as the fruitful discussions with other team members, which were wrapped up and presented for her internship thesis, which was scored with the highest grade in the class. After she graduated (2012), she enrolled in the Neuroscience Master-programme at the University of Barcelona. For her master internship, she continued in the research team of Prof. Dr Isabel llla and followed up on the identification of novel antigenic molecules enrolled in the pathogenesis of CIDP and developed novel assays to identify the presence of autoantibodies in the serum of patients, which resulted in several publications. Before successfully completing her master studies (2013), she was appointed as research assistant at the Inflammatory Arthritis Group lead by Dr Juan Cañete in a joined project with the group of Innate Immunity at the under the supervision of Prof. Dr Francisco Lozano at IDIBAPS research institute at the Clinic Hospital in Barcelona. She was involved in several projects investigating the potential role of molecules of the innate immune system in different immune mediated disorders. At the end of 2014, she moved to Maastricht and started her PhD project at the department of Psychiatry and Neuropsychology at Maastricht University, under the supervision of Dr Mario Losen and Prof. Dr Pilar Martinez. Throughout her $\mathrm{PhD}$, she worked at two main projects, the first project was aimed at the investigation and the elucidation of the role of autoantibodies in psychotic disorders. Intrigued by the controversial results in the field, she established several in vitro assays and started a human study to define the prevalence of neuronal autoantibodies in patients with psychosis. She joined the lab of Prof. Dr Dalmau, who is a key figure in the field of autoimm u8une encephalitis. In the second project, she contributed to the understanding of the role of different proteins in the pathogenic mechanisms of a well-known antibodymediated autoimmune disease: myasthenia gravis. Following previous studies, she proved the therapeutic effect of ixazomib, a second generation proteasome inhibitor. A clinical trial with this drug in myasthenia gravis patients will soon start to which the outcome of her study has strongly contributed. These results have been presented in several national and international conferences. Over the past years she has supervised numerous bachelor and master students and has participated in the coordination of different courses. Before finishing her PhD, Marina obtained a Kootstra postdoctoral fellowship to continue her research. Currently, she is interested in the immune subsets involved in autoimmune disorders, unveil the in vitro and in vivo effects of human derived autoantibodies from patients with antibody-mediated autoimmune disorders to gain knowledge and clear the path towards tailor made therapeutic strategies. 
Curriculum vitae 


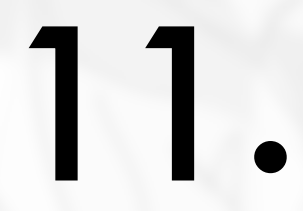

List of publications 
List of publications 


\section{Publications}

- Mané-Damas M, Vinke A, Hoffmann C, Zong S, Losen M, Molenaar P, Damoiseaux J, Koudijs S, Rouhl R, Martinez Martinez P. Unidentified neuronal surface IgG autoantibodies in a case of Hashimoto encephalopathy (accepted, Frontiers in Immunology)

- Marcuse F, Mercelis R, Van Schil P, Hochstenbag M, Maessen J, Abdul Hamid M, Mané-Damas M, Martinez-Martinez P, Losen M. De Baets M. Myasthenia gravis: hoe te (be)handelen?. Belgisch tijdschrift voor de Geneeskunde. 2020 (in press)

- Hoffmann C, Zong S, Mané-Damas M, Molenaar P, Losen M, Titulaer M.J, Martinez-Martinez P. Absence of autoantibodies against neuronal surface antigens in sera of patients with psychotic disorders. JAMA psychiatry. 2020; 77(3):322-325

- Mané-Damas M, Hoffmann C, Zong S, Tan A, Molenaar PC, Losen M, Martinez-Martinez P. Autoimmunity in psychotic disorders. Where we stand, challenges and opportunities. Autoimmununity Reviews. 2019 Sep; 18 (9): 102348

- Takata K, Stathopoulos P, Cao M, Mané-Damas M, Fichtner ML, Benotti ES, Jacobson L, Waters P, Irani SR, Martinez-Martinez P, Beeson D, Losen M, Vincent A, Nowak RJ, O'Connor KC. Characterization of pathogenic monoclonal autoantibodies derived from muscle-specific kinase myasthenia gravis patients. JC/ Insight. 2019 Jun; 4(12): 127167

- Koneczny I, Rennspiess D, Marcuse F, Dankerlui N, Abdul Hamid M, Mané-Damas M, Maessen J, Van Schil P, Saxena A, Zisimopoulou P, Lazaridis K, Woodhall M, Karagiorgou K, Tzartos J, Tzartos S, De Baets MH, Molenaar PC, Marx A, Zur Hausen A, Losen M, Martinez-Martinez P. Characterization of the thymus in Lrp4 myasthenia gravis: Four cases. Autoimmununity Reviews. 2019 Jan; 18 (1): 50-55

- Zong S, Hoffmann C, Mané-Damas M, Molenaar P, Losen M, Martinez-Martinez P. Neuronal Surface Autoantibodies in Neuropsychiatric Disorders: Are There Implications for Depression? Frontiers in Immunology. 2017 Jul 5; 8: 752.

- Losen M, Labrijn AF, van Kranen-Mastenbroek VH, Janmaat ML, Haanstra KG, Beurskens FJ, Vink T, Jonker M, 't Hart BA, Mané-Damas M, Molenaar PC, Martinez-Martinez P, van der Esch E, Schuurman J, de Baets MH, Parren PWHI. Hinge-deleted lgG4 blocker therapy for acetylcholine receptor myasthenia gravis in rhesus monkeys. Scientific Reports. 2017 Apr 20; 7 (1): 992 
- Gomez AM, Mané-Damas M*, Stevens JA*, Molenaar P, Duimel H, Verheyen F, Cossins J, Beeson D, De Baets MH, Losen M, Martinez-Martinez P. Silencing of Dok-7 in Adult Rat Muscle Increases Susceptibility to Passive Transfer Myasthenia Gravis. The American Journal of Pathology. 2016 Oct 186 (10). *equal contribution

- Hoffmann C*, Zong S*, Mané-Damas $\mathrm{M}^{*}$, Molenaar P, Losen M, Martinez-Martinez, P. Autoantibodies in Neuropsychiatric Disorders. Antibodies. 2016 Jun 5 (2): 9.*equal contribution

Book chapters

- Mané-Damas M, Tan A, Molenaar P, Hoffmann C, Zong S, Losen M, Martinez-Martinez P. Autoimmunity in psychosis. Psychotic Disorders: Comprehensive Conceptualization and Treatments. Clinical Medicine Books, Oxford University Press USA (in press)

- Mané-Damas M, Gomez A.M, Nogales-Gadea G, Stevens J, Molenaar P, de Baets M, Losen M, Martínez-Martínez M. "Mechanism of Action of the Antibodies in MG" . Miastenia Gravis y Alteraciones de la Union Neuromuscular (Myasthenia Gravis and Disorders of the Neuromuscular Junction). Editorial Inter-Medica S.A.I.C.I. República Argentina. Feb 2017

\section{Manuscripts in process}

- Zong S, Correia Hoffmann C, Mané-Damas M, Kappelmann N, Molenaar P, van Grootheest G, Penninx B.W.J.H, Rouhl R.P.W, Losen M, Martinez-Martinez P. Novel neuronal surface autoantibodies in plasma of patients with depression and anxiety (under review, Trans/ational Psychiatry)

- den Hoedt S, Crivelli S, Leijten F.P.J, Losen M, Stevens J, Mané-Damas M, de Vries H.E, Walter J, Sijbrands E.J.G, Verhoeven A.J.M, Martinez-Martinez P, Mulder M, Monique T. Brain ceramide levels are strongly affected by sex, but minimally by Apolipoprotein E4 in Alzheimer's disease and control mice. (submitted to BBA-Molecular and cell biology of lipids)

- Correia Hoffmann C, Zong S, Mané-Damas M, Stevens J, Malyavantham K, ismail Küçükali C, Tüzün E, De Hert M, van Beveren N.J.M, González-Vioque E, Arango C, Damoiseaux J.G.M.C, Molenaar P, Losen $M$. Martinez-Martinez $P$. The search for an autoimmune origin of psychotic disorders: Prevalence of autoantibodies against hippocampus, glutamic acid decarboxylase and antinuclear antigens. (submitted to Schizophrenia research)

- Mané-Damas M, Saxena A, Nogales-Gadea G, van Beek M, Van Den Hoogen N, Molenaar P, Joosten B, Willcox N, Martinez - Martinez P, Losen M. Therapeutic efficacy of MLN9708 (ixazomib) in 
experimental autoimmune myasthenia gravis and primary thymic cell cultures from myasthenia gravis patients. (in process, Journal of Autoimmunity)

- Mané-Damas $M$, et al. Novel treatment strategies for myasthenia gravis with autoantibodies against the AChR (in process, Autoimmunity reviews)

- Mané-Damas $M$, et al. Hinge-deleted lgG4 blocker therapy for acetylcholine receptor myasthenia gravis - in vitro data of competition efficacy (in preparation) 
List of publications 


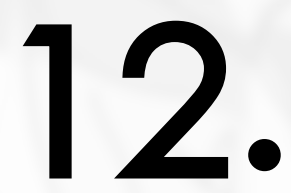

Acknowledgments 
Acknowledgments 
I would like to thank all the great people who accompanied me in this journey and made possible the completion of this thesis.

First of all, I would like to thank my promotion team for their guidance and support throughout the years. To my supervisor Prof. dr. Pilar Martinez, thank you for giving me the opportunity to join your team. I am sincerely grateful for your continuous support, positivity and contagious enthusiasm. Thanks for your patience, faith and trust. You have taught me to be critical, ask myself the right questions and gave me the confidence to grow as a scientist. I truly appreciate your proximity and kindness, especially during the last sprint. Es un placer (my pleasure)! Thank you Dr. Mario Losen for all the things you have taught me, laboratory-wise, microscopy-wise and much more. With you the saying of "you will never end the day without learning something new" becomes true (in Spanish it sounds better). You have provided me with the tools to develop and improve my research skills. Dr. Rob Rouhl, thank you for your valuable advice and for being the bridge between the lab and the clinic. Thanks for sharing with us the clinical concerns and all the interesting cases. This enhanced my curiosity and gave me the energy to continue with our studies.

Special mention to Dr. Peter Molenaar. Your kind guidance and knowledge has undoubtedly contributed to this thesis and to my experience in my PhD trajectory. I would like to also express my gratitude to Prof. dr. Marc de Baets and all the advice you gave me during these years. I admire your passion and enthusiasm for science, the good balance with traveling and enjoying good food! Thanks to Prof. dr. Davin Linden, Prof. dr. Jim van Os and Prof. dr. Bart Rutten for facilitating the realization of the work of this thesis.

Now, I would like to thank all the collaborators for the excellent science and contribution to this dissertation. Thanks Prof. dr. Therese van Amelsvoort, Dr. Machteld Marcelis and Dr. Patrick Domen for your knowledge regarding mental disorders and for the successful set up of the PSYNTIB study. Debora Eijnde, Bea Campforts and Truda Driesen, thanks for making all the logistics, paper work and patient visits possible, and thanks for the wines we shared with all the team, it has been a pleasure! Dr. Anna Mané Santacana, muchas gracias por hacer nuestra colaboración posible y sobretodo fácil. Por muchos más proyectos juntas.

Special thanks to Prof. dr. Josep Dalmau for providing me the opportunity to join your lab. Thanks for sharing your expertise and for taking the time to sit down with me and show me the tips and tricks and the relevance of the correct analysis and interpretation of the results. Furthermore, thanks to your amazing team for the detailed explanations, for the guidance and the assistance during the experiments and thanks for making me feel part of your team. 
Thanks to Dr. Maarten Titulaer, Prof. dr. Hardal Prüß and Prof. dr. Erdem Tüzün for sharing their control samples with us and for the scientific discussions. Dr. Frank Leypold, thanks for your valuable advice. And to Dr. Patrcik Waters, thanks for sharing your expertise.

Prof. dr. Jan Damoiseaux, thanks for sharing your limitless knowledge and for opening the doors of your laboratory to us. Jozien Jaspers-Spits and Erwin Wijnands, thanks for your patience in the FACS and for giving me advise on the panel design and always making time to check unforeseen problems. Dr. Suzanne Koudijs, thank you for kindly sharing with us the interesting cases. Dr. Myrurgia Abdul Hamid, I appreciate your perseverance, hard work and I would like to particularly thank you for facilitating communication. Florit Marcuse, thanks for the nice discussions, clinical advice and positive attitude. Thanks to Prof. dr. Axel zur Hausen for opening the doors of the pathology department to us.

I thank ImCheck therapeutics and to Prof. dr. René Hoet for hosting me at their lab in Marseille and for sharpening my skills in FACS analysis. Thanks to all the team members for facilitating and making my stay not only very productive but also pleasant. Dr. Peter Ulrichts, thanks for your scientific advice.

I would like to continue acknowledging all the people that have daily contributed to the science and the fun at the bench. I would like to thank Jo, or Mr Stevens, no sé si escribirte en inglés, en castellano o en català! The man that knows all about biomedicine, informatics and hairdressing. Thanks for your patience, for always offering your help and last but not least, thanks for the endless (and I mean it) party nights. Shannen, also known as the Ice Queen, thanks for your limitless sense of humor that helped me through the long hours, I enjoyed working with you a lot! Thanks for introducing me to Maastricht Carnival, I couldn' thave had a better guide! Carolin, colleague, scientist, friend, family! These are the words that for me define our friendship. Thanks for your guidance, for you kindness and for always being there. For all the recepies, the sewing and for taking me everywhere you went, no matter if it was raining, during a storm or in the snow. Thank you for all the nice memories and for empower my progress in English. Together with Joao you made me feel part of your family, and I am very happy to see how it is growing. I wish we were close so I could enjoy being together with you all more often (-). Simone, I admire your positivity and your limitless vitality in the long hours, I have enjoyed working with you. Abishek and Inga, thank you for your scientific support and advice. Shenghua, I admire your enthusiasm, your scientific curiosity, criticism and your clinical point of view. I especially acknowledge, besides the laboratory abilities, your culinary skills, you made us all master-chefs when it comes to cooking dumplings! Caterina, thanks for all the coffees, (Italian) wines, shopping and crochet nights. Besides being a hard worker, you are a great friend. Thanks for your moral support, understanding and for always being there. Tanya, thanks for the nice times at the basement and thanks for appreciating and improving my Spanglish. Qian and Daan, thanks for all the nice discussions and the great office atmosphere. Nikita and Anja, I am very 
happy you joined the team and I enjoy working with you on a daily basis. Thanks for keeping up and for continuing all the projects we share.

Anita, I did not know where to place you, with collaborators, colleagues or friends; you fit in all categories. It is always a fun pleasure to work with you and even more to have you as a friend. We both know that scientific discussions always works better walking in nature to be inspired and especially with a little bit of wine $:-$

And I could not finish up without mentioning all the students I had the pleasure to supervise, this gave me fresh energy to continue with my research. Rachid, Denise, Mortiz, Esther, Maud, Julia, Tom, Celestine, Amanda and Milan, thank you for your patience, especially at the beginning, and for all the hard work in all the projects we have shared. I am happy to still hear from some of you!

I would also like to thank all the wonderful people from the department. Besides the hard work, we also had a lot of fun! With you the entertainment and good memories were assured! Together we shared international lunches and dinners, new experiences, Christmas markets, and unforgettable Birthday parties... Yara, gracias por acogerme y arroparme cuando llegue, y sobretodo por enseñarme lo mejor de este pueblo, el Alla! Gracias por las gloriosas noches de fiesta, y porque, a pesar de estar lejos, hagamos por encontramos en Maastricht, Munich, en Reus o en Hospitalet! Fred, thanks for the piano lessons and for the great times we have spent together! Sandra, I appreciate your sarcasm and your scientific accuracy and vision. Gusta, free soul, kind woman, I am sure wherever you are you are making people around you feel wonderful with your presence. Joao or "the charming Professor" thanks for your kindness and for all the good memories. Maarten, I am thankful for your fitness motivation and the good vibes that you brought to the uni-parties. Roy, in my mind you are connected with movie-nights and sushi, could be worse right! Marion, thanks for all the dancing, Carnivals and raclette nights: let' s meet up soon in Paris. Bethany, I am impressed that we became friends even though I disrespect the English language on a daily basis. Glenn, thanks for your scientific advice and for educating me about toasties, an interesting Dutch tradition I might miss. Thanks to all the PhDs, for sharing their expertise and equipment. Rose, Perla, Lonne, Roul, Nynke, Eshan, Anne, Dean, Renzo, Ellis, Chris, Philippos, Jackson, Margot, Milane, Jeroen, Sylvana, Majed, Alix, Clara, Katherine, Christian, Wouter, Ralph and Wenting thanks for keeping up with the fun activities including the Thursdays and/or Fridays drinks, the Carnival parties and the Christmas drinks to mention some.

I would also like to thank all the seniors from the department for the fruitful discussions during the weekly meetings and for sharing your knowledge. Prof. dr. Jos Prickaerts, Prof. dr. Daniel van den Hove, Dr. Gunter Kenis, Dr. Theo Gorgels, Prof. dr. Bert Joosten, Prof. dr. Yasin Temel, Dr. Ali Jahanshahianvar, Dr. Laurence 
de Nijs and Dr. Govert Hoogland, thank your valuable advice during all these years and for all for the great memories from the lab days out, $\mathrm{PhD}$ videos and celebrations and for your professional dancing skills. Tom van den Crommenacker and Ankie Hochstenbach, thanks for facilitating all the paperwork and bureaucracy and also to help with the organization of all the fun events.

I am very thankful for the technical support that I received from the tech-team. Hellen and Marjan, thanks for sharing your laboratory experience. Wouter and Denise, thanks for all your help and support, for your positivity and patience. Sandra, "I know someone that knows a lot about it!" Chef, thanks for sharing your knowledge and your network but especially for your energy and enthusiasm. Barbie, thank you for your guidance in the experiments, it is a pleasure to learn from you and to work with you. And Rachelle, without your kindness and your reminders, I would have probably missed my own defense $\odot$.

And now, and immense thanks to the CPV and the IVD team. Thank you all for the positive and enthusiastic atmosphere you brought to the corridors and the coffee room and for the good vibes, especially Paul for his great talent when it comes to whistling happy songs. Special thanks to Clarice, Rik, Sytske and Nicole, your help and expertise has contributed to my research and also made my experiments much more bearable and fun! And no worries, you will not get rid of me anytime soon (-). Alice, thank you for your patience receiving emails, calls and tones of amendments during the past years. Dr. Ramon Langen, thank you for all your support and fruitful discussions on the working protocols. Dr. Saskia Seeldrayers, thanks for your advice and for your availability to discuss my doubts. And last but not least, thank you Richard Frijnts for always being there. I admire your character, your energy and your sense of humor and I hope I can keep enjoying it! We have a pending visit planned to Sonseca!

Sandra Zimny and Martine Hulsbosch, thanks for helping me in the RNL lab, for being there when I needed you and especially for giving me shoes of my size! Natasja Kisters, Vivian Leeuwen and Paul Willemsen, thanks for always keeping my permits up to date.

I am very grateful for my friends outside the lab that have made these years very fulfilling. Jeroen, no defense-party was complete without your presence. When the Covid-spell has been lifted I owe you a drink! Julien, thanks for your friendship, I am glad I got to know you and I enjoyed your particular sense of humor. Diego, el hombre del castellano perfecto y los calcetines de colorines. Amigo, vecino, que decirte... muchas gracias por las innumerables cenas en casa, los paseos por la ciudad, por nuestras escapadas (todavía recuerdo aquel maravilloso cóctel en Amberes) y por muchas cosas más. Y a María, mi compañera, mi amiga, mi hermana, gracias por estos años, por hacerme sentir en casa, por estar ahí, en las buenas y en las regulinchis, y porque estoy segura de que, a pesar de la distancia, nos vamos a seguir teniendo! 
Artemis, I owe a debt to my PhD -trajectory, because this has led to my encounter with you. You are a wonderful scientist, your commitment has always been inspiring. You were one of the only people that was able to understand my sarcasm; it took some tears, but we got there -). Thank you for your patience, for your honesty and all together for making me grow. Thanks for introducing me to all these beauty products I never used, for the talking and the not-talking nights, for sharing your cooking passion, for the music and the dancing, for all the trips, for all your advice and ultimately for making my life in Maastricht extraordinary. \#wheneverwherever, I will be there for you. You are family!

Y volviendo a mis raíces, me remonto a los años mozos de universidad. Que maravilla y que afortunadas hemos sido al encontrarnos. Los círculos simbolizan la unidad, lo absoluto y la perfección (dice una fuente fiable), y vosotras lo formáis. Compañeras de trabajos, de piso y de vida, Nuria, Àngela, Anna, Maria (Sanz), Paula, Vanesa y María (Carpintero), muchas gracias todo lo vivido y lo que queda por vivir! Gracias también a Pol, Claudia y Laura por el maravilloso año de master en la gran ciudad.

Gisela, muchas gracias por todo. Contigo empecé mis andaduras en el laboratorio y bajo tu supervisión creció mi entusiasmo y curiosidad por la ciencia. Gracias por ser como eres y por derrochar alegría y buen rollo. No quiero dejar de agradecer también al maravilloso equipo del Sant Pau: Eduard, Jordi, Luis, Eugenia, Fina, Miquel, Bárbara y Xavi, gracias a todos por todo lo que me habéis enseñado y en especial, gracias a Prof. dr. Isabel Illa, por darme la oportunidad de hacer las practicas en su grupo de investigación. También agradecer a todos mis compañeros del Clinic, gracias por compartir vuestro conocimiento y sobretodo por vuestra amistad.

Gracias a mis amigos del pueblo, a los de siempre. Mari, Cristina y Ángel, el balance perfecto, gracias por estar siempre ahí, por escucharme y por apoyarme en esta aventura. Gracias por todos los viajes hechos y los que quedan por hacer. Anna, Andrea, Sergio, Alicia, Verònica, María y Tania, gracias por hacer un hueco siempre que las extranjeras volvemos a casa y por hacerme sentir que el tiempo y la distancia no son obstáculo para nuestra amistad. Estoy inmensamente agradecida de teneros.

Juan, gracias pordarme las herramientas para crecer y el apolyo y empuje para llegar a buen puerto.

Thanks Ans, Jos and Anne to make me feel part of your family, for all the support and for reaching out when I needed it. Thanks to opa Piet and opa Jean for your kindness. I am very glad to have you in my life. 
A mi familia, a la que le estoy eternamente agradecida por estar siempre ahí, al pie del cañón. Alfonso, mi padrino preferido, admiro tu visión de la vida y tu fortaleza. Gracias por apoyarme, por llamarme y por venir a verme. A mi hermano Miguel, gracias por tu suspicaz sentido del humor, por organizar sorpresas conmigo y sobretodo porque, después de 4 años, cumpliste tu promesa y viniste a verme a Holanda! Espero que fuera la primera de muchas! Mamá, gracias por tu paciencia, por entenderme, apoyarme en esta aventura lejos de vosotros y en especial, por subirte a un avión, a un tren y a donde hiciera falta para venir a verme. Papá, gracias por enseñarme la importancia de la constancia y el esfuerzo. Por darme la confianza para perseguir mis objetivos y por todos los consejos que me han guiado durante todos estos años. Sois geniales. Gracias por todo vuestro cariño y por creer en mí!

Koen, you are my strength and my balance. Thanks for your patience, your understanding and for giving me the courage to keep improving and growing every day. Thank you for walking by my side and for believing in me!

For the all the people I might have forgotten: thank you for the wonderful time, I am happy that I was fortunate enough to spend this time with you in Maastricht! To all the people who crossed my life and contributed to what I have achieved, who I am and who I will be, thank you. 

